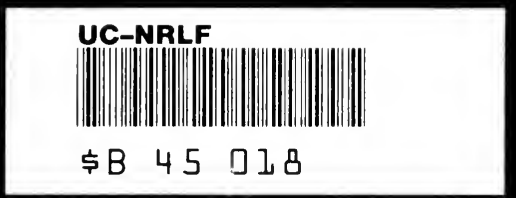




\section{EXCHANGE}

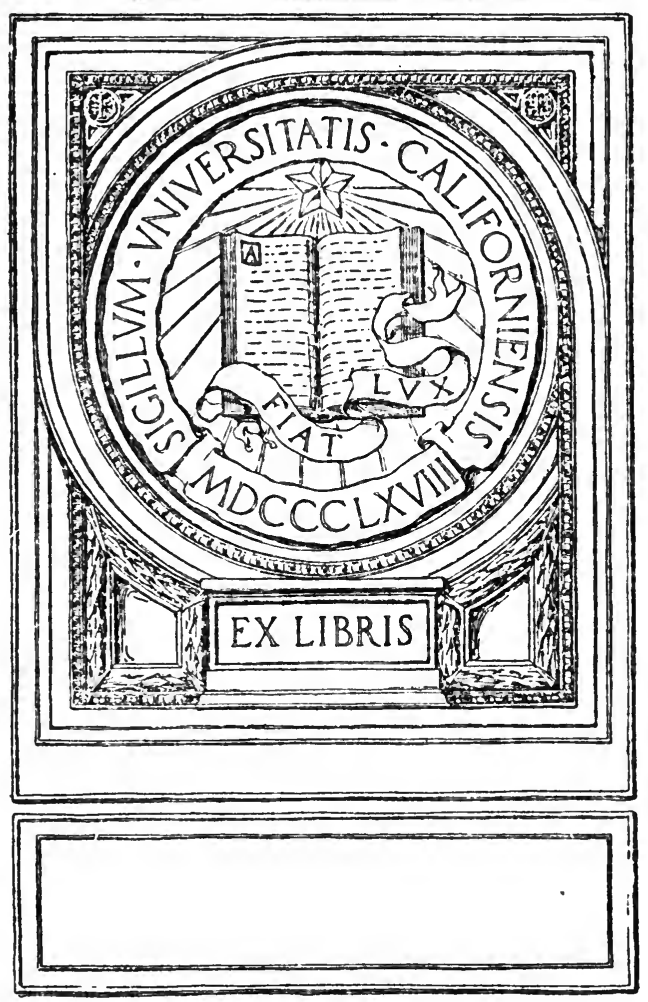


$x^{2}+x^{2}=$

Wen

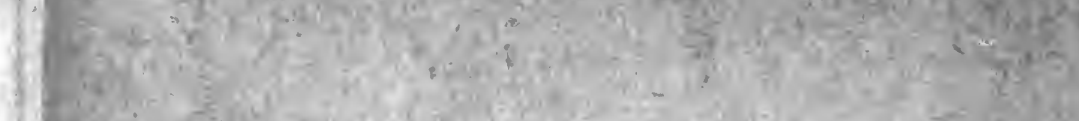

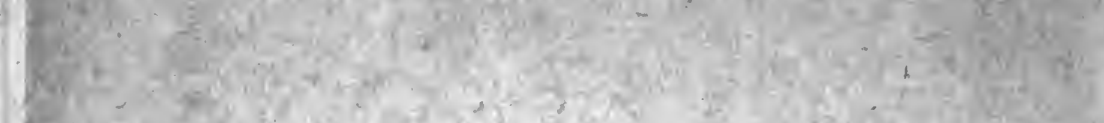

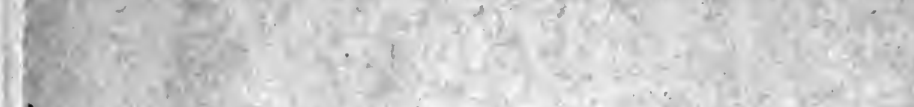

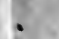

ais atis

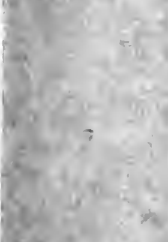

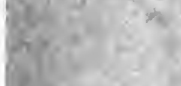

2.

$x^{2}+x^{2}$

$x^{2}=$

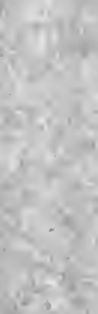

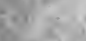

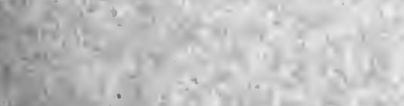

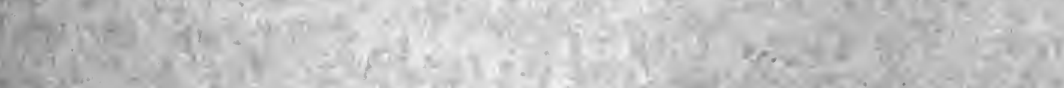

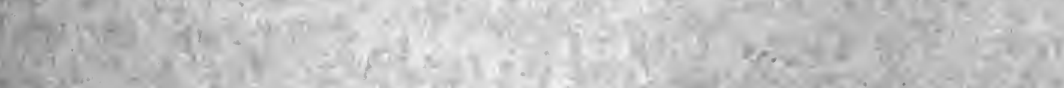

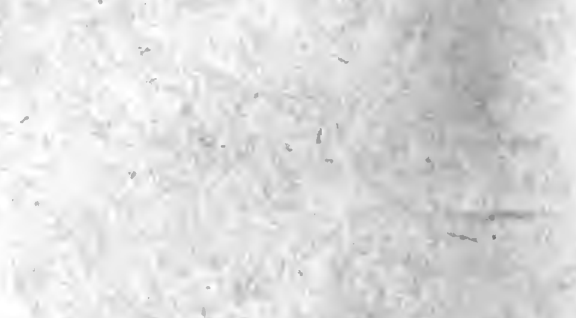

1.
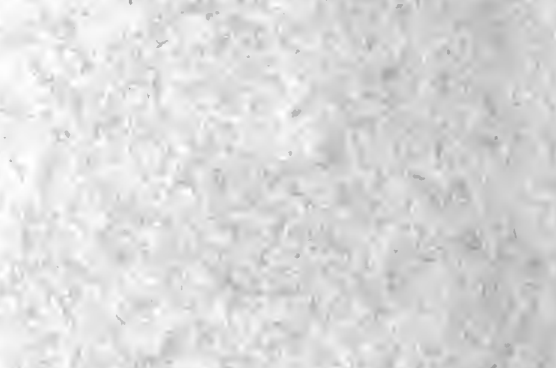

(4)

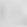

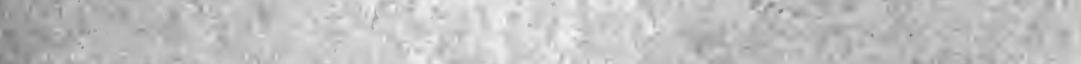

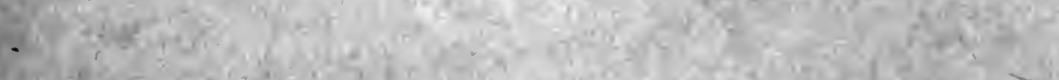

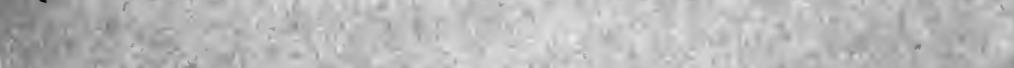

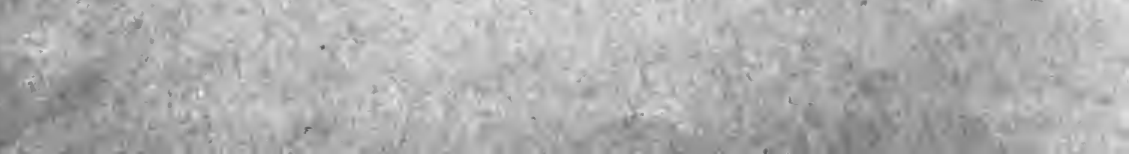




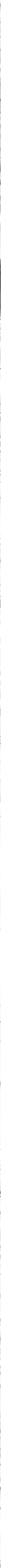


Digitized by the Internet Archive in 2007 with funding from Microsoft Corporation 


\section{CORNELL STUDIES IN PHILOSOPHY}

No. I I

\section{-JOHN DEWEY'S LOGICAL THEORY}

BY

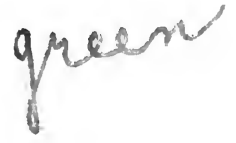

\section{DELTON THOMAS HOWARD, A.M.}

\section{A THESIS}

Presented to the Faculty of the Graduate School of Cornell University in Partial Fulfilment of the Requirements for the Degree of Doctor of Philosophy

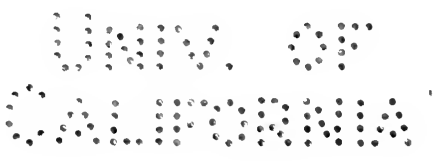

NEW YORK LONGMANS, GREEN, \& CO. 


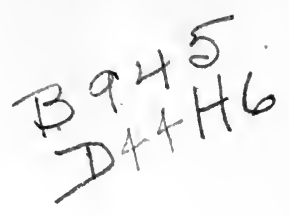

THE NEW ERA PRINTING COMPANY LANCASTER, PA.

$\because \because \because: \quad \vdots \because \because \vdots: \vdots \vdots \vdots$

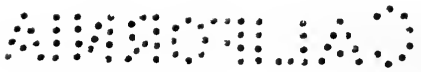




\section{PREFACE}

It seems unnecessary to offer an apology for an historical treatment of Professor Dewey's logical theories, since functionalism glories in the genetic method. To be sure, certain more extreme radicals are opposed to a genetic interpretation of the history of human thought, but this is inconsistent. At any rate, the historical method employed in the following study may escape censure by reason of its simple character, for it is little more than a critical review of Professor Dewey's writings in their historical order, with no discussion of influences and connections, and with little insistence upon rigid lines of development. It is proposed to "follow the lead of the subject-matter" as far as possible; to discover what topics interested Professor Dewey, how he dealt with them, and what conclusions he arrived at. This plan has an especial advantage when applied to a body of doctrine which, like Professor Dewey's, does not possess a systematic form of its own, since it avoids the distortion which a more rigid method would be apt to produce.

It has not been possible, within the limits of the present study, to take note of all of Professor Dewey'swritings, and no reference has been made to some which are of undoubted interest and importance. Among these may be mentioned especially his books and papers on educational topics and a number of his ethical writings. Attention has been devoted almost exclusively to those writings which have some important bearing upon his logical theory. The division into chapters is partly arbitrary, although the periods indicated are quite clearly marked by the different directions which Professor Dewey's interests took from time to time. It will be seen that there is considerable chance for error in distinguishing between the important and the unimportant, and in selecting the essays which lie in the natural line of the author's development. But, valeat quantum, as William James would say.

The criticisms and comments which have been made from time to time, as seemed appropriate, may be considered pertinent or irrelevant according to the views of the reader. It is hoped that 
they are not entirely aside from the mark, and that they do not interfere with a fair presentation of the author's views. The last chapter is devoted to a direct criticism of Professor Dewey's functionalism, with some comments on the general nature of philosophical method.

Since this thesis was written, Professor Dewey has published two or three books and numerous articles, which are perhaps more important than any of his previous writings. The volume of Essays in Experimental Logic (1916) is a distinct advance upon The Influence of Darwin on Philosophy and Other Essays, published six years earlier. Most of these essays, however, are considered here in their original form, and the new material, while interesting, presents no vital change of standpoint. It might be well to call attention to the excellent introductory essay which Professor Dewey has provided for this new volume. Some mention might also be made of the volume of essays by eight representative pragmatists, which appeared last year (I9I7) under the title, Creative Intelligence. My comments on Professor Dewey's contribution to the volume have been printed elsewhere. ${ }^{1}$ It has not seemed necessary, in the absence of significant developments, to extend the thesis beyond its original limits, and it goes to press, therefore, substantially as written two years ago.

I wish to express my gratitude to the members of the faculty of the Sage School of Philosophy for many valuable suggestions and kindly encouragement in the course of my work. I am most deeply indebted to Professor Ernest Albee for his patient guidance and helpful criticism. Many of his suggestions, both as to plan and detail, have been adopted and embodied in the thesis, and these have contributed materially to such logical coherence and technical accuracy as it may possess. The particular views expressed are, of course, my own. I wish also to thank Professor J. E. Creighton especially for his friendly interest and for many suggestions which assisted the progress of my work, as well as for his kindness in looking over the proofs.

D. T. HOWARD.

Evanston, Illinois, June, 1918.

I "The Pragmatic Method," Journal of Philosophy, Psychology, and Scientific Methods, I918, Vol. XV, pp. I49-156. 


\section{CONTENTS}

Chapter

PAGE

I. "Psychology as Philosophic Method"......... I

II. The Development of the Psychological Standpoint .. I5

$\angle$ III. "Moral Theory and Practice"............ 33

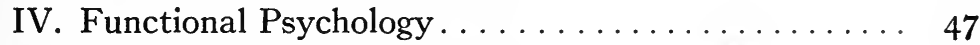

V. The Evolutionary Standpoint. . . . . . . . . . 59

¿I. "Studies in Logical Theory" . . . . . . . . . . . $7^{2}$

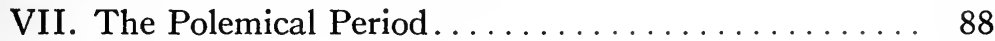

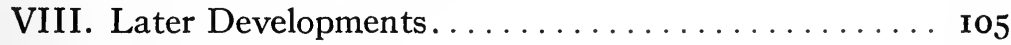

IX. Conclusions.................... I I9 



\section{CHAPTER I}

\section{"PSYCHOLOGY AS PHILOSOPHIC METHOD"}

DEWEY's earliest standpoint in philosophy is presented in two articles published in Mind in I886: "The Psychological Standpoint," and "Psychology as Philosophic Method." These articles appear to have been written in connection with his Psychology, which was published in the same year, and which represents the same general point of view as applied to the study of mental phenomena. For the purposes of the present study attention may be confined to the two articles in Mind.

Dewey begins his argument, in "The Psychological Standpoint," with a reference to Professor Green's remark that the psychological standpoint is what marks the difference between transcendentalism and British empiricism. Dewey takes exception to this view, and asserts that the two schools hold this standpoint in common, and, furthermore, that the psychological standpoint has been the strength of British empiricism and desertion of that standpoint its weakness. Shadworth Hodgson's comment on this proposal testifies to its audacity. In a review of Dewey's article, he says: "If for instance we are told by a competent writer, that Absolute Idealism is not only a truth of experience but one attained directly by the method of experiential psychology, we should not allow our astonishment to prevent our examining the arguments, by virtue of which English psychology attains the results of German transcendentalism without quitting the ground of experience."2

Dewey defines his psychological standpoint as follows: "We are not to determine the nature of reality or of any object of philosophical inquiry by examining it as it is in itself, but only as it is an element in our knowledge, in our experience, only as it is related to our mind, or is an 'idea'... Or, in the ordinary

1 Vol. XI, pp. I-I9; pp. I53-I73.

2 "Illusory Psychology," Mind, Vol. XI, r886, p. 478. 
way of putting it, the nature of all objects of philosophical inquiry is to be fixed by finding out what experience says about them."1 The implications of this definition do not appear at first sight, but they become clearer as the discussion proceeds.

Locke, Dewey continues, deserted the psychological standpoint because he did not, as he proposed, explain the nature of such things as matter and mind by reference to experience. On the contrary, he explained experience through the assumption of the two unknowable substances, matter and mind. Berkeley also deserted the psychological standpoint, in effect, by having recourse to a purely transcendent Spirit. Even Hume deserted it by assuming as the only reals certain unrelated sensations, and by trying to explain the origin of experience and knowledge by their combination. These reals were supposed to exist in independence of an organized experience, and to constitute it by their association. It might be argued that Hume's sensations are found in experience by analysis, and this would probably be true. But the sensations are nothing apart from the consciousness in which they are found. "Such a sensation," Dewey says, "a sensation which exists only within and for experience, is not one which can be used to account for experience. It is but one element in an organic whole, and can no more account for the whole, than a given digestive act can account for the existence of a living body.",2

So far.Dewey is merely restating the criticism of English empiricism that had been made by Green and his followers. Reality, as experienced, is a whole of organically related parts, not a mechanical compound of elements. Whatever is to be explained must be taken as a fact of experience, and its meaning will be revealed in terms of its position and function within the whole. But while Dewey employs the language of idealism, it is doubtful whether he has grasped the full significance of the "concrete universal" of the Hegelian school. The following passage illustrates the difficulty: "The psychological standpoint as it has developed itself is this: all that is, is for consciousness or knowledge. The business of the psychologist is to give a genetic

1 "The Psychological Standpoint," Mind, I886, Vol. XI, p. 2.

2 Ibid., p. 7 . 
account of the various elements within this consciousness, and thereby fix their place, determine their validity, and at the same time show definitely what the real and eternal nature of this consciousness is."

Consciousness (used here as identical with 'experience') is apparently interpreted as a structure made up of elements related in a determinable order, and having, consequently, a 'real and eternal nature.' The result is a 'structural' view of reality, and the type of idealism for which Dewey stands may fittingly be called 'structural' idealism. This type of idealism does, in fact, hold a position intermediate between English empiricism and German transcendentalism. But it would not commonly be considered a synthesis of the best characteristics of the two schools. 'Structural' idealism is, historically considered, a reversion to Kant which retains the mechanical elements of the Critique, but fails to reckon with the truly organic mode of interpretation in which it culminates. As experience, from Kant's undeveloped position, is a structure of sensations and forms, so Dewey's 'consciousness' is a compound of separate elements or existences related in a 'real and eternal' order.

Dewey illustrates his method, in the discussion which follows, by employing it, or showing how it should be employed, in the definition of certain typical objects of philosophical inquiry. The first to be considered are subject and object. In dealing with the relation of subject to object, the psychological method will attempt to show how consciousness differentiates itself, or 'specifies' itself, into subject and object. These terms will be viewed as related terms within the whole of 'consciousness,' rather than as elements existing prior to or in independence of the whole in which they are found.

There is a type of realism which illustrates the opposite or ontological method. It is led, through a study of the dependence of the mind upon the organism, to a position in which subject and object fall apart, out of relation to each other. The separation of the two leads to the positing of a third term, an unknown $x$, which is supposed to unite them. The psychological method

${ }^{1}$ Op. cit., p. 8 f. 
would hold that the two objects have their union, not in an unknown 'real,' but in the 'consciousness' in which they appear. The individual consciousness as subject, and the objects over against it, are elements at once distinguished and related within the whole. All the terms are facts of experience, and none are to be assumed as ontological reals.

Subjective idealism, Dewey continues, makes a similar error in failing to discriminate between the ego, or individual consciousness, and the Absolute Consciousness within which ego and object are differentiated elements. It fails to see that subject and object are complements, and inexplicable except as related elements in a larger whole. The individual consciousness, again, and the universal 'Consciousness,' are to be defined by reference to experience. It is not to be assumed at the start, as the subjective idealists assume, that the nature of the individual consciousness is known. The ego is to be defined, not assumed, and this is the essence of the psychological method.

So far, two factors in Dewey's standpoint are clearly discernible. In the first place, all noumena and transcendent reals are to be rejected as means of explanation, and definition is to be wholly in terms of experienced elements, as experienced. In the second place, experience is to be regarded as a rational system of related elements, while explanation is to consist in tracing out the relations which any element bears to the whole. The universal 'Consciousness' is the whole, and the individual mind, again, is an element within the whole, to be explained by tracing out the relations which it bears to other elements and to the whole system. It is not easy to avoid the conclusion that Dewey conceives of 'consciousness' as a construct of existentially distinct terms.

Dewey does not actually treat subject and object, individual and universal consciousness, in the empirical manner for which he contends. He merely outlines a method; and, while this has a negative bearing as against transcendent modes of explanation, it has little content of its own. But in spite of Dewey's lack of explicitness, it is evident that he tends to view his 'objects of philosophical inquiry' as so many concrete particular existences 
or things. The idea that they can be empirically marked out and investigated seems to imply this. But subject, object, individual, and universal are certainly not reducible to particular sensations, even though it must be admitted that they have a reference to particulars. These abstract concepts had been a source of difficulty to the empiricists, because they had not been able to reduce them to particular impressions, and Dewey's proposed method appears to involve the same difficulty.

In his second article, on "Psychology as Philosophic Method," Dewey proposes to show that his standpoint is practically identical with that of transcendental idealism. This is made possible, he believes, through the fact that, since experience or consciousness is the only reality, psychology, as the scientific account of this reality, becomes identical with philosophy.

In maintaining his position, Dewey finds it necessary to criticise the tendency, found in certain idealists, to treat psychology merely as a special science. This view of psychology is attained, Dewey observes, by regarding man under two arbitrarily determined aspects. Taken as a finite being acting amid finite things, a knowing, willing, feeling phenomenon, man is said to be the object of a special science, psychology. But in another aspect man is infinite, the universal self-consciousness, and as such is the object of philosophy. This distinction between the two aspects of man's nature, Dewey believes, cannot be maintained. As a distinction, it must arise within consciousness, and it must therefore be a psychological distinction. Psychology cannot limit itself to anything less than the whole of experience, and cannot, therefore, be a special science dependent, like others, upon philosophy for its working concepts. On the contrary, the method of psychology must be the method of philosophy.

Dewey reaches this result quite easily, because he makes psychology the science of reality to begin with. "The universe," he says, "except as realized in an individual, has no existence. .. . Self-consciousness means simply an individualized universe; and if this universe has not been realized in man, if man be not self-conscious, then no philosophy whatever is possible. If it has been realized, it is in and through psychological experience 
that this realization has occurred. Psychology is the scientific account of this realization, of this individualized universe, of this self-consciousness." 1

It is difficult to understand exactly what these expressions meant for Dewey. Granting that the human mind is both individual and universal, what objection could be raised against the study of its individual or finite aspects as the special subjectmatter of a particular science? All the sciences, as Dewey was aware, are abstract in method. Dewey's position appears to be that the universal and individual aspects of consciousness are nothing apart from each other, and must be studied together. But 'consciousness' in Dewey's view is, in fact, two consciousnesses. Reality as a whole is a Consciousness, and the individual mind is another consciousness. A problem arises, therefore, as to their connection. Dewey affirms that, unless they are united, unless the universal is given in the individual consciousness, there can be no science of the whole, and therefore no philosophy. The epistemological problem of the relation of the mind to reality becomes, accordingly, the raison d'être of his method. The problem was an inheritance from subjective idealism. It may be pointed out that there is some similarity between Dewey's standpoint and Berkeley's. Both conceive of consciousness as a construct of elements, and Dewey's 'Consciousness in general' holds much the same relation to the finite consciousness that the Divine Mind holds to the individual consciousness in Berkeley's system. The similarity between the two standpoints must not be overemphasized, but it is none the less suggestive and interesting.

In attempting to determine the proper status of psychology as a science, Dewey is led into a more detailed exposition of his standpoint. His position in general is well indicated in the following passage: "In short, the real esse of things is neither their percipi, nor their intelligi alone; it is their experiri." 2 The science of the intelligi is logic, and of the percipi, philosophy of nature. But these are abstractions from the experiri, the science of which is psychology. If it be denied that the experiri, self-conscious-

1 "Psychology as Philosophic Method," Mind, r886, Vol. XI, p. I57.

2 Ibid., p. r6o. (Observe that this is a direct reference to Berkeley.) 
ness in its wholeness, can be the subject-matter of psychology, then the possibility of philosophy is also denied. "If man, as matter of fact, does not realise the nature of the eternal and the universal within himself, as the essence of his own being; if he does not at one stage of his experience consciously, and in all stages implicitly, lay hold of this universal and eternal, then it is mere matter of words to say that he can give no account of things as they universally and eternally are. To deny, therefore, that self-consciousness is a matter of psychological experience is to deny the possibility of any philosophy." 1 Dewey assures us again that his method alone will solve the epistemological problem.

Self-consciousness, as that within which things exist sub specie aternitatis and in ordine ad universum, must be the object of psychology. The refusal to take self-consciousness as an experienced fact, Dewey says, results in such failures as are seen in Kant, Hegel, and even Green and Caird, to give any adequate account of the nature of the Absolute. Kant, for purely logical reasons, denied that self-consciousness could be an object of experience, although he admitted conceptions and perceptions as matters of experience. As a result of his attitude, conception and perception were never brought into organic connection; the self-conscious, eternal order of the world was referred to something back of experience. Dewey attributes Kant's failure to his logical method, which led him away from the psychological standpoint in which he would have found self-consciousness as a directly presented fact.

This criticism of Kant's 'logical method' fails to take account of the transitional nature of Kant's standpoint. Looking backward, it is easy enough to ask why Kant did not begin with the organic view of experience at which he finally arrived. But the answer must be that the organic standpoint did not exist until Kant, by his 'logical method,' had brought it to light. The Kantian interpretation of experience, in which, as Dewey asserts, conception and perception were never brought into organic relation, is a half-way stage between mechanism and organism.

${ }^{1}$ Op. cit. 
But how does Dewey propose to improve upon Kant's position? He will first of all put Kant's noumenal self back into experience, as a fact in consciousness. But how will this help to bring perception and conception into closer union? There seems to be no answer. Dewey's view appears to be that organic relations are achieved whenever an object is made a part of experience and so brought into connection with other experienced facts. 'Organic relation' is interpreted as equivalent to 'mental relation.' But mental relations are not organic because they are mental. It would be as easy to assert that they are mechanical. The test lies in the nature of the relations which are actually found in the mental sphere and the fitness of the organic categories to express them. Dewey's 'consciousness,' as has been said before, appears to be a structure, not an organism. Its parts are external to each other, however closely they may be related. An organic view of experience would begin with a denial of the actuality of bare facts or sensations, and would not waver in maintaining that standpoint to the end.

Hegel's advance upon Kant, Dewey continues, "consisted essentially in showing that Kant's logical standard was erroneous, and that, as a matter of logic, the only true criterion or standard was the organic notion, or Begriff, which is a systematic totality, and accordingly able to explain both itself and also the simpler processes and principles." ${ }_{1}$ The logical reformation which Hegel accomplished was most important, but the work of Kant still needed to be completed by "showing self-consciousness as a fact of experience, as well as perception through organic forms and thinking through organic principles."2 This element is latent in Hegel, Dewey believes, but needs to be brought out.

T. H. Green comes under the same criticism. He followed Kant's logical method, and as a consequence arrived at the same negative results. The nature of self-consciousness remains unknown to Green; he can affirm its existence, but cannot describe its nature. Dewey quotes that passage from the Prolegomena to Ethics in which Green says:3 "As to what that conscious-

1Op.cit., p. I6r.

2 Ibid.

${ }^{3}$ Third Edition, p. 54. 
ness in itself or in its completeness is, we can only make negative statements. That there is such a consciousness is implied in the existence of the world; but what it is we only know through its so far acting in us as to enable us, however partially and interruptedly, to have knowledge of a world or an intelligent experience." If, Dewey observes, Green had begun with the latter point of view, and had taken self-consciousness as at least partially realized in finite minds, he would have been able to make some positive statements about it. Dewey, however, has not given the most adequate interpretation of Green's 'Spiritual Principle in Nature.' This was evidently, for Green, a symbol of the intelligibility of the world as organically conceived, an order which could not be comprehended by the mechanical categories, but which was nevertheless real. As Green tended to hypostatize the organic conception, so Dewey would make it a concrete reality, with the further specification that it must be something given to psychological observation.

The chief point of Dewey's criticism of the idealists is that they fail to establish self-consciousness as an experienced fact; and, Dewey maintains, it must be so established if it is to be anything real and genuine. If it is anything that can be discussed at all, it must be an element in experience; and if it is in experience, it must be the subject-matter of psychology. It is inevitable, from Dewey's standpoint, that transcendentalism should adopt his psychological method.

In the further development of his standpoint, Dewey considers (I) the relations of psychology to the special sciences, and (2) the relation of psychology to logic. Dewey's conception of the relation of psychology to the special sciences is well illustrated in the following passage: "Mathematics, physics, biology exist, because conscious experience reveals itself to be of such a nature, that one may make virtual abstraction from the whole, and consider a part by itself, without damage, so long as the treatment is purely scientific, that is, so long as the implicit connection with the whole is left undisturbed, and the attempt is not made to present this partial science as metaphysic, or as an explanation of the whole, as is the usual fashion of our uncritical so-called 
'scientific philosophies.' Nay more, this abstraction of some one sphere is itself a living function of the psychologic experience. It is not merely something which it allows: it is something which it does. It is the analytic aspect of its own activity, whereby it deepens and renders explicit, realizes its own nature. . . . The analytic movement constitutes the special sciences; the synthetic constitutes the philosophy of nature; the self-developing activity itself, as psychology, constitutes philosophy." 1

The special sciences are regarded as abstractions from the central or psychological point of view, but they are legitimate abstractions, constituted by a proper analytic movement of the total self-consciousness, which specifies itself into the special branches of knowledge. If we begin with any special science, and drive it back to its fundamentals, it reveals its abstractness, and thought is led forward into other sciences, and finally into philosophy, as the science of the whole. But philosophy, first appearing as a special science, turns out to be science; it is presupposed in all the special sciences, and is their basis. But where does psychology stand in this classification?

At first sight psychology appears to be a special science, abstract like the others. "As to systematic observation, experiment, conclusion and verification, it can differ in no essential way from any one of them."' But psychology, like philosophy, turns out to be a science of the whole. Each special science investigates a special sphere of conscious experience. "From one science to another we go, asking for some explanation of conscious experience, until we come to psychology. . . But the very process that has made necessary this new science reveals also that each of the former sciences existed only in abstraction from it. Each dealt with some one phase of conscious experience, and for that very reason could not deal with the totality which gave it its being, consciousness." 3 Philosophy and psychology therefore mainly coincide, and the method of psychology, properly developed, becomes the method of philosophy.

If psychology is to be identified with philosophy in this fashion,

1 Mind, Vol. XI, p. $166 \mathrm{f}$.

2 Ibid., p. 166.

${ }^{3}$ Ibid. 
the mere change of name would seem to be superfluous. There would be no reason for maintaining psychology as a separate discipline. Perhaps Dewey did not intend that it should be maintained separately. In that case, the total effect of his argument would be to prescribe certain methods for philosophy. It seems necessary to suppose that Dewey proposed to merge philosophy in psychology, and make it an exact science while retaining its universality. "Science," he argued, "is the systematic account, or reason of fact; Psychology is the completed systematic account of the ultimate fact, which, as fact, reveals itself as reason...."1 Self-consciousness in its ultimate nature is conceived of as a special fact, over and above what it includes in the way of particulars. Psychology, as the science of this ultimate fact, must at the same time be philosophy. The identification of the two disciplines depends upon taking the 'wholeness' of reality as a 'fact,' which can be brought under observation. This is a natural conclusion from Dewey's structural view of reality.

In taking up the subject of the relation of psychology to logic, Dewey remarks that in philosophy matter and form cannot be separated. "Self-consciousness is the final truth, and in selfconsciousness the form as organic system and the content as organized system are exactly equal to each other." 2 Logic abstracts from the whole, gives us only the form, or intelligi of reality, and is therefore only one moment in philosophy. Since logic is an abstraction from Nature, we cannot get from logic back to Nature, by means of logic. We do, as a matter of fact, make the transition in philosophy, because the facts force us back to Nature. Just as in Hegel's logic, the category of quality, when pressed, reveals itself as inadequate to express the facts, and is compelled to pass into the category of quantity, so does logic as a whole, when pressed, reveal its inadequacy to express the whole of reality. The transition from category to category in the Hegelian logic is not an unfolding of the forms as forms, but results from a compulsion exerted by the facts, when the

1 Op.cit., p. I7o.

${ }^{2}$ Ibid. 
categories are used to explain them. Logic is, and must remain, abstract in all its processes, and its outcome (with Hegel, Geist) may assert the abstract necessity of one self-conscious whole, but cannot give the reality. "Logic cannot reach, however much it may point to, an actual individual. The gathering up of the universe into one self-conscious individuality it may assert as necessary, it cannot give it as reality." 1 Taken as an abstract method, logic is apt to result in a pantheism, "where the only real is the Idee, and where all its factors and moments, including spirit and nature, are real only at different stages or phases of the Idee, but vanish as imperfect ways of looking at things... . when we reach the Idee."2

Dewey has in mind logic as a science of the forms of reality taken in abstraction from their content. In reality, however, there can be no logic of concepts apart from their concrete application. Hegel certainly never believed that it was possible to abstract the logical forms from reality and study them in their isolation. As against a purely formal logic, if such a thing were possible, Dewey's criticism would be valid, but the transcendental logic of his time was not formal in this sense. The psychological method which Dewey offers as a substitute for the logical method escapes, he believes, the difficulties of the latter method. At the same time it preserves, in his opinion, the essential spirit of the Hegelian method. Dewey's comments show that he conceives his method to be a restatement, in improved form, of the doctrine of the 'concrete universal.' But the 'psychological method' and the method of idealism are, if anything, antithetical. An excellent summary of Dewey's theory is afforded by the following passage: "Only a living actual Fact can preserve within its unity that organic system of differences in virtue of which it lives and moves and has its being. It is with this fact, conscious experience in its entirety, that psychology as method begins. It thus brings to clear light of day the presupposition implicit in every philosophy, and thereby affords logic, as well as the philosophy of nature, its basis, ideal and surety. If we have determined the nature of reality, by a 
process whose content equals its form, we can show the meaning, worth and limits of any one moment of this reality."'1

It would be useless to speculate upon the various possible interpretations that might be given of Dewey's psychological method. The most critical examination of the text will not dispel its vagueness, nor afford an answer to the many questions that arise. It does, however, throw an interesting light on certain tendencies in Dewey's own thinking.

Dewey's attempt to show that English empiricism and transcendentalism have a common psychological basis must be regarded as a failure. That the nature of the attempt reveals a misunderstanding, or fatal lack of appreciation, on the part of Dewey, of the critical philosophy and the later development of idealism by Hegel, has already been suggested. He does not appear to have grasped the significance of the movement from Kant to Hegel. Kant, of course, believed that the $a$ priori forms of experience could be determined by a process of critical analysis, which would reveal them in their purity. The constitutive relations of experience were supposed by him to be limited to the pure forms of sensibility, space and time, and the twelve categories of the understanding, which, being imposed upon the manifold of sensations, as organized by the productive imagination, determined once and for all the order of the phenomenal world. His logic, therefore, as an account of the forms of experience, would represent logic of the type which Dewey criticized. But with the rejection of Kant's noumenal world, the critical method assumed a different import. It was no longer to be supposed that reality, as knowable, was organized under the forms of a determinate number of categories, which could be separated out and classified. Kant's idea that experience was an intelligible system was retained, but its intelligibility was not supposed to be wholly comprised in man's methods of knowing it. The instrumental character of the categories was recognized. Criticism was directed upon the categories, with the object of determining their validity, spheres of relevance, and proper place in the system of knowledge. Such a criticism,

${ }^{1}$ Op. cit. 
in the nature of things, could not deal with the forms of thought in abstraction from their application. Direct reference to experience, therefore, became a necessary element in idealism. At the same time, philosophy became a 'criticism of categories.' The method is empirical, but never psychological.

Dewey recognized the need of an empirical method in philosophy, but failed to show specifically how psychology could deal with philosophical problems. He appears to have conceived that sensation and meaning, facts and forms, were present in experience or 'Consciousness,' as if this were some total understanding which retained the elements in a fixed union and order. While, according to his method, the forms of this universal consciousness could not be considered apart from the particulars in which they inhered, they might be studied by a survey of experience, a direct appeal to consciousness, in which 'form and content are equal.' / He seems to have held that truth is given in immediate experience. A study of reality as immediately given, therefore, to psychological observation, would provide an account of the eternal nature of things, as they stand in the universal mind. Dewey did not attempt a criticism of the categories and methods which psychology must employ in such a task. Had he done so, the advantages of a critical method might have occurred to him. 


\section{CHAPTER II}

THE DEVELOPMENT OF THE PSYCHOLOGICAL STANDPOINT

THE "psychological method," as so far presented, is an outline which must be developed in detail before its philosophical import is revealed. For several years following the publication of his first articles in Mind Dewey was occupied with the task of working out his method in greater detail, and giving it more concrete form. His thought during this period follows a fairly regular order of development, which is to be sketched in the present chapter.

In 1887 Dewey published in Mind an article entitled "Knowledge as Idealisation." 1 This article is, in effect, a consideration of one of the special problems of the "psychological method." If reality is an eternal and all-inclusive consciousness, in which sensations and meanings are ordered according to a rational system, what must be the nature of the finite thought-process which apprehends this reality? In his previous articles Dewey had proposed the "psychological method" as an actual mode of investigation, and questions concerning the nature of the human thought-process naturally forced themselves upon his attention. The thought-process is, to begin with, a relating activity which gives meaning to experience. Says Dewey: "When Psychology recognizes that the relating activity of mind is one not exercised upon sensations, but one which supplies relations and thereby makes meaning (makes experience, as Kant said), Psychology will be in a position to explain, and thus to become Philosophy." ${ }^{-} \backslash$ This statement raises the more specific question, what is meaning?

Every idea, Dewey remarks, has two aspects: existence and meaning. "Recognizing that every psychical fact does have these two aspects, we shall, for the present, confine ourselves to

1 Vol. XII, pp. 382-396.

2 Ibid., p. 394. 
asking the nature, function and origin of the aspect of meaning or significance-the content of the idea as opposed to its existence."1 1 The meaning aspect of the idea cannot be reduced to the centrally excited image existences which form a part of the existence-aspect of the idea. "I repeat,/as existence, we have only a clustering of sensuous feelings, stronger and weaker."2 But the thing is not perceived as a clustering of feelings; the sensations are immediately interpreted as a significant object. "Perceiving, to restate a psychological commonplace, is interpreting. The content of the perception is what is signified." 3 Dewey's treatment of sensations, at this point, is somewhat uncertain. If it be a manifold that is given to the act of interpretation, Kant's difficulty is again presented. The bare sensations taken by themselves mean nothing, and yet everything does mean something in being apprehended. The conclusion should be that there is no such thing as mere existence. Dewey's judgment is undecided on this issue. "It is true enough," he says, "that without the idea as existence there would be no experience; the sensuous clustering is a condition sine qua non of all, even the highest spiritual, consciousness. But it is none the less true that if we could strip any psychical existence of all its qualities except bare existence, there would be nothing left, not even existence, for our intelligence. . . . If we take out of an experience all that it means, as distinguished from what it isa particular occurrence at a certain time, there is no psychical experience. The barest fragment of consciousness that can be hit upon has meaning as well as being." 4 An interpretation of reality as truly organic would treat mechanical sensation as a pure fiction. But Dewey clings to 'existence' as a necessary 'aspect' of the psychical fact. The terms and relations never entirely fuse, although they are indispensable to each other. There is danger that the resulting view of experience will be somewhat angular and structural.

At one point, indeed, Dewey asserts that there is no such thing

${ }^{1}$ Op. cit., p. 383.

2 Ibid.

${ }^{3}$ Ibid., p. 384.

4 Ibid. 
as a merely immediate psychical fact, at least for our experience. "So far is it from being true that we know only what is immediately present in consciousness, that it should rather be said that what is immediately present is never known."1 But in the next paragraph Dewey remarks: "That which is immediately present is the sensuous existence; that which is known is the content conveyed by this existence."2 The sensation is not known, and therefore probably not experienced. In this case Dewey is departing from his own principles, by introducing non-experienced factors into his interpretation of experience. The language is ambiguous. If nothing is immediately given, then the sensuous content is not so given.

The 'sensuous existences' assumed by Dewey are the ghosts of Kant's 'manifold of sensation.' The difficulty comes out clearly in the following passage: "It is indifferent to the sensation whether it is interpreted as a cloud or as a mountain; a danger signal, or a signal of open passage. The auditory sensation remains unchanged whether it is interpreted as an evil spirit urging one to murder, or as intra-organic, due to disordered bloodpressure. . . . It is not the sensation in and of itself that means this or that object; it is the sensation as associated, composed, identified, or discriminated with other experiences; the sensation, in short, as mediated. The whole worth of the sensation for intelligence is the meaning it has by virtue of its relation to the rest of experience." 3

There is an obvious parallel between this view of experience and Kant's. Kant, indeed, transcended the notion that experience is a structure of sensations set in a frame-work of thought forms; but the first Critique undoubtedly leaves the average reader with such a conception of experience. It is unjust to Kant, however, to take the mechanical aspect of his thought as its most important phase. He stands, in the opinion of modern critics, at a half-way stage between the mechanism of the eighteenth century and the organic logic of the nineteenth, and his works point the way from the lower to the higher point of view.

1 op. cit., p. 385 .

2 Ibid.

${ }^{3}$ Ibid., p. 388. 
This was recognized by Hegel and by his followers in England. How does it happen, then, that Dewey, who was well-read in the philosophical literature of the day, should have persisted in a view of experience which appears to assume the externally organized manifold of the Critique of Pure Reason? Or, to put the question more explicitly, why did he retain as a fundamental assumption Kant's 'manifold of sensations'?

So far, Dewey has been concerned with the nature of meaning. He now turns to knowledge, and the knowing process as that which gives meaning to experience. Knowledge, or science, he says, is a process of following out the ideal element in experience. "The idealisation of science is simply a further development of this ideal element. It is, in short, only rendering explicit and definite the meaning, the idea, already contained in perception."1 But if perception is already organized by thought, the sensations must have been related in a 'productive imagination.' Dewey, however, does not recognize such a necessity. The factor of meaning is ideal, he continues, because it is not present as so much immediate content, but is present as symbolized or mediated. But the question may be asked, "Whence come the ideal elements which give to experience its meaning?" No answer can be given except by psychology, as an inquiry into the facts, as contrasted with the logical necessity of experience.

Sensations acquire meaning through being identified with and discriminated from other sensations to which they are related. But it is not as mere existences that they are compared and related, but as already ideas or meanings. "The identification is of the meaning of the present sensation with some meaning previously experienced, but which, although previously experienced, still exists because it is meaning, and not occurrence."2 The existences to which meanings attach come and go, and are new for every new appearance of the idea in consciousness; but the meanings remain. "The experience, as an existence at a given time, has forever vanished. Its meaning, as an ideal quality, remains as long as the mind does. Indeed, its remaining

1 Op. cit., p. 390.

${ }^{2}$ Ibid., p. 392. 
is the remaining of the mind; the conservation of the ideal quality of experience is what makes the mind a permanence."1

It is not possible, Dewey says, to imagine a primitive state in which unmeaning sensations existed alone. Meaning cannot arise out of that which has no meaning. "Sensations cannot revive each other except as members of one whole of meaning; and even if they could, we should have no beginning of significant experience. Significance, meaning, must be already there. Intelligence, in short, is the one indispensable condition of intelligent experience." 2

Thinking is an act which idealizes experience by transforming sensations into an intelligible whole. It works by seizing upon the ideal element which is already there, conserving it, and developing it. It produces knowledge by supplying relations to experience. Dewey realizes that his act of intelligence is similar to Kant's 'apperceptive unity.' He says: “The mention of Kant's name suggests that both his strength and his weakness lie in the line just mentioned. It is his strength that he recognizes that an apperceptive unity interpreting sensations through categories which constitute the synthetic content of self-consciousness is indispensable to experience. It is his weakness that he conceives this content as purely logical, and hence as formal."'3 Kant's error was to treat the self as formal and held apart from its material. "The self does not work with $a$ priori forms upon an $a$ posteriori material, but intelligence as ideal (or $a$ priori) ${ }^{\circ}$ constitutes experience (or the $a$ posteriori) as having meaning." 4 Dewey's standpoint here seems to be similar to that of Green. But as Kant's unity of apperception became for Green merely a symbol of the world's inherent intelligibility, the latter did not regard it as an actual process of synthesis. Dewey fails to make a distinction, which might have been useful to him, between Kant's unity of apperception and his productive imagination. It is the latter which Dewey retains, and he tends to identify it with the empirical process of the understanding.

1 Op. cit.

2 Ibid., p. 393.

3 Ibid., p. 394.

${ }_{4}^{4}$ Ibid., p. 395. 
Knowing, psychologically considered, is a synthetic process. "And this is to say that experience grows as intelligence adds out of its own ideal content ideal quality. . . The growth of the power of comparison implies not a formal growth, but a synthetic internal growth." 1 Dewey, of course, views understanding as an integral part of reality's processes rather than as a process apart, but it is for him a very special activity, which builds up the meaning of experience. "Knowledge might be indifferently described, therefore, as a process of idealisation of experience, or of realisation of intelligence. It is each through the other. Ultimately the growth of experience must consist in the development out of itself by intelligence of its own implicit ideal content upon occasion of the solicitation of sensation."'2

The difficulties of Dewey's original position are numerous. The relation of the self, as a synthetic activity, to the "Eternal Consciousness," in which meaning already exists in a completed form, is especially perplexing. Does the self merely trace out the meaning already present in reality, or is it a factor in the creation of meaning? It is clear that if the thinking process is a genuinely synthetic activity, imposing meaning on sensations, it literally 'makes the world' of our experience. But, on the other hand, if meaning is given to thought, as a part of its data, the self merely reproduces in a subjective experience the thought which exists objectively in the eternal mind. The dilemma arises as a result of Dewey's initial conception of reality as a structure of sensations and meanings. This conception of reality must be given up, if the notion of thought as a process of idealization is to be retained.

In I888, Dewey's Leibniz's New Essays Concerning the Human Understanding appeared, and during the two years following he appears to have become interested in ethical theory, the results of his study beginning to appear in 1890. Dewey's ethical theories have so important a bearing upon his logical theory as to demand special attention. They will be reserved, therefore,

${ }^{1}$ Op. cit.

${ }^{2}$ Ibid., p. 396. (The last sentence forecasts Dewey's later contention that knowing is a specific act operating upon the occasion of need.) 
for a separate chapter, and attention will be given here to the more strictly logical studies of the period.

The three years which intervened between the publication of the essay on "Knowledge as Idealisation" and the appearance of an article "On Some Current Conceptions of the term 'Self,', in Mind (I890), ${ }^{1}$ did not serve to divert Dewey's attention from the inquiries in which he had previously been interested. On the contrary, the later article shows how persistently his mind must have dwelt upon the problems connected with the notion of the self as a synthetic activity in experience.

The immediate occasion for the article on the Self was the appearance of Professor Andrew Seth's work, Hegelianism and Personality (1889). Dewey appears to have been influenced by Seth at an even earlier period, ${ }^{2}$ and he now found the lectures on Hegel stimulating in connection with his own problems about thought and reality.

It will not be necessary to go into the details of Dewey's criticism of the three ideas of the self presented by Seth. Since it is Dewey's own position that is in question, it is better to begin with his account of the historical origin of these definitions, "chiefly as found in Kant, incidentally in Hegel as related to Kant."3 Dewey turns to the 'Transcendental Deduction,' and follows Kant's description of the synthetic unity of apperception. "Its gist," he says, "in the second edition of the K.d.r.V., is the proof that the identity of self-consciousness involves the synthesis of the manifold of feelings through rules or principles which render this manifold objective, and that, therefore, the analytic identity of self-consciousness involves an objective synthetic unity of consciousness." 4 To say that self-consciousness is identical is a merely analytical proposition, and, as it stands, unfruitful. "But if we ask how we know this sameness or identity of consciousness, the barren principle becomes wonderfully fruitful."5 In order to know reality as mine, not only must the

${ }^{1}$ Vol. XV, pp. 58-74.

2 See Mind, Vol. XI, I886, p. I 70.

3 Ibid., p. 63.

${ }^{4}$ Ibid.

5 Ibid., p. 64 . 
consciousness that it is mine accompany each particular impression, but each must be known as an element in one consciousness. "The sole way of accounting for this analytic identity of consciousness is through the activity of consciousness in connecting or 'putting together' the manifold of sense."1

In the 'Deduction' of the first Critique, Dewey continues, Kant begins with the consciousness of objects, rather than with the identity of self-consciousness. Here also consciousness implies a unity, which is not merely formal, but one which actually connects the manifold of sense by an act. "Whether, then, we inquire what is involved in mere sameness of consciousness, or what is involved in an objective world, we get the same answer: a consciousness which is not formal or analytic, but which is synthetic of sense, and which acts universally (according to principles) in this synthesis.",2

The term 'Self,' as thus employed by Kant, Dewey says, is the correlative of the intelligible world. "It is the transcendental self looked at as 'there,' as a product, instead of as an activity or process." 3 This, however, by no means exhausts what Kant means by the self, for while he proceeds in the 'Deduction' as if the manifold of sense and the synthetic unity of the self were strictly correlative, he assumes a different attitude elsewhere. The manifold of sense is something in relation to the thing-initself, and the forms of thought have a reference beyond their mere application to the manifold. In the other connections the self appears as something purely formal; something apart from its manifestation in experience. In view of the wider meaning of the self, Dewey asks, "Can the result of the transcendental deduction stand without further interpretation?" It would appear that the content of the self is not the same as the content of the known world. The self is too great to exhaust itself in relation to sensation. "Sense is, as it were, inadequate to the relations which constitute self-consciousness, and thus there must also remain a surplusage in the self, not entering into

1 Op. cit.

2 Ibid., p. 65.

${ }^{3}$ Ibid. 
the make-up of the known world."1 This follows from the fact that, while the self is unconditioned, the manifold of sensation is conditioned, as given, by the forms of space and time. "Experience can never be complete enough to have a content equal to that of self-consciousness, for experience can never escape its limitation through space and time. Self-consciousness is real, and not merely logical; it is the ground of the reality of experience; it is wider than experience, and yet is unknown except so far as it is reflected through its own determinations in experience,this is the result of our analysis of Kant, the Ding-an-Sich being eliminated but the Kantian method and all presuppositions not involved in the notion of the Ding-an-Sich being retained.",2

Dewey's interpretation of Kant's doctrine as presented in the 'Deductions' is no doubt essentially correct. But granting that Kant found it necessary to introduce a synthesis in imagination to account for the unity of experience and justify our knowledge of its relations, it must not be forgotten that this necessity followed from the nature of his presuppositions. If the primal reality is a 'manifold of sensations,' proceeding from a noumenal source, and lacking meaning and relations, it follows that the manifold must be gathered up into a unity before the experience which we actually apprehend can be accounted for. But if reality is experience, possessing order and coherence in its own nature, the productive imagination is rendered superfluous. Dewey, however, clings to the notion that thought is a "synthetic activity" which makes experience, and draws support from Kant for his doctrine.

Dewey now inquires what relation this revised Kantian conception of the self bears to the view advanced by Seth, viz., that the idea of self-consciousness is the highest category of thought and explanation. Kant had tried to discover the different forms of synthesis, by a method somewhat artificial to be sure, and had found twelve of them. While Hegel's independent derivation and independent placing of the categories must be accepted, it does not follow that the idea of self-consciousness can be included in the list, even if it be considered the highest

1 Op. cit., p. 67.

2 Ibid., p. 68. 
category. "For it is impossible as long as we retain Kant's fundamental presupposition-the idea of the partial determination of sensation by relation to perception, apart from its relation to conception-to employ self-consciousness as a principle of explaining any fact of experience." 1 It cannot be said of the self of Kant that it is simply an hypostatized category. "It is more, because the self of Kant . . . is more than any category: it is a real activity or being.",

Hegel, Dewey continues, develops only one aspect of Kant's Critique, that is, the logical aspect, and consequently does not fulfil Kant's entire purpose. "This is, I repeat, not an immanent 'criticism of categories' but an analysis of experience into its aspects and really constituent elements."'3 Dewey, as usual, shows his opposition to a 'merely logical' method in philosophy. He plainly indicates his dissatisfaction with the Hegelian development of Kant's standpoint. He is unfair to Hegel, however, in attributing to him a 'merely logical' method. Kant's self was, as Dewey asserts, something more than a category of thought, but it is scarcely illuminating to say of Kant that his purpose was the analysis of experience into its 'constituent elements.' Kant did, indeed, analyze experience, but this analysis must be regarded as incidental to a larger purpose. No criticism need be made of Dewey's preference for the psychological, as opposed to the logical aspects of Kant's work. The only comment to be made is that this attitude is not in line with the modern development of idealism.

The question which finally emerges, as the result of Dewey's inquiry, is this: What is the nature of this self-activity which is more than the mere category of self-consciousness? "As long as sensation was regarded as given by a thing-in-itself, it was possible to form a conception of the self which did not identify it with the world. But when sense is regarded as having meaning only because it is 'there' as determined by thought, just as thought is 'there' only as determining sense, it would seem either that the self is just their synthetic unity (thus equalling the

1 Op. cit., p. 70.

2 Ibid., p. 7 r.

${ }^{3}$ Ibid., 
world) or that it must be thrust back of experience, and become a thing-in-itself. The activity of the self can hardly be a third something distinct from thought and from sense, and it cannot be their synthetic union. What, then, is it?"' Green, Dewey says, attempted to solve the difficulty by his "idea of a completely realized self making an animal organism the vehicle of its own reproduction in time." ${ }^{2}$ This attempt was at least in the right direction, acknowledging as it did the fact that the self is something more than the highest category of thought.

Dewey admits his difficulties in a way that makes extended comment unnecessary. He does not challenge the validity of the Hegelian development of the Kantian categories, but proposes to make more of the self than the Hegelians ordinarily do. This synthetic self-activity must reveal itself as a concrete process; that is one of the demands of his psychological standpoint. It is impossible to foresee what this process would be as an actual fact of experience.

Although the next article which is to be considered does not offer a direct answer to the problems which have so far been raised, it nevertheless indicates the general direction which Dewey's thought is to take. This article, on "The Present Position of Logical Theory," was published in the Monist in I89I. ${ }^{3}$ Dewey appears at this time as the champion of the transcendental, or Hegelian logic, in opposition to formal and inductive logic. His attitude toward Hegel undergoes a marked change at this period. Dewey's general objection to formal logic is well expressed in the following passage: "It is assumed, in fine, that thought has a nature of its own independent of facts or subject-matter; that this thought, per se, has certain forms, and that these forms are not forms which the facts themselves take, varying with the facts, but are rigid frames, into which the facts are to be set. Now all of this conception-the notion that the mind has a faculty of thought apart from things, the notion that this faculty is constructed, in and of itself, with a fixed framework, the notion that thinking is the imposing of this fixed

1 Op. cit., p. 73.

2 Ibid.

${ }^{3}$ Vol. II, pp. I-17. 
framework on some unyielding matter called particular objects, or facts-all of this conception appears to me as highly scholastic." 1 The inductive logic, Dewey says, still clings to the notion of thought as a faculty apart from its material, operating with bare forms upon sensations. Kant had been guilty of this separation and never overcame it successfully. Because formal logic views thought as a process apart from the matter with which it has to deal, it can never be the logic of science. "For if science means anything, it is that our ideas, our judgments may in some degree reflect and report the fact itself. Science means, on one hand, that thought is free to attack and get hold of its subject-matter, and, on the other, that fact is free to break through into thought; free to impress itself-or rather to express itself-in intelligence without vitiation or deflection. Scientific men are true to the instinct of the scientific spirit in fighting shy of a distinct a priori factor supplied to fact from the mind. Apriorism of this sort must seem like an effort to cramp the freedom of intelligence and of fact, to bring them under the yoke of fixed, external forms."'2

In opposition to this formal, and, as he calls it, subjective standpoint in logic, Dewey stands for the transcendental logic, which supposes that there is some kind of vital connection between thought and fact; "that thinking, in short, is nothing but the fact in its process of translation from brute impression to lucent meaning." 3 Hegel holds this view of logic. "This, then, is why I conceive Hegel-entirely apart from the value of any special results-to represent the quintessence of the scientific spirit. He denies not only the possibility of getting truth out of a formal, apart thought, but he denies the existence of any faculty of thought which is other than the expression of fact itself." At another place Dewey expresses his view of Hegel as follows: "Relations of thought are, to Hegel, the typical forms of meaning which the subject-matter takes in its various progressive stages of being understood." 5

\footnotetext{
1 Op. cit., p. 4.

2 Ibid., p. I2.

${ }^{3}$ Ibid., p. 3.

${ }^{4}$ Ibid., p. I4.

5Ibid., p. 13.
} 
Dewey's defence of the transcendental logic is vigorous. He maintains that the disrespect into which the transcendental logic had fallen, was due to the fact that the popular comprehension of the transcendental movement had been arrested at Kant, and had never gone on to Hegel.

The objection made to Kant's standpoint is that it treated thought as a process over against experience, imposing its forms upon it from without. "Kant never dreams, for a moment, of questioning the existence of a special faculty of thought with its own peculiar and fixed forms. He states and restates that thought in itself exists apart from fact and occupies itself with fact given to it from without."' While Kant gave the death blow to a merely formal conception of thought, indirectly, and opened up the way for an organic interpretation, he did not achieve the higher standpoint himself. Remaining at the standpoint of Kant, therefore, the critic of the transcendental logic has much to complain of. Scientific men deal with facts, look to them for guidance, and must suppose that thought and fact pass into each other directly, and without vitiation or deflection. They are correct in opposing a conception which would interpose conditions between thought on the one hand and the facts on the other.

But Hegel is true to the scientific spirit. "When Hegel calls thought objective he means just what he says: that there is no special, apart faculty of thought belonging to and operated by a mind existing separate from the outer world. What Hegel means by objective thought is the meaning, the significance of the fact itself; and by methods of thought he understands simply the processes in which this meaning of fact is evolved."2

If Hegel is true to the scientific spirit; if his logic presupposes that there is an intrinsic connection of thought and fact, and views science simply as the progressive realization of the world's ideality, then the only questions to be asked about his logic are questions of fact concerning his treatment of the categories. Is the world such a connected system as he holds it to be? "And, if a system, does it, in particular, present such phases (such

1 Op. cit., p. II.

2 Ibid., p. I2 f. 
relations, categories) as Hegel shows forth?"1 These questions are wholly objective. Such a logic as Hegel's could scarcely make headway when it was first produced, because the significance of the world, its ideal character, had not been brought to light through the sciences. We are now reaching a stage, however, where science has brought the ideality of the world into the foreground, where it may become as real and objective a material of study as molecules and vibrations.

This appreciation of Hegel would seem to indicate that Dewey has finally grasped the significance of Hegel's development of the Kantian standpoint. A close reading of the article, however, dispels this impression. Dewey believes that he has found in Hegel a support for his own psychological method in philosophy. It is scarcely necessary to say that Hegel's standpoint was anything but psychological. Dewey has already given up Kant; he will presently desert Hegel. A psychological interpretation of the thought-process in its relations to reality is not compatible with the critical method in philosophy.

In the next article to be examined, "The Superstition of Necessity," in the Monist (1893)," Dewey begins to attain the psychological description of thought at which he had been aiming. This article was suggested, as Dewey indicates in a foot-note, by Mr. C. S. Pierce's article, "The Doctrine of Necessity Examined," in the Monist (1892). ${ }^{3}$ Although Dewey acknowledges his indebtedness to Pierce for certain suggestions, the two articles have little in common.

Dewey had consistently maintained that thought is a synthetic activity through which reality is idealized or takes on meaning. Is it from this standpoint that he approaches the subject of necessity. The following passage reveals the connection between his former position and the one that he is now approaching: "The whole, although first in the order of reality, is last in the order of knowledge. The complete statement of the whole is the goal, not the beginning of wisdom. We begin, therefore, with fragments, which are taken for wholes; and it is only by

1 Op. cit., p. I4:

2 Vol. III, pp. 362-379.

${ }^{3}$ Vol. II, pp. $32 \mathrm{I}-337$. 
piecing together these fragments, and by the transformation of them involved in this combination, that we arrive at the real fact. There comes a stage at which the recognition of the unity begins to dawn upon us, and yet, the tradition of the many distinct wholes survives; judgment has to combine these two contradictory conceptions; it does so by the theory that the dawning unity is an effect necessarily produced by the interaction of the former wholes. Only as the consciousness of the unity grows still more is it seen that instead of a group of independent facts, held together by 'necessary' ties, there is one reality, of which we have been apprehending various fragments in succession and attributing to them a spurious wholeness and independence. We learn (but only at the end) that instead of discovering and then connecting together a number of separate realities, we have been engaged in the progressive definition of one fact."'1

Dewey adds to his idea that our knowledge of reality is a progressive development of its implicit ideality through a synthetic thought-process, the specification that the process of idealization occurs in connection with particular crises and situations. There comes a stage, he says, when unity begins to dawn and meaning emerges. Necessity is a term used in connection with these transitions from partial to greater realization of the world's total meaning. Necessity is a middle term, or go-between. It marks a critical stage in the development of knowledge. No necessity attaches to a whole, as such. "Qua whole, the fact simply is what it is; while the parts, instead of being necessitated either by one another or by the whole, are the analyzed factors constituting, in their complete circuit, the whole." But when the original whole breaks up, through its inability to comprehend new facts under its unity, a process of judgment occurs which aims at the establishment of a new unity. "The judgment of necessity, in other words, is exactly and solely the transition in our knowledge from unconnected judgments to a more comprehensive synthesis. Its value is just the value of this transition; as negating the old partial and isolated judg-

1 The Monist, Vol. III, I893, p. 364 .

2 Ibid., p. 363. 
ments-in its backward look-necessity has meaning; in its forward look-with reference to the resulting completely organized subject-matter-it is itself as false as the isolated judgments which it replaces." 1 We say that things must be so, when we do not know that they are so; that is, while we are in course of determining what they are. Necessity has its value exclusively in this transition.

Dewey attempts to show, in a discussion which need not be followed in detail, that there is nothing radical in his view, and that it finds support among the idealists and empiricists alike. Thinkers of both schools (he quotes Caird and Venn) admit that the process of judgment involves a change in objects, at least as they are for us. There is a transformation of their value and meaning. "This point being held in common, both schools must agree that the progress of judgment is equivalent to a change in the value of objects - that objects as they are for us, as known, change with the development of our judgments."'2 Dewey proposes to give a more specific description of this process of transformation, and especially, to show how the idea of necessity is involved in it.

The process of transformation is occasioned by practical necessity. Men have a tendency to take objects as just so much and no more; to attach to a given subject-matter these predicates, and no others. There is a principle of inertia, or economy, in the mind, which leads it to maintain objects in their status quo as long as possible. "There is no doubt that the reluctance of the mind to give up an object once made lies deep in its economies. ... I wish here to call attention to the fact that the forming of a number of distinct objects has its origin in practical needs of our nature. The analysis and synthesis which is first made is that of most practical importance. . . ."3 We tend to retain such objects as we have, and it is not until "the original subject-matter has been overloaded with various and opposing predicates that we think of doubting the correctness of our first judgments, of putting our first objects under suspicion."4

1 op. cit.

2 Ibid., p. 364 f.

${ }^{3}$ Ibid., p. 367.

${ }^{4}$ Ibid., p. 366. 
Once the Ptolemaic system is well established, cycles and epicycles are added without number, rather than reconstruct the original object. When, finally, we are compelled to make some change, we tend to invent some new object to which the predicates can attach. "When qualities arise so incompatible with the object already formed that they cannot be referred to that object, it is easier to form a new object on their basis than it is to doubt the correctness of the old. . . ." 1 Let us suppose, then, that under stress of practical need, we refer the new predicates to some new object, and have, as a consequence, two objects. (Dewey illustrates this situation by specific examples.) This separation of the two objects cannot continue long, before we begin to discover that the two objects are related elements in a larger whole. "The wall of partition between the two separate 'objects' cannot be broken at one attack; they have to be worn away by the attrition arising from their slow movement into one another. It is the 'necessary' influence which one exerts upon the other that finally rubs away the separateness and leaves them revealed as elements of one unified whole."'2

The concept of necessity has its validity in such a movement of judgment as has been described. "Necessity, as the middle term, is the mid-wife which, from the dying isolation of judgments, delivers the unified judgment just coming into life-it being understood that the separateness of the original judgments is not as yet quite negated, nor the unity of the coming judgment quite attained." 3 The judgment of necessity connects itself with certain facts in the situation which are immediately concerned with our practical activities. These are facts which, before the crisis arises, have been neglected; they are elements in the situation which have been regarded as unessential, as not yet making up a part of the original object. "Although after our desire has been met they have been eliminated as accidental, as irrelevant, yet when the experience is again desired their integral membership in the real fact has to be recognized. This is done under the guise of considering them as means which are

${ }^{1}$ Op. cit., p. 367 .

2 Ibid., p. 368.

${ }^{3}$ Ibid., p. 363 . 
/ necessary to bring about the end."1 We have the if so, then so situation. "If we are to reach an end we must take certain means; while so far as we want an undefined end, an end in general, conditions which accompany it are mere accidents."2 The end of this process of judgment in which necessity appears as a half-way stage, is the unity of reality; a whole into which the formerly discordant factors can be gathered together.

Only a detailed study of the original text, with its careful illustrations, can furnish a thorough understanding of Dewey's position. Enough has been said, however, to show that this psychological account of the judgment process is a natural outgrowth of his former views, and that, as it stands, it is still in conformity with his original idealism. The article as a whole marks a half-way stage in Dewey's philosophical development. Looking backward, it is a partial fulfilment of the demands of "The Psychological Standpoint." It is a psychological description of the processes whereby self-consciousness specifies itself into parts which are still related to the whole. Looking forward, it forecasts the functional theory of knowledge. We have, to begin with, objects given as familiar or known experiences. So long as these are not put under suspicion or examined, they simply are themselves, or are non-cognitionally experienced. But on the occasion of a conflict in experience between opposed facts and their meanings, a process of judgment arises, whose function is to restore unity. It is in this process of judgment as an operation in the interests of the unity of experience, that the concepts, necessity and contingency, have their valid application and use. They are instruments for effecting a transformation of experience. This is the root idea of functional instrumentalism. It is apparent, therefore, that Dewey's later functionalism resulted from the natural growth and development of the psychological standpoint which he adopted at the beginning of his philosophical career.

1 op. cit., p. 372.

${ }^{2}$ Ibid. 


\section{CHAPTER III}

\section{"MORAL THEORY AND PRACTICE"}

DEWEy's ethical theory, as has already been indicated, stands in close relation to his general theory of knowledge. Since it has been found expedient to treat the ethical theory separately, it will be necessary to go back some two years and trace it from its beginnings. The order of arrangement that has been chosen is fortunate in this respect, since it brings into close connection two articles which are really companion pieces, in spite of the twoyear interval which separates them. These are "The Superstition of Necessity," which was considered at the close of the last chapter, and "Moral Theory and Practice," an article published in The International Journal of Ethics, in January, I89I. ${ }^{1}$ This latter article, now to be examined, is one of Dewey's first serious undertakings in the field of ethical theory, and probably represents some of the results of his study in connection with his text-book, Outlines of a Critical Theory of Ethics, published in the same year (I89r).

The immediate occasion for the article is explained by Dewey in his introductory remarks: "In the first number of this journal four writers touch upon the same question,- the relation of moral theory to moral practice." 2 The four writers mentioned were Sidgwick, Adler, Bosanquet, and Salter. None of them, according to Dewey, had directly discussed the relation of moral theory to practice. "But," he says, "finding the subject touched upon ... . in so many ways, I was led to attempt to clear up my own ideas."'3

There seems to exist, Dewey continues, "the idea that moral theory is something other than, or something beyond, an analysis of conduct, - the idea that it is not simply and wholly 'the theory

1 Vol. I, pp. 186-203.

${ }^{2}$ Ibid., p. 186.

3 Ibid. 
of practice." ", It is often defined, for instance, as an inquiry into the metaphysics of morals, which has nothing to do with practice. But, Dewey believes, there must be some intrinsic connection between the theory of morals and moral practice. Such intrinsic connection may be denied on the ground that practice existed long before theory made its appearance. Codes of morality were in existence before Plato, Kant, or Spencer rose to speculate upon them. This raises the question, What is theory?

Moral theory is nothing more than a proposed act in idea. It is insight, or perception of the relations and bearings of the contemplated act. "It is all one with moral insight, and moral insight is the recognition of the relationships in hand. This is a very tame and prosaic conception. It makes moral insight, and therefore moral theory, consist simply in the everyday workings of the same ordinary intelligence that measures drygoods, drives nails, sells wheat, and invents the telephone."2 The nature of theory as idea is more definitely described. "It is the construction of the act in thought against its outward construction. It is, therefore, the doing, - the act itself, in its emerging."3

Theory is practice in idea, or as foreseen; it is the perception of what ought to be done. This, at least, is what moral theory is. Dewey's demand that fact and theory must have some intrinsic connection, unsatisfied in the articles reviewed in the previous chapter, is met here by discovering a connecting link in action. Theory is "the doing,- - the act itself in its emerging." The reduction of thought to terms of action, here implied, is a serious step. It marks a new tendency in Dewey's speculation. Dewey does not claim, in the present article, that his remarks hold good for all theory. "Physical science," he remarks, "does deal with abstractions, with hypothesis. It says, 'If this, then that.' It deals with the relations of conditions and not with facts, or individuals, at all. It says, 'I have nothing to do with your concrete falling stone, but I can tell you this, that it is a law of falling bodies that, etc." ", But moral theory is compelled to deal

1 op. cit., p. 187 .

${ }^{2}$ Ibid., p. 188.

${ }^{3}$ Ibid.

${ }^{4}$ Ibid., p. I9I f. 
with concrete situations. It must be a theory which can be applied directly to the particular case. Moral theory cannot exist simply in a book. Since, moreover, there is no such thing as theory in the abstract, there can be no abstract theory of morals.

There can be no difficulty, Dewey believes, in understanding moral theory as action in idea. All action that is intelligent, all conduct, that is, involves theory. "For any act (as distinct from mere impulse) there must be 'theory,' and the wider the act, the greater its import, the more exigent the demand for theory."'1 This does not, however, answer the question how any particular moral theory, the Kantian, the Hedonistic, or the Hegelian, is related to action. These systems present, not 'moral ideas' as explained above, but 'ideas about morality.' What relation have ideas about morality to specific moral conduct?

The answer to this question is to be obtained through an understanding of the nature of the moral situation. If an act is moral, it must be intelligent; as moral conduct, it implies insight into the situation at hand. This insight is obtained by an examination and analysis of the concrete situation. "This is evidently a work of analysis. Like every analysis, it requires that the one making it be in possession of certain working tools. I cannot resolve this practical situation which faces me by merely looking at it. I must attack it with such instruments of analysis as I have at hand. What we call moral rules are precisely such tools of analysis." 2 The Golden Rule is such an instrument of analysis. Taken by itself, it offers no direct information as to what is to be done. "The rule is a counsel of perfection; it is a warning that in my analysis of the moral situation (that is, of the conditions of practice) I be impartial as to the effects on me and thee." "3 Every rule which is of any use at all is employed in a similar fashion.

But this is not, so far, a statement of the nature of moral theory, since only particular rules have been considered. Ethical theory, in its wider significance, is a reflective process in which, as

1 op. cit., p. 189.

${ }^{2}$ Ibid., p. I94. Author's Italics.

${ }^{3}$ Ibid. 
one might say, the 'tools of analysis' are shaped and adapted to their work. These rules are not fixed things, made once and for all, but of such a nature that they preserve their effectiveness only as they are constantly renewed and reshaped. Ethical theory brings the Golden Rule together with other general ideas, conforms them to each other, and in this way gives the moral rule a great scope in practice. All moral theory, therefore, is finally linked up with practice. "It bears much the same relation to the particular rule as this to the special case. It is a tool for the analysis of its meaning, and thereby a tool for giving it greater effect." 1 In ethical theory we find moral rules in the making. Ideas about morals are simply moral ideas in the course of being formed.

Dewey presents here an instrumental theory of knowledge and concepts. But it differs widely from the instrumentalism of the Neo-Hegelian school both in its form and derivation. Dewey reaches his instrumentalism through a psychological analysis of the judgment process. He finds that theory is related to fact through action, and since he had been unable to give a concrete account of this relationship at a previous time, the conclusion may be regarded as a discovery of considerable moment for his philosophical method. Dewey's instrumentalism rests upon a very special psychological interpretation, which puts action first and thought second. Unable to discover an overt connection between fact and thought, he delves underground for it, and finds it in the activities of the nervous organism. This discovery, he believes, solves once and for all the ancient riddle of the relation of thought to reality.

In the concluding part of the article Dewey takes up the consideration of moral obligation. "What is the relation of knowledge, of theory, to that Ought which seems to be the very essence of moral conduct?"2 The answer anticipates in some measure the position which was taken later, as has been seen, in regard to necessity. The concept of obligation, like that of necessity, Dewey believes, has relevance only for the judgment situation. "But," Dewey says, "limiting the question as best I can, I

1 op. cit., p. 195.

${ }^{2}$ Ibid., p. 198. 
should say (first) that the 'ought' always rises from and falls back into the 'is,' and (secondly) that the 'ought' is itself an 'is,'-the 'is' of action." 1 Obligation is not something added to the conclusion of a judgment, something which gives a moral aspect to what had been a coldly intellectual matter. The 'ought' finds an integral place in the judgment process. "The difference between saying, 'this act is the one to be done . . . ,' and saying, 'The act ought to be done,' is merely verbal. The analysis of action is from the first an analysis of what is to be done; how, then, should it come out excepting with a 'this should be done'?"' The peculiarity of the 'ought' is that it applies to conduct or action, whereas the 'is' applies to the facts. It has reference to doing, or acting, as the situation demands. "This, then, is the relation of moral theory and practice. Theory is the cross-section of the given state of action in order to know the conduct that should be; practice is the realization of the idea thus gained: in is theory in action."'3

The parallel between this article and "The Superstition of Necessity" is too obvious to require formulation, and the same criticism that applies to the one is applicable to the other. "The Superstition of Necessity" is more detailed and concrete in its treatment of the judgment process than this earlier article, as might be expected, but the fundamental position is essentially the same. The synthetic activity of the self, the thoughtprocess, finally appears as the servant of action, or, more exactly, as itself a special mode of organic activity in general.

From the basis of the standpoint which he had now attained Dewey attempted a criticism of Green's moral theory, in two articles in the Philosophical Review, in 1892 and $\mathrm{r} 893$. The first of these, entitled "Green's Theory of the Moral Motive," appeared almost two years after the article on "Moral Theory and Practice." The continuity of Dewey's thought during the intervening period, however, is indicated by the fact that the first four pages of the article to be considered are given over to

1 Op. cit.

2 Ibid., p. 202.

${ }^{3}$ Ibid., p. 203.

4 Philosophical Review, Vol. I, I892, pp. 593-612. 
an introductory discussion which repeats in almost identical terms the position taken in "Moral Theory and Practice." Dewey himself calls attention to this fact in a foot-note.

There must be, Dewey again asserts, some vital connection of theory with practice. "Ethical theory must be a general statement of the reality involved in every moral situation. It must be action stated in its more generic terms, terms so generic that every individual action will fall within the outlines it sets forth. If the theory agrees with these requirements, then we have for use in any special case a tool for analyzing that case; a method for attacking and reducing it, for laying it open so that the action called for in order to meet, to satisfy it, may readily appear."1 Dewey argues that moral theory cannot possibly give directions for every concrete case, but that it by no means follows that theory can stand aside from the specific case and say: "What have I to so with thee? Thou art empirical, and I am the metaphysics of conduct."

Dewey's preliminary remarks are introductory to a consideration of Green's ethical theory. "His theory would, I think," Dewey says, "be commonly regarded as the best of the modern attempts to form a metaphysic of ethic. I wish, using this as type, to point out the inadequacy of such metaphysical theories, on the ground that they fail to meet the demand just made of truly ethical theory, that it lend itself to translation into concrete terms, and thereby to the guidance, the direction of actual conduct."2 Dewey recognizes that Green is better than his theory, but says that the theory, taken in logical strictness, cannot meet individual needs.

Dewey makes a special demand of Green's theory. $\mathrm{He}$ demands, that is, that it supply a body of rules, or guides to action which can be employed by the moral agent as tools of analysis in cases requiring moral judgment. It is evident in advance that Green's theory was built upon a different plan, and can not meet the conditions which Dewey prescribes. The general nature of Green's inquiry is well stated in the following summary by Professor Thilly: 'The truth in Green's thought is

i Op. cit., p. 596.

2 Ibid., p. 597. 
this: the purpose of all social devotion and reform is, after all, the perfection of man on the spiritual side, the development of men of character and ideals. . . . The final purpose of all moral endeavor must be the realization of an attitude of the human soul, of some form of noble consciousness in human personalities. ... It is well enough to feed and house human bodies, but the paramount question will always be: What kinds of souls are to dwell in these bodies?"1 To put the matter in more technical terms, Green is concerned with ends and values. His question is not, What is the best means of accomplishing a given purpose, but, What end is worth attaining? Such an inquiry has no immediate relation to action. It may lead to conclusions which become determining factors in action, but the process of inquiry has no direct reference to conduct. Dewey, having reduced thought to a function of activity, must proceed, by logical necessity, to carry the same reduction into the field of theory in general. This he does in thorough style. His demand that moral theory shall concern itself with concrete and 'specific' situations is a result of the same tendency. Since action can only be described as response to a 'situation,' thought, as a function of activity, must likewise be directed upon a 'situation.' Conduct in general and values in general become impossible under his system, because there is no such thing as an activityin-general of the organism. Ends, in other words, exist only for thought, when thought is interpreted as transcending action, and being, in some sense, self-contained. When thought is interpreted as a kind of 'indirect activity,' its capacity for metaphysical inquiry vanishes along with its independence.

It would have been more in keeping with sound criticism had Dewey himself taken note of the important divergence in aim and intent between his work and Green's. As a consequence of his failure to do so, he fails, necessarily, to do justice to Green's standpoint. The criticism which he directs against Green's moral theory may be briefly summed up as follows.

Green tends to repeat the Kantian separation of the self as reason from the self as want or desire.

"The dualism between

1 History of Philosophy, p. 555. 
reason and sense is given up, indeed, but only to be replaced by a dualism between the end which would satisfy the self as a unity or whole, and that which satisfies it in the particular circumstances of actual conduct." 1 As a consequence of the separation of the ideal from the actual, no action can satisfy the whole self, and thus no action can be truly moral. "No thorough-going theory of total depravity ever made righteousness more impossible to the natural man than Green makes it to a human being by the very constitution of his being. ..." Dewey traces this separation of the self as reason from the self as desire through those passages in which Green describes the moral agent as one who distinguishes himself from his desires (Book II, Prolegomena to Ethics). "The process of moral experience involves, therefore, a process in which the self, in becoming conscious of its want, objectifies that want by setting it over against itself; distinguishing the want from self and self from want. . . . Now this theory so far might be developed in either of two directions." 3

In the first place, the self-distinguishing process may be an activity by means of which the self specifies its own activity and satisfaction. "The particular desires and ends would be the modes in which the self relieved itself of its abstractness, its undeveloped character, and assumed concrete existence. ... The unity of the self would stand in no opposition to the particularity of the special desire; on the contrary, the unity of the self and the manifold of definite desires would be the synthetic and analytic aspects of one and the same reality, neither having any advantage metaphysical or ethical over the other!" But Green, unfortunately, does not develop his theory in this concrete direction. The self does not specify itself in the particulars, but remains apart from them. "The objectification is not of the self in the special end; but the self remains behind setting the special object over against itself as not adequate to itself. . . . The unity of the self sets up an ideal of satisfaction for itself as it

1 Philosophical Review, Vol. I, I892, p. 598.

2 Ibid.

Ibid., p. 599.

"Ibid. Compare with the passage in "Psychology as Philosophic Method," Mind, Vol. XI, p. 9. 
withdraws from the special want, and this ideal set up through negation of the particular desire and its satisfaction constitutes the moral ideal. It is forever unrealizable, because it forever negates the special activities through which alone it might, after all, realize itself." In completing this argument Dewey refers to certain well-known passages in the Prolegomena to Ethics, in which Green states that the moral ideal is never completely attainable. Green's abstract conception of the self as that which forever sets itself over against its desires is, Dewey argues, not only useless as an ideal for action, but positively opposed to moral striving. "It supervenes, not as a power active in its own satisfaction, but to make us realize the unsatisfactoriness of such seeming satisfactions as we may happen to get, and to keep us striving for something which we can never get!"'2 The most that can be made of Green's moral ideal is to conceive it as the bare form of unity in conduct. Employed as a tool of analysis, as a moral rule, it might tell us, "Whatever the situation, seek for its unity." But it can scarcely go even as far as this in the direction of concreteness, for it says: "No unity can be found in the situation because the situation is particular, and therefore set over against the unity."3

Most students of Green would undoubtedly say that this account of his moral theory is entirely one-sided, and fails to reckon with certain elements which should properly be taken into account. In the first place, Green is defining the moral agent as he finds him, and is reporting what seems to him a fact when he says that the moral ideal is too high to be realized in this life. Having a spiritual nature, man fails to find satisfaction in the goods of natural life. Dewey should address himself to the facts in refuting Green's analysis of human nature. In the second place, with respect to Green's separation of the self as unity from the self as a manifold of desires, Dewey's criticism may be flatly rejected. Green raises the question himself: “' Do you mean,' it may be asked, 'to assert the existence of a mysterious abstract entity which you call the self of a man, apart from all his par-

1 op. cit., p. 600.

2 Ibid., p. 60I.

'Ibid., p. 602. 
ticular feelings, desires, and thoughts -all. the experience of his inner life?"', Green takes time to state his position as clearly as possible. He repudiates the idea of an abstract self apart from desire. The following passage is typical of his remarks: "Just as we hold that our desires, feelings, and thoughts would not be what they are-would not be those of a man-if not related to a subject which distinguishes itself from each and all of them; so we hold that this subject would not be what it is, if it were not related to the particular feelings, desires, and thoughts, which it thus distinguishes from and presents to itself." ${ }^{2}$ It will be remembered also, that in moral action the agent identifies himself with his desires, or adopts them as his own, and the ability to do this is the chief mark of human intelligence. But man could not identify himself with his desires, or 'specify himself in them,' as Dewey says, did he not at the same time have the capacity to differentiate himself from them.

Dewey's further remarks on Green's ideal need not be followed in detail, since they rest upon a misapprehension of Green's purpose, and add little to what he has already said. Taking the moral ideal as something that can never be realized in this life, Dewey inquires what use can be made of it. He considers three modes in which Green might have given content to the ideal, as a working principle, and finds that it cannot be made, in any of these ways, to serve as a tool of analysis. Green was not prepared to meet these 'pragmatic' requirements. He did not propose his ideal as a principle of conduct, in Dewey's sense; he stated that, as a matter of fact, man is more than natural, and that, as such a being, his ideals can never be completely met by natural objects. How man is to act, in view of his spiritual nature, is a further question: but the realization which the individual has of his own spiritual nature must of necessity be a large factor in the determination of his conduct. The 'Spiritual Nature,' in Green's terminology, meant a 'not-natural' nature, and 'not-natural' in turn meant a nature that is not definable in mechanical or biological terms. Dewey's criticism, therefore, went wide of the mark.

1 Prolegomena to Ethics, third ed., p. 103.

2 Ibid., p. ro4. 
In November, 1893, Dewey followed his criticism of Green's moral motive by a second article in the Philosophical Revierw on "Self-realization as the Moral Ideal." 1 It continues the criticism which has already been made of Green, but from a different point of departure.

The idea of self-realization in ethics, Dewey begins, may be helpful or harmful according to the way in which the ideas of the self and its realization are worked out in the concrete. The mere idea of a self to be realized is, of course, abstract; it is merely the statement of a problem, which needs to be worked out and given content. By way of introducing his own idea of selfrealization, Dewey proposes to criticize a certain conception of the self which he finds in current discussion. "The notion which I wish to criticize," he says, "is that of the self as a presupposed fixed schema or outline, while realization consists in the filling up of this schema. The notion which I would suggest as substitute is that of the self as always a concrete specific activity; and, therefore, (to anticipate) of the identity of self and realization." Such a presupposed fixed self is to be found in Green's "Eternally complete Consciousness."

The idea of self-realization implies capacities or possibilities. To translate capacity into actuality, as the conception of the fixed self seems to do, is to vitiate the whole idea of possibility. There must, then, be some conception of unrealized powers which will meet this difficulty. The way to a valid conception is through the realization that capacities are always specific. "The capacities of a child, for example, are not simply of $a$ child, not of a man, but of this child, not of any other."3 Whatever else capacity may be, whether infinite or not, it must be an element in an actual situation. As specific things, moreover, capacities reside in activities, which are now going on. The capacity of a child to become a musician consists in this fact: "Even now he has a certain quickness, vividness, and plasticity of vision, a certain deftness of hand, and a certain motor coördi-

1 Vol. II, pp. 652-664.

${ }^{2}$ Ibid., p. 653.

${ }^{3}$ Ibid., p. 655 . 
nation by which his hand is stimulated to work in harmony with his eye."1

How do these specific, actual activities come to be called capacities? There is a peculiar psychological reason for this which James has pointed out, in his statement that essence "is that which is so important for my interests that, comparatively, other properties may be omitted." 2 When we pay attention to any activity, there is a natural tendency to select only that portion of it that is of immediate interest, and to exclude the rest as irrelevant. "In the act of vision, for example," Dewey tells us, "the thing that seems nearest us, that which claims continuously our attention, is the eye itself. We thus come to abstract the eye from all special acts of seeing; we make the eye the essential thing in sight, and conceive of the circumstances of vision as indeed circumstances; as more or less accidental concomitants of the permanent eye." 3 There is no eye in general; the eye is always given along with other circumstances which in their totality make up a concrete seeing situation. Nevertheless, we abstract the eye from other circumstances and set it up as the essence of seeing. But we cannot retain the eye in absolute abstraction, because the concrete circumstances of vision force themselves upon the attention. So we lump these together on the other side as a new object, and take as their essence the vibrations of ether. "The eye now becomes the capacity of seeing; the vibrations of ether, conditions required for the exercise of the capacity." 4 We keep the two abstractions, but try to restore the unity of the situation through taking one as capacity and the other as the condition of the exercise of capacity.

But we cannot stop even with this double abstraction. "The eye in general and the vibrations in general do not, even in their unity, constitute the act of vision. A multitude of other factors are included."5 Preserving the original 'core' as capacity, we tend to treat all the attendant circumstances which occur fre-

1 Op. cit., p. 656.

${ }^{2}$ Ibid., p. 657.

${ }^{3}$ Ibid.

${ }^{4}$ Ibid., p. 658. Author's italics.

${ }^{5}$ Ibid. 
quently enough to require taking account of, as conditions which help realize the abstracted reality called capacity.

The discussion here is very much like that in "The Superstition of Necessity" (published in the same year), which was reviewed in the last chapter. Dewey calls attention to this connection in a foot-note, remarking that he has already developed at greater length "the idea that necessity and possibility are simply the two correlative abstractions into which the one reality falls apart during the process of our conscious apprehension of it."' The danger, Dewey says, is that the merely relative character of a given capacity may be overlooked, and that it may be ontologized into a fixed entity. This is the error, he thinks, into which Green fell. The ideal self, as that which capacity may realize, is ontologized into an already existent fact. Then we get a separation between the present self, as capacity, and the ideal self which is to be realized. The self already realized is opposed to the self as yet ideal. "This 'realized self' is no reality by itself; it is simply our partial conception of the self erected into an entity. Recognizing its incomplete character, we bring in what we have left out and call it the 'ideal self.' Then by way of dealing with the fact that we have not two selves here at all, but simply a less and a more adequate insight into the same self, we insert the idea of one of these selves realizing the other." 2 It is in this manner that error arises.

But what is the correct attitude toward the self? First of all, the self must be conceived as "a working, practical self, carrying within the rhythm of its own process both 'realized' and 'ideal' self. The current ethics of the self . . . are too apt to stop with a metaphysical definition, which seems to solve problems in general, but at the expense of the practical problems which alone really demand or admit solution." 3 The first point of the argument is that the self activity is individual, concrete, and specific, here and now, and the second point is that if the self is to be talked of in an intelligent way it must be taken as something empirically given. "The whole point is expressed when we say

1 op. cit., note.

2 Ibid., p. 663.

${ }^{3}$ Ibid. 
that no possible future activities or conditions have anything to do with the present action except as they enable us to take deeper account of the present activity, to get beyond the mere superficies of the act, to see it in its totality." 1 The phrase, ' realize yourself,' is a direction for knowledge; it means, see the wider consequences of your act, realize its wider bearings.

Dewey says: "The fixed ideal is as distinctly the bane of ethical science today as the fixed universe of mediævalism was the bane of the natural science of the Renascence." 2 This is a strong statement, which indicates how wide was the gulf which now separated Dewey from Green, whom he formerly acknowledged as his master.

Dewey's interpretation of Green's ideal self is far from satisfactory, largely because of its lack of insight and appreciation. The reduction of thought to a 'form of activity' renders a purely theoretical inquiry impossible. The 'present activity,' the biological situation, becomes the measure of all things, even of thought. Ideals, in his own words, have nothing to do with present action, "except as they enable us to take deeper account of the present activity." Dewey's self and Green's are incommensurable. The former is the biological organism, with a capacity for indirect activity called thinking; the latter is a notnatural being, whose reality escapes the logic of descriptive science, because of the fulness of its content. Dewey's failure to understand this difference is significant. His acquaintance with Green seems to have been formal from the beginning, never intimate, and the articles just reviewed mark the end of Dewey's idealistic discipleship. His psychological idealism, in fact, was fundamentally antithetical to the Neo-Hegelianism which he had sought to espouse, and the development of his own standpoint brought out the vital differences which had been hidden from his earlier understanding. The idealism which seeks to view reality together and as a whole is forever incompatible with a method which seeks to interpret the whole in terms of one of its parts.

1 Op. cit., p. 659 .

2 Ibid., p. 664. 


\section{CHAPTER IV}

\section{FUNCTIONAL PSYCHOLOGY}

IT now becomes necessary to review that period of Dewey's philosophical career which is marked by the definite abandonment of the idealistic standpoint, and the adoption of the method of instrumental pragmatism. It has already been seen that there is a close connection between the "functionalism" which now begins to appear, and the "Psychological Standpoint" set forth in the preceding pages of this review. It is not possible, however, to account for all the elements which contribute to this development. Dewey was active in many fields and received suggestions from many sources. It seems best, in dealing with this period, to "follow the lead of the subject-matter" and avoid a priori speculation on the factors which determined the precise form of Dewey's mature standpoint in philosophy.

Dewey had always kept in mind the idea that the synthetic activity whereby self-consciousness evolves the ideality of the world must operate through the human organism. He had frequently referred to Green's saying that the Eternal Self-Consciousness reproduces itself in man, and to similar notions in Caird and Kant; but he had never considered, in a detailed way, how the organism might serve as the vehicle for such a process. His ethical theory, with its analysis of individuality into capacity and environment, tended to bring the body-world relationship into the foreground, and the idea that theory is relative to action tended to emphasize still more the relation of thought to the bodily processes. Dewey finally discovers the basis upon which the synthetic activity of the self, the thought process, may be described empirically and concretely. Organism-in-relation-toenvironment becomes the key-stone of his theory of knowledge. Thought is interpreted as a function of the organism, biologically considered, and the biological psychology which results from this mode of interpretation is commonly known as 'functional psychology.' 
The functional psychology is presented in a series of articles in the Philosophical Review and the Psychological Review, published between I 894 and I898. The most important of these is "The Reflex Arc Concept in Psychology," published in the Psychological Review in 1896.1 Since it is the only article in the series which gives a complete view of the theory, it will be made the basis for the discussion of the functional theory of psychology.

The reflex arc concept in psychology, Dewey says, recognizes that the sensory-motor arc is to be taken as the unit of nerve structure, and the type of nerve function. But psychologists do not avail themselves of the full value of this conception, because they still retain in connection with it certain distinctions which were used in the older psychology. "The older dualism between sensation and idea is repeated in the current dualism of peripheral and central structures and functions; the older dualism of body and soul finds a distinct echo in the current dualism of stimulus and response." 2 These rigid distinctions must be set aside, and the separated elements must be viewed as elements in one sensory-motor coördination. Each is to be defined, not as something existing by itself, but as an element functioning in a concrete whole of activity. Thus, if we are to study vision, we must first take vision as a sensory-motor coördination, the act of seeing, and within the whole we may then be able to distinguish certain elements, sensations, or movements, and define them according to their function in the total act of seeing. The reflex arc idea, as commonly employed, takes sensation as stimulus, and movement as response, as if they were actually separate existences, apart from a coördination. Response is said to follow sensation, but it is forgotten that the sensation which preceded was corrèlated with a response, and that the response which follows is also correlated with sensation. Sound, for instance, is not a mere sensation in itself, apart from sensory-motor coördination. Hearing is an act, and while sound may, for purposes of study, be abstracted from the total, it is not, in itself, independent of the total act of hearing.

1 Vol. III, pp. 357-370.

2 Ibid., p. 357 . 
"But, in spite of all this, it will be urged, there is a distinction between stimulus and response, between sensation and motion. Precisely; but we ought now to be in a condition to ask of what nature is the distinction, instead of taking it for granted as a distinction somehow lying in the existence of the facts themselves." 1 The distinction which is to be made between them must be made on a teleological basis. "The fact is that stimulus and response are not distinctions of existence, but teleological distinctions, that is, distinctions of function, or part played, with reference to reaching or maintaining an end."2 There are two kinds of teleological distinction that can be made between stimulus and response, or rather, the teleological interpretation has two phases.

In the first place, it may be assumed that all of man's activity furthers some general end, as, for instance, the maintenance of life. Then man's activity may be viewed as a sequence of acts, which tend to further this end, and on this basis we may separate out stimulus and response. "It is only when we regard the sequence of acts as if they were adapted to reach some end that it occurs to us to speak of one as stimulus and the other as response. Otherwise, we look at them as a mere series." 3 In these cases the stimulus is as truly an act as the response, and what we have is a series of sensory-motor coördinations. Looking, for instance, is a sensory-motor coördination which is the stimulus or antecedent of another coördinated act, running away. The first coördination passes in to the second, and the second may be viewed as a modification or reconstitution of the first.

But this external teleological distinction between sensation and response is not so important as the distinction now to be made. So far only fixed coördinations, habitual modes, of action, have been considered. But there are situations in which habitual responses and fixed modes of action fail: situations in which new habits are formed. In these situations there arises a special distinction between stimulus and response, for in these formative situations the stimuli and responses are consciously present in

1 Op. cit., p. 365.

${ }^{2}$ Ibid.

${ }^{3}$ Ibid., p. 366 , note. 
experience as such. "The circle is a coördination, some of whose members have come into conflict with each other. It is the temporary disintegration and need of reconstitution which occasions, which affords the genesis of, the conscious distinction into sensory stimulus on one side and motor response on the other."1 The distinction which arises between stimulus and response is a distinction of function within the problematical situation. Suppose that a sound is heard, the character of which is uncertain, and which, as a coördination, does not readily pass into its following coördination, or habitual response. The sound is puzzling, and moves into the center of attention. It is fixed upon, abstracted, studied on its own account. In that event, the sound may be spoken of as a sensation. As a sensation, it is the datum of a reflective process of thought, or conscious inference, whose aim is to constitute the sound a stimulus, or, in other words, to find what response belongs to it. When this response is determined the problem is done with and sensorymotor unity is achieved.

The stimulus, in these cases, is simply "that phase of activity requiring to be defined in order that a coördination may be completed."' It is not any particular existence, and is not to be taken as an element apart from others, having an independent existence. But the conscious process of attending to the sensation and finding a response to it arises only when coördination is disturbed by conflicting factors, and the separation of stimulus from response arises only as a means for bringing unity into the coördination. The sensation, then, is that element which is to be attended to; upon which further response depends. This phase of the teleological interpretation defines each element by the part which it plays in the reflective process.

If this brief summary of the article is difficult to comprehend, a reading of the original text will do little towards making it more intelligible. The doctrine presented there, however, is simple and coherent enough when its bearings and purpose are once understood, and, at the risk of being over-elaborate, it seems

${ }^{1}$ Op. cit., p. 370.

2 Ibid., p. 368. 
advisable to attempt some remarks on the general bearing and applications of the theory.

It must be remembered that Dewey is seeking an interpretation of the thought process which shall reveal it as an actual fact of experience. A thought which is apart from experience and not in it, which is shut up to the contemplation of its own mental states is, by its definition, non-experienced. It is, like Kant's 'productive imagination,' formative of experience, but not a part of it. Dewey holds to the belief that experience must be explained in terms of itself; he would do away with all transcendental factors in the explanation of reality. But modern psychological theory, Dewey believes, tends to shut thought in to the contemplation of its own subjective states, and thus gives it an extra-experiential status. A stimulus is said to strike upon an end organ, which sends an impulse to the cortex and there gives rise to a sensation which, as the effect of a stimulus, is representative of the real, but not real in itself. Thought, again, interprets the sensation, and sends out a motor impulse appropriate to the situation. These mental states and the thought which interprets them are, in Dewey's mind, wholly fictitious. The problem, then, is to give an account of the perceptual processes which shall eliminate the artificial states of mind and present mental operations as natural processes.

The difficulty with customary psychological explanation is that it breaks the reflex arc of the nervous system into three parts whose relations are successive and causal rather than simultaneous and organic. There is not first a stimulus, then perception, then response; these processes are supplementary, not separate. Or, from another point of view, psychological explanation must begin with a whole process which, when analyzed, is seen to contain the three moments or phases: stimulus, sensation, and response. The whole process is primary and actual, the abstracted phases are secondary and derivative.

With the disappearance of the mechanical interpretation of the perceptual process, mental states vanish. Representative perceptionism is thus done away with, together with all the problems which it generates. 
The position of conscious, or reflective thought, in Dewey's scheme, is especially interesting. This mode of thought is not constantly operative, but arises only in situations of stress and strain, when habitual modes of response break down. A dualism is established between reflective thought and the habitual life processes. Dewey does not take the ground that these processes are supplementary, as he had done in the case of stimulus, sensation, and response. It will be remembered that Dewey had defined judgment, in his logical and ethical writings of an earlier period, as a special activity operating in critical situations. This conception of judgment is now carried over into his psychology, and given a biological basis. It is worth noting that this view of judgment was worked out in logical terms before it was reinforced by biological data. Nevertheless, it is through biology that Dewey is able to give his interpretation of the thought process that empirical concreteness which he demanded from the beginning, but achieved very slowly.

The value of the functional psychology, considered merely as psychology, is undeniable. It is, in fact, a natural and almost inevitable step in the development of psychological theory. Dewey's achievement consists in the establishment of an organic mode of interpretation in psychology, intended to displace the mechanical interpretation. The mechanical causal series is displaced by an organic system of internally related parts. Dewey, however, does not display any interest in the logical aspects of his doctrine. He takes the biological situation literally, as a fact empirically given, and to be accepted without criticism.

A discussion of the period now under consideration would not be complete without reference to certain articles which supplement the essay discussed above. The first of these is an article on "The Psychology of Effort," published in the Philosophical Review in $1897 .{ }^{1}$

It is not proposed to follow the argument of this article in detail, but to center attention upon those parts of it, especially the concluding pages, which have a special interest in connection

1 Vol. VI, pp. 43-56. 
with the subject under discussion. Dewey returns, in this article, to the situation of effort at adjustment; to the situation in which an effort is made to determine the proper response to a stimulus. The opening pages are devoted, in the first place, to a discussion of the distinction between conscious effort and the mere expenditure of energy or effort as it appears to an outsider, and, in the second place, to maintaining, by means of examples, the proposition that the sense of effort is sensationally mediated. "How then does, say, a case of perception with effort differ from a case of 'easy' or effortless perception? The difference, I repeat, shall be wholly in sensory quale; but in what sensory quale?"'1

The conscious sense of effort arises, Dewey answers, when there is a rivalry or conflict between two sensational elements in experience. "In the case of felt effort, certain sensory quales, usually fused, fall apart in consciousness, and there is an alternation, an oscillation, between them, accompanied by a disagreeable tone when they are apart, and an agreeable tone when they become fused again." 2 These two sets of sensory elements have each a significance in terms of adjustment; one of them is a correlate of a habit, or fixed mode of response, and the other is an intruder which resists absorption into, or fusion with, the dominant images of the current habit or purpose. The same idea of a natural tendency to persist in a habitual mode of regarding things was met with in the last two chapters, and is qualified here by the addition of the idea that each sensory element represents a typical mode of response on the part of the organism. Dewey illustrates his notion by the case of learning to ride a bicycle. "Before one mounts one has perhaps a pretty definite visual image of himself in balance and in motion. This image persists as a desirability. On the other hand, there comes into play at once the consciousness of the familiar motor adjustments,-for the most part, related to walking. The two sets of sensations refuse to coincide, and the result is an amount of stress and strain relevant to the most serious problems of the

1 op. cit., p. 46.

2 Ibid., p. 48. 
universe."1 In another passage, which brings out even more clearly the rivalry of the two sets of sensations, he says: "It means that the activity already going on (and, therefore, reporting itself sensationally) resists displacement, or transformation, by or into another activity which is beginning, and thus making its sensational report."'2

The sense of effort, then, reduces itself to an awareness of conflict between two sensational elements and their motor correlates. "Practically stated, this means that effort is nothing more, and also nothing less, than tension between means and ends in action, and that the sense of effort is the awareness of this conflict."'3

The important aspect of Dewey's argument, for the present discussion, is that awareness reduces to these sensational elements and their attributes. Throughout the article Dewey is opposing his sensational view of the sense of effort to what he calls the 'spiritual' or non-sensational view, which supposes that the sense of effort is something purely psychical, which accompanies the expenditure of physical energy. The consciousness of effort, Dewey says, is not something added to the effort, but is itself a certain condition existing in the sensory quales.

This provision would make it necessary to identify consciousness, and, therefore, conscious inference, with the tensional situation which has been described. This being granted, all that pertains to conscious inference, all the methods and categories of science, would be applicable only in such situations of stress and strain; they would appear simply as instruments for effecting a readjustment; they would be employed exclusively in the interests of action. This is the direction in which Dewey is tending. No criticism of this treatment of judgment need be made at this time, beyond pointing out that it presents itself, at first sight, as an awkward and indirect mode of describing the relations between organic activity and intelligence, and between psychology and logic.

Nothing has so far been said of the historical sources of Dewey's

1 Op. cit., p. 50.

2 Ibid., p. 52.

3 Ibid., p. 5 r. 
theory, and these may be briefly considered. There are at least two sources which must be taken into account: the JamesLange theory of the emotions, and the Neo-Hegelian ethical theory. The latter has already been considered to some extent, as it manifests itself in Dewey's own ethical theory, but its relation to his psychology has not been indicated. In his textbook, the Outlines of a Critical Theory of Ethics (1891), Dewey advanced certain ideas for which he claimed originality, at least in treatment. Among these was the analysis of individuality into function including capacity and environment. ${ }^{1}$

Bradley appears to have been the first among English philosophers to introduce that synthesis of the internal and external, of the intuitional and utilitarian modes of judging conduct, which became characteristic of Neo-Hegelian ethics. The synthesis, of course, is Hegelian in temper, and the Ethical Studies are much more suggestive, in general method, of the Philosophie des Rechts than of any previous English work. Utilitarianism tended to judge the moral act by its external, de facto results; intuitionism, on the contrary, attributed morality to the will of the agent. The former found morality to consist in a certain state of affairs, the latter in a certain internal attitude. According to the synthetic point of view, these opposed ethical systems are one-sided representations of the moral situation, each being true in its own way. To state the matter in another form, the moral act has a content as well as a purpose. "Let us explain," says Bradley. "The moral world, as we said, is a whole, and has two sides. There is an outer side, systems and institutions, from the family to the nation; this we may call the body of the moral world. And there must also be a soul, or else the body goes to pieces; every one knows that institutions without the spirit of them are dead. . . . We must never let this out of our sight, that, where the moral world exists, you have and you must have these two sides." " Dewey expresses the same idea in a more detailed fashion. "What do we mean by individuality? We may distinguish two factors-or better two aspects, two sides-in indi-

1 Op. eit., p. viii.

${ }^{2}$ Ethical Studies, p. $160 \mathrm{f}$. 
viduality. On one side it means special disposition, temperament, gifts, bent, or inclination; on the other side it means special station, situation, limitations, surroundings, opportunities, etc. Or, let us say, it means specific capacity and specific environment. Each of these elements apart from the other, is a bare abstraction, and without reality. Nor is it strictly correct to say that individuality is contributed by these two factors together. It is, rather, as intimated above, that each is individuality looked at from a certain point of view, from within and from without." 1 It is a fact, empirically demonstrable, according to Dewey, that body and object, intention and foreseen consequence, interest and environment, attitude and objectivity, are parts of one another and of the whole moral situation. Each is relative to the other. "It is not, then, the environment as physical of which we are speaking, but as it appears to consciousness, as it is affected by the make-up of the agent. This is the practical or moral environment." 2 When this relation of the inner to the outer is taken literally and universally, we have the essence of the functional psychology. Organism-in-relation-to-environment becomes the catch-word of instrumental pragmatism.

The other source of Dewey's psychology, which is now to be considered, is the James-Lange theory of the emotions. The connection here is more obvious, but perhaps not so vital, as in the case of the ethical theory. From the numerous references which Dewey made to James's Principles of Psychology (1890), it is evident that he was much impressed with this work. The theory of emotion there presented seems to have had a special interest for him; so much so that he made it the subject of two articles in the Psychological Review, in 1894 and I895, under the general title, "The Theory of Emotion."3 These studies bear a very close relation to the article on "The Reflex Arc Concept in Psychology" (1896), the standpoint being essentially the same, although developed in reference to a technical problem. Some indications may be given here of the relationships which they

1 Outlines of Ethics, p. 97.

2 Ibid., p. 99.

${ }^{3}$ Vol. I, pp. 553-569; Vol. II, pp. 13-32. 
bear to the James-Lange theory on the one side, and functional psychology on the other. The James-Lange theory is itself concerned with order and connection between emotional states, perceptions, and responses. James says: "Our natural way of thinking about these coarser emotions is that the mental perception of some fact excites the mental affection called the emotion, and that this latter state of mind gives rise to the bodily expression. My theory, on the contrary, is that the bodily changes follow directly the perception of the exciting fact, and that our feeling of the same changes as they occur IS the emotion."1 It is all a question, James says, of the order and sequence of these elements, and his contention is that the bodily changes should be interposed between the two mental states. This is the question with which Dewey's functional psychology is also concerned, the relation of response to stimulus, and the manner in which a stimulus is determined by a reaction 'into it.' Dewey's theory rises so naturally out of James's theory of the emotions as to seem but little more than its universal application.

This connection is revealed in several passages in Dewey's study of the emotions. It is said, for instance, that the emotional situation must be taken as a whole, as a state, for instance, of 'being angry.' The several constituents of the state of anger, idea or object, affect or emotion, and mode of expression or behavior, are not to be taken separately, but all together as elements in one whole. ${ }^{2}$ Another characteristic doctrine appears in the affirmation that the emotional attitude is to be distinguished from other attitudes by certain special features which it possesses. Particularly, it involves a special relation of stimulus to response. ${ }^{3}$ Again, there is a tendency to translate meaning in terms of projected activity. "The consciousness of our mode of behavior as affording data for other possible actions constitutes the bear an objective or ideal content." 4

It is enough, perhaps, to reveal these two sources as probable factors in the development of Dewey's psychological method.

1 Principles of Psychology, Vol. II, p. 449.

${ }^{2}$ Psy. Rev., Vol. II, p. I5 f.

3 Ibid., p. 24 f.

4 Ibid., p. 24. 
No speculation upon them is necessary. At most, they were merely contributory to Dewey's thought, and by fitting in with his previous ideas enabled him to give a more concrete presentation of his psychological theory than would otherwise have been $\backslash$ possible. 


\section{CHAPTER V}

\section{THE EVOLUTIONARY STANDPOINT}

Dewey's psychology is linked up with his logical theory, as has already been suggested, through the interpretation of the thought-process as a mode of adjustment involving inference. This conception of thought implies, of course, that thought is an instrument of adaptation, and this in turn suggests that the organ of reflection is a product of evolutionary forces operating on the individual and on the race. In the period now to be reviewed Dewey, for the first time in his career, displays an active and intense interest in evolutionary theory, especially as applied in the fields of ethics and psychology.

An article published in the Monist, in 1898 , on "Evolution and Ethics,"1 deserves special attention. The central thought of the article is to be found in the following passage: "The belief that natural selection has ceased to operate [in the human sphere] rests upon the assumption that there is only one form of such selection: that where improvement is indirectly effected by the failure of species of a certain type to continue to reproduce; carrying with it as its correlative that certain variations continue to multiply, and finally come to possess the land. This ordeal by death is an extremely important phase of natural selection, so called. ... However, to identify this procedure absolutely with selection, seems to me to indicate a somewhat gross and narrow vision. Not only is one form of life as a whole selected at the expense of other forms, but one mode of action in the same individual is constantly selected at the expense of others. There is not only the trial by death, but there is the trial by the success or failure of special acts-the counterpart, I suppose, of physiological selection so called."'2 We have here a refinement upon the doctrine of natural selection. The key'note of Dewey's new

1 Vol. VIII, pp. $32 \mathrm{I}-34 \mathrm{r}$. The article is a criticism of Huxley's essay with the same title.

2 Ibid., p. 337. Italics mine. 
psychology is a process of selection constantly occurring within the individual organism. He points out that, in dealing with man, we have a highly adaptable, not merely a highly adapted animal. "It is certainly implied in the idea of natural selection that the most effective modes of variation should themselves be finally selected." 1 . The capacity to vary, or adapt, is highly developed in man. Through these variations, the organism is able to react against the environment, changing its character quite completely. The environment of the modern human is tremendously complicated by his reaction upon it. "The growth of science, its application in invention to industrial life, the multiplication and acceleration of means of transportation and intercommunication, have created a peculiarly unstable environment."'2 Under these conditions, the ability of the individual to adapt himself to changing circumstances is largely determined by his degree of flexibility in the selection of right acts and responses. "In the present environment, flexibility of function, the enlargement of the range of uses to which one and the same organ, grossly considered, may be put, is a great, almost the supreme, condition of success." 3 The human mind is to be interpreted as a highly developed organ whose special function is to make adaptation more flexible and response more varied and discriminating. "That which was "tendency to vary' in the animal is conscious foresight in man. That which was unconscious adaptation and survival in the animal, taking place by the 'cut and try' method until it worked itself out, is with man conscious deliberation and experimentation."

This view of consciousness is worked out on the basis of an evolutionary metaphysics. Man is viewed as an organism, placed amid the changing whirl of things, stimulated into action by his needs and wants, adapting himself to conditions, making the situation over, or meeting it habitually where he can and suffering the consequences where he cannot make the necessary

1 op. cit., p. 338.

2 Ibid., p. 340.

${ }^{3}$ Ibid.

${ }^{4}$ Ibid. It should be observed that this conclusion is reached on a purely theoretical basis. 
adjustment. If this be taken, as would seem, for the ultimate truth about reality and man's place in it, it must be called a metaphysics. Against this background Dewey's logical theory is developed. The most important result, from the standpoint of the student of mind and spirit, is the reduction of self-conscious reflection to the position of a nervous function of the organism. The purely theoretical evidence by which this position is sustained should be subjected to closer scrutiny than can be undertaken in this limited space.

The purpose of reflection, then, is to enable man to adapt himself to his environment, understanding by the environment the whole of the reality which surrounds him. The test of the mind and its newly projected modes of response [ideas] lies in its ability to meet the demands of the situation. The capacities and limits of mind are determined by the purpose for which it was evolved; it can enable a man to deal more effectively with his environment; it can do nothing else. It cannot speculate on the nature of reality as such, nor voyage on long journeys in search of truth. Its business is practical, here and now. Its problems are always set for it by circumstances, and these circumstances are concrete and specific. There is no such thing as adaptation at large or in general.

The business of mind is to have, and to continually reconstruct, useful habits. So Dewey assures the American Psychological Association in I899, in an address on "Psychology and Social Practice."1 We must recognize, he says, " that the existing order is determined neither by fate nor by chance, but is based on law and order, on a system of existing stimuli and modes of reaction, through knowledge of which we can modify the practical outcome."2 Psychology uninterpreted, he says, will never provide ready-made materials and prescriptions for the ethical life. "But science, both physical and psychological, makes known the conditions upon which certain results depend, and therefore puts at the disposal of life a certain method of controlling them."'3 These statements show the extent to which Dewey's view of

1 Printed in the Psychological Review, Vol. VII, r900, pp. 105-124.

2 Ibid., p. 123.

${ }^{3}$ Ibid., p. 124 . 
knowledge has come to be controlled by biological conceptions.

The evolutionary method is investigated in considerable detail in the next article to be considered, which was published in two parts in the Philosophical Review, r902, under the title, "The Evolutionary Method as Applied to Morality."'

The fact that some philosophers deny the importance of the evolutionary method for ethics, holding that morality is purely a matter of value, and that the evolutionary method tends only to obscure differences of value, makes it necessary to inquire into the import and nature of this method. "Anyway," Dewey says, "before we either abuse or recommend genetic method we ought to have some answers to these questions: Just what is it? Just what is to come of it and how ?"2

The experimental method in science has at least some of the traits of a genetic method. The nature of water, for instance, cannot be determined by simply observing it. But experiment brings to light the exact conditions under which it came into being and therefore explains it. "Through generating water we single out the precise and sole conditions which have to be fulfilled that water may present itself as an experienced fact. If this case be typical, then the experimental method is entitled to rank as genetic method; it is concerned with the manner or process by which anything comes in to experienced existence."3

Some would deny this, on the ground that a genuinely historical event occupies a particular place in a historical series, from which it is inseparable, while in experimental science the sets or pairs of terms are not limited to any particular place in a historical series, but occur and recur. "Water is made over and over again, and, so to speak, at any date in the cosmic series. This deprives any account of it of genuinely historic quality."4 Again, it might be said in opposition to treating the experimental method as a genetic method, that it is interested in individual cases not as such, but as samples or instances. The particular case is only an illustration of the general relation which is being sought.

1 Vol. XI, pp. 107-124; 353-37I.

2 Ibid., p. 108.

${ }^{3}$ Ibid., p. 109.

${ }^{4}$ Ibid. 
It will turn out in the course of the discussion, Dewey says, that, although science deals with origins, it is not, in strictness, a historical discipline. The distinction between the historical and other sciences is based on an abstraction, which has been introduced for the sake of more adequate control. It is only by abstraction that we get the pairs of facts that may show up at any time, and by abstraction we attribute to them a generalized character. The facts, in themselves, are historic.

There is no such thing as water in general, but water is just this water, at this time, in this place, and it never shows itself twice, never recurs. The scientist must deal, therefore, with particular historic cases of water, and with their specific origins. "Experiment has to do with the conditions of production of a specific amount of water, at a specific time and place, under specific circumstances: in a word, it must deal with just this water. The conditions which define its origin must be stated with equal definiteness and circumstantiality."1 The instance has as definite a place in an historical series as has Julius Caesar. But the difference in treatment of the water and Caesar is due to the difference in interest. "Julius Caesar served a purpose which no other individual, at any other time, could have served. There is a peculiar flavor of human meaning and accomplishment about him which has no substitute or equivalent. Not so with water. While each portion is absolutely unique in its occurrence, yet one lot will serve our intellectual or practical needs just as well as any other."2 For this reason the specific case of water is not dealt with on its own account, but only as giving insight into the processes of its generation in general. In this way the difference arises between the generalized statements of physical science and the individualized form demanded in historical science. The abstract character of the physical result is recognized by the hypothetical form of judgment in modern logic; if certain conditions, then certain consequences. But the counterpart of this must not be forgotten, that every categorical proposition applies to an individual. Experimental propositions,

1 op. cit., p. Iro.

${ }^{2}$ Ibid., p. II I. 
therefore, have an historical value. "They take their rise in, and they find their application to, a world of unique and changing things: an evolutionary universe." 1 The recognition of the historical character of experimental science does not in any way derogate from its value, but, properly understood, gives a deeper insight into its significance. It should be observed that here also Dewey treats thought, hypothesis, as coming 'after something, and for the sake of something.'

This attempt to justify the historical method by showing that it is implied in physical experiment is of dubious value. Its net result would seem to be the conclusion that every fact may be dealt with either as a historical fact or as a datum for physical science. Even here, however, Dewey slurs over certain difficulties which demand close scrutiny. The treatment of individuality is most unsatisfactory. While each portion or instance of water is itself, and has its own unquestionable uniqueness, no case is a mere particular, but each is a true individual, which means that it is, as it occurs, an instance of a general phenomenon. While the scientist must deal with specific cases of water, he has no regard for their particularity, but chooses them as instances, and is from first to last occupied with their typical characteristics. The historian, also, selects relevant and representative instances, in so far as his history is interpretative and not mere narrative.

A merely factual account of a series of events is not science, and never could be.

Dewey now turns to the ethical field, with the purpose of showing that the historical method in ethics does for this science precisely what the experimental method does for other sciences. "History offers to us the only available substitute for the isolation and for the cumulative recombination of experiment. The early periods present us in their relative crudeness and simplicity with a substitute for the artificial operation of an experiment: following the phenomenon into the more complicated and refined form which it assumes later, is a substitute for the synthesis of the experiment."' Hydrogen and oxygen are the historical

1 Op. cit., p. II2.

${ }^{2}$ Ibid., p. II3. 
antecedents of water, whose synthesis the scientist observes, and so the more primitive forms of conduct are the elements which the moralist traces in their process of becoming fused into the present social fabric. Primitive social practices cannot be artificially isolated, like the physical elements, but they can be traced to their historical origins, and their interweaving towards present complex conditions can be observed.

The historical method is subject to two misunderstandings, Dewey says, one by the empiricists and materialists, the other by the idealists. The former, having isolated the primitive facts, suppose them to have a superior logical and existential value. "'The earlier is regarded as somehow more 'real' than the later, or as furnishing the quality in terms of which the reality of all the later must be stated." 1 The later is looked upon as simply a recombination of the earlier existences. "Writers who ought to know better tell us that if we only had an adequate knowledge of the 'primitive' state of the world, if we only had some general formula by which to circumscribe it, we could deduce down to its last detail the entire existing constitution of the world, life, and society." 2 The primitive elements, however, take on new qualities on entering into new combinations. Water is more than hydrogen and oxygen. There is a similar process intervening between the earlier and the later in the moral field, of which the primitive state and the present are merely end terms. Actual study must take account of the whole process.

The idealistic fallacy is of the opposite nature. It takes the final term of the process to be exclusively real. "The later reality is, therefore, to him the persistent reality in contrast with which the first forms are, if not illusions, at least poor excuses for being. :. . . It is enough for present purposes to note that we have here simply a particular case of the general fallacy just discussed-the emphasis of a particular term of the series at the expense of the process operative in reference to all terms."'3 The true reality is the whole process, which is represented in empiricism only by the primitive terms, and in idealism only by

1 Op. cit., p. II4.

2 Ibid., p. I 6 6.

${ }^{3}$ Ibid., p. $1 \mathrm{I} 8$. 
the end terms. Only a historical method can deal with it in its entirety.

In summing up the advantages of the historical method, Dewey says that it gives a complete account of the origin and development of ethical ideas, opinions, beliefs, and practices. "It is concerned with the origin and development of these customs and ideas; and with the question of their mode of operation after they have arisen. The described facts-yes; but among the facts described is precisely certain conditions under which various norms, ideals, and rules of action have originated and functioned."' Dewey finds it irritating that the facts thus singled out should be treated as mere facts, apart from their significance. The historical method employs description, to be sure, but it also aims at interpretation. "The historic method is a method, first, for determining how specific moral values (whether in the way of customs, expectations, conceived ends, or rules) came to be; and second, for determining their significance as indicated in their career."'2

It is true, as Dewey holds, that the historical method may furnish a basis for interpretation, as well as description. But the mere scrutiny of what has happened will not reveal the elements, nor determine their significance. The historian must approach his material with something more than his eyes. But there are many historical methods. Which shall be used in dealing with the development of morals? ${ }^{3}$ Chemistry, for instance, in interpreting the fusion of hydrogen and oxygen into water, employs a system of atoms related to each other in a mathematical order, and something similarly definite must underlie the study of morals. The historical method, in general, needs no defence, but since it takes many forms, great care must be exercised in its application. Dewey seems to ignore these difficulties.

Dewey's argument now leads him to a comparison of the - evolutionary methods with the intuitional and empirical methods in ethics. In making the comparison, he does not propose to

1 Op. cit., p. 355 .

2 Ibid., p. 356.

${ }^{3}$ See Bosanquet's Logic, second edition, Chapter VII, and especially page 240. 
raise the question of fact concerning the existence of intuitions. The question to be confronted is rather a logical one, concerning the validity of beliefs. "Under what conditions alone, and in what measure or degree, are we justified in arguing from the existence of moral intuitions as mental states and acts to facts taken to correspond to them?"1

The answer is that the existence of a belief argues nothing as to its validity. The intuitionist takes his belief as a brute fact, unrelated to objective conditions. The 'inexpugnable' character of the belief cannot establish its validity, because the life of a single individual occupies but a brief span in the continuity of the social life in which the belief is embedded. Beliefs last for generations, and then very often disappear. "What guarantee have we that our present 'intuitions' have more validity than hundreds of past ideas that have shown themselves by passing away to be empty opinion or indurated prejudice?"'2 Intuitionism has no way of guaranteeing its beliefs.

The evolutionary method, on the other hand, is able to determine the validity of beliefs. "The worth of the intuition depends upon genetic considerations. In so far as we can state the intuition in terms of the conditions of its origin, development, and later career, in so far we have some criterion for passing judgment upon its pretensions to validity.... But if we cannot find such historic origin and functioning, the intuition remains a mere state of consciousness, a hallucination, an illusion, which is not made more worthy by simply multiplying the number of people who have participated in it."3 Certain savage races, for instance, possessed moral intuitions which made the practice of infanticide an obligation. But the fact that it was universally held does not establish its validity. It must be condemned or justified by the results to which it led.

Dewey's criticism of intuitionism scarcely does justice to that method, whatever may be its inherent weakness. There doubtless have been thinkers who held that truth is revealed to the reason of man in its naked purity, in the shape of apodictic intel-

1 Philosophical Review, Vol. XI, p. 357.

2 Ibid., p. 360.

${ }^{3}$ Ibid., p. 358. 
lectual principles. But even in the case of so extreme a position as that of Kant, there are important qualifying considerations to be taken into account. There is no reason to suppose that moral judgment, as Kant conceived it, was excluded from the consideration of relevant data, such as the knowledge of actual effects produced by given courses of conduct. His position seems to have been, not that moral judgment lacked specific content, but that reason took something with it to the moral situation. The intuitionists may have over-estimated the original endowment of the mind, but it must be admitted with them that the mind which approaches the moral situation empty of concepts cannot make moral decisions. If man is to hold no beliefs except those proved valid by experience, how can there be any to validate? Intelligence must have the capacity to frame beliefs in the light of its past knowledge, and its acts of judgment, consequently, presuppose a test of the validity of ideas which belongs to intelligence as such, and not to history taken abstractly. Beliefs are adapted to their objects in the making, and on this account are usually found to have had some justification, even where set aside. 'A principle that is suitable for universal legislation already presupposes a content.'

Dewey next considers the relation of the evolutionary methods to empiricism. "Empiricism," he says, "is no more historic in character than is intuitionalism. Empiricism is concerned with the moral idea or belief as a grouping or association of various elementary feelings. It regards the idea simply as a complex state which is to be explained by resolving it into its elementary constituents. By its logic, both the complex and the elements are isolated from an historic context. . . . The empirical and the genetic methods thus imply a very different relationship between the moral state, idea, or belief, and objective reality. . . The empirical theory holds that the idea arises as a reflex of some existing object or fact. Hence the test of its objectivity is the faithfulness with which it reproduces that object as copy. The genetic theory holds that the idea arises as a response, and that the test of its validity is found in its later career as manifested with reference to the needs of the situation that evoked it."1

${ }^{1}$ Op. cit., p. $364 \mathrm{f}$. 
Only a method that takes the world as a changing, historical thing, can deal with the adaptation of morality to new conditions. "Both empiricism and intuitionalism, though in very different ways, deny the continuity of the moralizing process. They set up timeless, and hence absolute and disconnected, ultimates; thereby they sever the problems and movements of the present from the past, rob the past, the sole object of calm, impartial, and genuinely objective study, of all instructing power, and leave our experience to form undirected, at the mercy of circumstance and arbitrariness, whether that of dogmatism or scepticism." 1

In evaluating the article as a whole, it must be said that Dewey's study is not productive of definite results. The history of the past can undoubtedly offer to the student a mass of data that is interesting and instructive. The importance of this or that belief, or its value, can be gauged by the results which it is known to have produced. But when, in this day and age, the moralist sets out to find the principles which shall guide his own conduct, the history of morals is of no more importance than the observations of every day life, which reveal the consequences of conduct in the lives of men about him. But more particularly, it should be added, an estimate of present moral action depends, not upon truth uttered by the past, but upon truth discovered and interpreted by an intelligence which surveys the past and makes it meaningful. The past in itself is nothing; thought alone can create real history.

Another article, published by Dewey in the Philosophical Review in 1900, "Some Stages of Logical Thought," illustrates the employment of the genetic method in a more specific way. ${ }^{2}$ In his introductory remarks, Dewey says: "I wish to show how a variety of modes of thinking, easily recognizable in the progress of both the race and the individual, may be identified and arranged as successive species of the relationship which doubting bears to assurance; as various ratios, so to speak, which the vigor of doubting bears to mere acquiescence. The presumption is that the function of questioning is one which has continually grown in intensity and range, that doubt is continually chased

1 Op.cit., p. 370.

2 Vol. IX, pp. 465-489. 
back, and, being cornered, fights more desperately, and thus clears the ground more thoroughly."1 Dewey finds four stages of relationship between questioning and dogmatism: dogmatism, discussion, proof, and empirical science; and he seeks to show how each stage involves a higher degree of free inquiry. "Modern scientific procedure, as just set forth, seems to define the ideal or limit of this process. It is inquiry emancipated, universalized, whose sole aim and criterion is discovery, and hence it makes the terminus of our description. It is idle to conceal from ourselves, however, that this scientific procedure, as a practical undertaking, has not as yet reflected itself into any coherent and generally accepted theory of thinking. . . ."2

It is not necessary to comment on Dewey's stages of thought. The similarity of this division to Comte's theological, metaphysical and scientific stages of explanation will be apparent. Dewey's remarks on the logic of the scientific stage, however, are interesting. "The simple fact of the case is," he says, "that there are at least three rival theories on the ground, each claiming to furnish the sole proper interpretation of the actual procedure of thought." 3 There is the Aristotelian logic, with its fixed forms; the empirical logic, which holds "that only particular facts are self-supporting, and that the authority allowed to general principles is derivative and second hand;"4 and finally there is the transcendental logic, which claims, "by analysis of science and experience, to justify the conclusion that the universe itself is a construction of thought, giving evidence throughout of the pervasive and constitutive action of reason; and holds, consequently, that our logical processes are simply the reading off or coming to consciousness of the inherently rational structure already possessed by the universe in virtue of the presence within it of this pervasive and constitutive action of thought."5

None of these logics, Dewey finds, is capable of dealing with

1 Op. cit., p. 465.

2 Ibid., p. 486 f.

${ }^{3}$ Ibid., p. 487 .

${ }^{4}$ Ibid.

${ }^{5} I b \cdot d$. 
the actual procedure of science, because none of them treats thought as a doubt-inquiry process, but rather as something fixed and limited by conditions which determine its operations in advance. Dewey asks: "Does not an account or theory of thinking, basing itself on modern scientific procedure, demand a statement in which all the distinctions and terms of thoughtjudgment, concept, inference, subject, predicate and copula of judgment, etc. ad indefinitum - shall be interpreted simply and entirely as distinctive functions or divisions of labor within the doubt-inquiry process?"1

Seven years before, Dewey had been an ardent champion of the transcendental logic, on the ground that it was progressive, and he contrasted it most favorably with the formal logics which treat thought as a self-contained process. Now, however, he has a new insight. Logic must be reinterpreted in the light of the evolutionary or biological method. We shall see how this is accomplished in the next chapter.

To the student of the history of philosophy, Dewey's treatment of the genetic and historical methods must seem seriously inadequate. The idealist, moreover, will feel that Dewey should have taken note, in his criticism of the idealistic standpoint, of the fact that Hegelianism was from first to last a historical method; that the German idealists gave the impulse to modern historical research, and provoked a study of the historical method whose results are still felt. But in turning away from idealism, Dewey has no word of appreciation for this aspect of the Hegelian philosophy.

When the truth is boiled down, it appears that Dewey's historical method, in so far as he had one, was based on biological evolutionism. He had no interest in any other form of historical interpretation.

1 Op. cit., p. 489. 


\section{CHAPTER VI}

\section{"STUDIES IN LOGICAL THEORY"}

IN 1903 a volume entitled Studies in Logical Theory, consisting of essays on logical topics by Dewey and his colleagues and pupils, was published under the auspices of the University of Chicago. In a review of this volume, Professor Pringle-Pattison remarks: "It is, indeed, most unusual to find a series of philosophical papers by different writers in which (without repetition or duplication) there is so much unity in the point of view and harmony in results. That this is so is a striking evidence of the moulding influence of Professor Dewey upon his pupils and coadjutors in the Chicago School of Philosophy." 1 It would be a needless task to review the whole volume, and attention will be confined to the essays which constitute Dewey's special contribution to the undertaking. These constitute the first four chapters of the volume, and are devoted to a critical examination of Lotze's logic. ${ }^{2}$ Here, for the first time, Dewey presents in complete form the logical theory which stands as the goal of his previous endeavors, and marks the beginning of his career as a pragmatist. $^{3}$

The first chapter of the "Studies" is devoted to a general consideration of the nature of logical theory. Dewey begins his discussion with an account of the naive view of thought, the view of the man of affairs or of the scientist, who employs ideas and reflection but has never become critical of his mental pro-

1 The Philosophical Radicals, "Dewey's Studies in Logical Theory," p. I79. The essay was originally printed as a critical notice in the Philosophical Review, November, r904.

${ }^{2}$ Since this was written (I9I5-I6), Dewey's chapters have been reprinted in a volume entitled Essays in Experimental Logic, published by the University of Chicago Press (June, I9I6). They are preceded, in this new setting, by a special introductory chapter, and numerous alterations have been made which do not, however, affect the fundamental standpoint.

${ }^{3}$ See James's review, "The Chicago School," Psychological Bulletin, Vol. I, 1904, pp. I-5. 
cesses; who has never reflected upon reflection. "If we were to ask," he says, "the thinking of naive life to present, with a minimum of theoretical elaboration, its conception of its own practice, we should get an answer running not unlike this: Thinking is a kind of activity which we perform at specific need, just as at other need we engage in other sorts of activity."1 While the standpoint of the naïve man is usually hard to determine, there appears to be considerable justification for Dewey's statement. The common man does tend to view thinking as a special kind of activity, performed by an organ which can be 'trained,' and he is inclined to speak of education as a process of 'training the mind.'2

Dewey finds a large measure of truth in this naïve view of thought. Thought appears to be derivative and secondary. "It comes after something and out of something, and for the sake of something." ${ }^{3}$ It is employed at need, and ceases to operate when not needed. "Taking some part of the universe of action, of affection, of social construction, under its special charge, and having busied itself therewith sufficiently to meet the special difficulty presented, thought releases that topic and enters upon further more direct experience." ${ }_{4}$ There is a rhythm of practice and thought; man acts, thinks, and acts again. The business of thought is to solve practical difficulties, such as arise in connection with the conduct of life. The purpose for which thought intervenes is to enable action to get ahead by discovering a way out of the given difficulty. Ordinarily, the transition from thought to action and the reverse is accomplished without break or difficulty.

Occasions arise, however, when thought is balked by a situation with which it is unable to deal, after repeated attempts. Critical reflection is then directed upon thought itself, and logical theory is the result. "The general theory of reflection, as over against its concrete exercise, appears when occasions for reflection are

1 Studies in Logical Theory, p. 2.

2 Compare Dewey, How We Think (I9ro), Chapter II, “The Need for Training Thought."

${ }^{3}$ Studies in Logical Theory, p. $x$.

${ }^{4}$ Ibid., p. 2. 
so overwhelming and so mutually conflicting that specific adequate response in thought is blocked." 1 The purpose of logical theory is therefore a practical one, and logical theory, like ordinary reflection, is directed toward the removal of difficulties which stand in the way of the achievement of practical ends.

This description of thought and of the nature of logical theory invites suspicion by its very simplicity. Nobody would deny that thought is linked up with practice, that the processes of life link up into one whole organic process, and that it would be a mistake to treat the cognitive processes as if they were separate from the whole. But Dewey's account of thought seems to fall into the very abstractness which he is so anxious to avoid. Experience is represented as a series of acts, attitudes, or functions, which follow one another in succession. "Thinking follows, we will say, striving, and doing follows thinking. Each in the fulfilment of its own function inevitably calls out its successor."2 The functions are distinct, but are united to each other, end to end, like links in a chain. They pass into and out of one another, but are not simultaneous. This description gives rise, as Bosanquet observes, ${ }^{3}$ to a kind of dualism between thinking and the other processes of life, which is made deeper because thinking is regarded as a very special activity, which "passes judgment upon both the processes and contents of other functions," and whose aim and work is "distinctively reconstructive or transformatory." 4

Dewey's description of the processes of experience is undoubtedly plausible, but should not be accepted without close scrutiny of the facts. It has been held, in opposition to such a view, that the cognitive processes are so bound up with perception, feeling, willing, and doing, that they cannot be separated from the complex. $^{5}$ Or it might be held that thinking and doing are simul-

${ }^{1}$ Op. cit.. p. 3 f.

2 Ibid., p. I6.

${ }^{3}$ Logic, second ed., Vol. II, p. 270.

${ }^{4}$ Studies in Logical Theory, p. x.

5 "Thinking or rationality is not limited to the process of abstract cognition, but it includes feeling and will, and in the course of its development carries these along with it. There is, of course, such a thing as what we have called abstract cognition; but the different moments are all united in the concrete experience which 
taneous and complementary processes, rather than successive and supplementary. Dewey does not concern himself with these possibilities, seeming to take it for granted that his interpretation is the 'natural' one. It must be said, however, that Dewey's description of thought as a process is by no means obvious and simple; thought is not easy to describe.

When we turn to logical theory, Dewey says, there are two directions which may be taken. The general features of logical theory are indicated by its origin. When ordinary thinking is impeded, an examination of the thinking function is undertaken, with the purpose of discovering its business and its mode of operation. The object of the examination is practical; to enable thinking to be carried on more effectively. If these conditions are kept in mind, logical theory will be guided into its proper channels: it will be assumed that every process of reflection arises with reference to some specific situation, and has to subserve a specific purpose dependent upon the occasion which calls it forth. Logical theory will determine the conditions which arouse thought, the mode of its operation, and the testing of its results. Such a logic, being true to the problems set for it by practical needs, is in no danger of being lost in generalities.

But there is another direction which logical theory sometimes takes, unmindful of the conditions imposed by its origin. This is the epistemological direction. Epistemological logic concerns itself with the relation of thought at large to reality at large. It assumes that thought is a self-contained activity, having no vital connection with the world which is to be known. Such a logic can never be fruitful, for it has lost sight of its purpose in the formulation of its problem.

Dewey is quite right in opposing a conception of thought which makes it a self-contained activity, having no vital connection with other life processes. Few recent thinkers have been guilty of that error. Lotze, to be sure, made the mistake of separating thought from the reality to be known, and therefore serves as a ready foil for Dewey's criticism. But Lotze's age is past and gone.

we may name the life of thought." Creighton, "Experience and Thought," Philosophical Review, Vol. XV, 1906, p. 487 f. 
When the abstract conception of thought is set aside, and it is agreed that thought must be treated as a process among the processes of experience, there is still room for divergence of opinion as to the exact manner in which thought is related to other functions. Dewey's logical theory, as outlined above, depends upon a very special interpretation of the place which thought occupies in experience. For this reason he considers logic to be inseparable from psychology. "Psychology . . . is indispensable to logical evaluation, the moment we treat logical theory as an account of thinking as a mode of adaptation to its own generating conditions, and judge its validity by reference to its efficiency in meeting its problems."1 Psychology, in other words, must substantiate Dewey's account of thought, else his 'logic' has no foundation. But if it were held that the cognitive processes cannot be separated (except by abstraction for psychological purposes) from other processes, there could manifestly be no such logical problem as Dewey has posited. Logic would be freed from reliance upon psychology. In this case, logical inquiry would be directed to the study of concepts, forms of judgment, and methods of knowledge, with the purpose of determining their relations, proper applications, and spheres of relevance. Logic would be a 'criticism of categories' rather than a criticism of the function of thinking. Dewey recognizes that such a study of method might be useful, but holds that it would be subsidiary to the larger problems of logic. "The distinctions and classifications that have been accumulated in 'formal' logic are relevant data; but they demand interpretation from the standpoint of use as organs of adjustment to material antecedents and stimuli." 2 It will be seen that the treatment of the forms of thought as "organs of adjustment" makes logic subsidiary to psychology, necessarily and completely. All follows, however, from the original assumption that thought is a special activity, clearly distinguishable from other experienced processes, and possessing a special function of its own.

In his further analysis of logical theory, Dewey states that it

1 Op.cit., p. 15.

${ }^{2}$ Ibid., p. 8. 
has two phases, one general and one specific. The general problem concerns the relations of the various functions of experience to one another; how they give rise to each other, and what is their order of succession. This wider logic is identified with philosophy in general. ${ }^{1}$ The specific phase of logic, logic proper, concerns itself with the function of knowing as such, inquiring into its typical behavior, occasion of operation, divisions of labor, content, and successful employment. Dewey indicates the danger of identifying logic with either of these to the exclusion of the other, or of supposing that they can be finally isolated from one another. "It is necessary to work back and forth between the larger and the narrower fields."'

Why is it necessary to make such a distinction at all? And why necessary to move back and forth between the two provisional standpoints? Dewey might answer by the following analogy: The thought function may be studied, first of all, as a special organ, as an anatomist might study the structure of any special organ of the body; but in order to understand the part played by this member in the organism as a whole, it would be necessary to adopt a wider view, so that its place in the system could be determined. This is probably what Dewey means by his two standpoints. He says: "We keep our paths straight because we do not confuse the sequential, efficient, and functional relationship of types of experience with the contemporaneous, correlative, and structural distinctions of elements within a given function." 3 The first objection to be made to this treatment of thought is that it makes knowing the activity of a special organ, like liver or lungs. If this objection is surmounted, there remains another from the side of general method. The biologist not only studies the particular organs as to their structure and their relationships within the body, but he has a view of the body as a whole, of its general end and purpose. His study of the particular organ is in part determined by his knowledge of the relations between body and environment. But experience as a whole cannot be treated like a body, because it has no environ-

1 Op. cit., pp. 18-19.

2 Ibid., p. 23.

${ }^{3}$ Ibid., p. I7. 
ment. The analogy between body and its processes and experience and its processes breaks down, therefore, at a vital point. Dewey's genetic interpretation gains in plausibility when the human body, and not the whole of experience, is taken as the ground upon which the 'functions' are to be explained, for the body has an environment and purposes in relation to that environment. Experience as a whole possesses no such external reference.

It will be seen that Dewey's interpretation of the function of knowing is not as empirical as it proposes to be. Its underlying conceptions are biological in character, and these conceptions are brought ready-made to the study of thought. Logical theory does not arise naturally and spontaneously from a study of the facts of mind, but the facts are aligned and interpreted in terms of categories selected in advance. Empiricism develops its theories in connection with facts, but rationalism (in the bad sense of the word) fits the facts into prepared theories. Dewey's treatment of thought is, after all, more rationalistic than empirical.

To sum up Dewey's conclusions so far: Logic is the study of the function of knowing in relation to the other functions of experience. The wider logic distinguishes the function of knowing from other activities, and discovers its general purpose; the narrower logic examines the function of knowing in itself, with the object of determining its structure and operation. The aim of logic as a whole is to understand the operations of the concrete activity called knowing, with the purpose of rendering it more efficient. This concrete treatment of thought contrasts sharply with the 'epistemological' method, which sets thought over against the concrete processes of experience, and thus generates the false problem of the relation of thought in general to reality in general.

Having stated his position, we might expect Dewey, in the course of the next three chapters, to enter upon a consideration of one phase or other of his logic. On the contrary, he proposes to take up "some of the considerations that lie on the borderland between the larger and the narrower conceptions of logical theory."1

1 Op. cit., p. 23. 
First, he will consider the antecedent conditions and cues of the thought-process; the conditions which lead up to and into the function of knowing. These conditions lie between the thoughtprocess and the preceding function (in order of time), and are therefore on the borderland between the wider and narrower spheres of logic.

In defining the conditions which precede and evoke thought, Dewey says: "There is always as antecedent to thought an experience of some subject-matter of the physical or social world, or organized intellectual world, whose parts are actively at war with each other-so much so that they threaten to disrupt the entire experience, which accordingly for its own maintenance requires deliberate re-definition and re-relation of its tensional parts." 1 Thought is always called into action by the whole concrete situation in which it occurs, not by any particular sensation, idea, or feeling.

The opposite interpretation of the nature of the antecedents of thought is furnished by Lotze, who makes them consist in bare impressions, 'moods of ourselves,' mere states of consciousness. Dewey is quite right in calling these bare impressions purely fictitious, though the observation is by no means original. From the manner in which he approaches the study of the "antecedents of thought" it appears, however, that Dewey has something in common with Lotze. The functional theory, that is, allows a certain initial detachment of thought from reality, which must be bridged over by an empirical demonstration of its natural connection with preceding processes.

Dewey is wholly justified, again, in maintaining that thought is not a faculty set apart from reality, and that what is 'given' to thought is a coherent world, not a mass of unmeaning sensations. He recognizes his substantial agreement with the modern idealists in these matters. ${ }^{2}$ But the idealists, he believes,

${ }^{1} O$ p. cit., p. 39 f. Bradley suggests a similar idea of the 'tensional situation.' See, for instance, Ethical Studies, p. 65, where he remarks: “We have conflicting desires, say A and B; we feel two tensions, two drawings (so to speak) but we can not actually affirm ourselves in both." A more complete statement of the "tensional situation' will be found on page 239 of the same work and in various other passages.

${ }^{2}$ Ibid., pp. 43-44. 
hold a constitutive conception of thought which is in conflict with the empirical description of thinking as a concrete activity in time. Reality, according to this conception, is a vast system of sensations brought into a rational order by logical forms, and finite thought, in its operations, simply apprehends or discovers the infinite order of the cosmos. "How does it happen," Dewey asks, "that the absolute constitutive and intuitive Thought does such a poor and bungling job that it requires a finite discursive activity to patch up its products?"1

Against Lotze, such an indictment has considerable force, but its applicability to modern idealism is not so obvious. Modern idealism has insisted upon an empirical treatment of thought, and has definitely surrendered the abstract sensations of the older psychologies. Nor does idealism tend to treat finite thought as a process which merely 'copies' an eternally present nature. The issue between Dewey and the idealists is this: Does functionalism render an accurate empirical account of the nature of thought as a concrete process?

In his third chapter Dewey discusses "Thought and its Subject-matter: The Datum of Thinking." The tensional situation passes into a thought situation, and reflection enters upon its work of restoring the equilibrium of experience. Certain characteristic processes attend the operation of thought. "The conflicting situation inevitably polarizes or dichotomizes itself. There is somewhat which is untouched in the contention of incompatibles. There is something which remains secure, unquestioned. On the other hand, there are elements which are rendered doubtful and precarious." 2 The unquestioned element is the datum; the uncertain element, the ideatum. Ideas are "impressions, suggestions, guesses, theories, estimates, etc., the facts are crude, raw, unorganized, brute."3 There is an approximation to bare meaning on the one hand, and bare existence on the other.

The first dichotomy passes into a second. "Once more, and briefly, both datum and ideatum may . . . break up, each for

1 Op.cit., p. 45.

2 Ibid., p. 50.

${ }^{3}$ Ibid., p. 52. 
itself, into physical and psychical."' 1 The datum, or sense material, is all, somehow, matter and real, but one part of it turns out to have a psychical, another a physical form. Similarly, the ideatum divides into what is mere fancy, the psychical, and what is objectively valid, the physical.

These distinctions are divisions of labor within the thoughtprocess. "All the distinctions of the thought-function, of conception as over against sense-perception, of judgment in its various modes and forms, of inference in its vast diversity of operation-all these distinctions come within the thought situation as growing out of a characteristic antecedent typical formation of experience. . . "'2 Great confusion results in logical theory, Dewey believes, when it is forgotten that these distinctions are valid only within the thought process. Their order of occurrence within the thought process must also be observed, if confusion is to be prevented. Datum and ideatum come first, psychical and physical next in order. "Thus the distinction between subjectivity and objectivity is not one between meaning as such and datum as such. It is a specification that emerges, correspondently, in both datum and ideatum, as affairs of the direction of logical movement. That which is left behind in the evolution of accepted meaning is characterized as real, but only in a psychical sense; that which is moved toward is regarded as real in an objective, cosmic sense." ${ }^{3}$

Dewey does well to call attention to the limitations of these categories, which cannot, indeed, be treated as absolute without serious error. It may be questioned, however, whether their limitations are of the precise nature which he describes. All depends upon the initial conception of the nature of thought. From Dewey's standpoint, these categories are 'tools of analysis' which function only within the thinking process; but his description of the function of knowing may be questioned, in which case his instrumental view of the concepts is rendered meaningless. A logical, as distinct from a psychological, treatment of the concepts mentioned, would show that their validity is limited to a

1 op. cit.

2 Ibid., p. 47.

${ }^{3}$ Ibid., p. 53. 
certain 'sphere of relevance;' that they are applicable within a certain context and to a particular subject-matter. The danger of indiscriminate use of the categories would be avoided by the logical criticism even better, perhaps, than by Dewey's method.

The discussion in Dewey's fourth and last chapter, concerning "The Content and Object of Thought," hinges upon a detailed criticism of Lotze's position, which cannot be presented here. The general bearing of the discussion, however, may be indicated. "To regard," says Dewey, "the thought-forms of conception, judgment, and inference as qualifications of 'pure thought, apart from any difference in objects,' instead of as successive dispositions in the progressive organization of the material (or objects) is the fallacy of rationalism." 1

Pure thought, of course, cannot be defended. At the same time, Dewey, like Lotze, tends to regard thought as a special function with a 'content' of its own. If thought is regarded as a special kind of process, having its own content in the way of instrumental concepts, the question inevitably arises: How shall these forms be employed to reach truth? How apply them correctly to the matter in hand?

Dewey answers that the forms and hypotheses of thought, like the tools and scaffoldings for its operations, are especially designed for the labor which they have to perform. "There is no miracle in the fact that tool and material are adapted to each other in the process of reaching a valid conclusion. . . Each has been slowly evolved with reference to its fit employ in the entire function; and this evolution has been checked at every point by reference to its own correspondent."'2

It is no doubt true that established conceptions, no less than temporary hypotheses, have been evolved in connection with, as a feature or part of, the subject-matter to which they pertain. But it is quite another thing to say that these evolved forms belong to thought, if by thought be meant the functional activity of Dewey's description. Dewey stresses the relevance of these forms to the thought-process, rather than their relevance to a

1 Op.cit., p. 6I f.

2 Ibid., p. 80. 
particular sphere of discourse. His purpose is to show that distinctions which are valid within the process of knowing are not valid elsewhere, and the net result is to limit the faculty of thought as a whole, as well as the forms of thought.

This result reveals itself most clearly in his discussion of the test of truth. "In that sense the test of reality is beyond thought, as thought, just as at the other limit thought originates out of a situation which is not reflectional in character. Interpret this before and beyond in a historic sense, as an affair of the place occupied and role played by thinking as a function in experience in relation to other functions, and the intermediate and instrumental character of thought, its dependence upon unreflective antecedents for its existence, and upon a consequent experience for its test of final validity, becomes significant and necessary." 1 This notion that the test of thought must be external to thought depends directly upon the doctrine that thought is a special activity of the kind heretofore described. It results from the occasionalism attributed by Dewey to the thinking process.

If the truth or falsity of an idea is not discovered by thought, then by what faculty might it be discovered? Perhaps by experience as a whole or in general. Dewey, on occasion, speaks as follows: "Experience is continually integrating itself into a wholeness of coherent meaning deepened in significance by passing through an inner distraction in which by means of conflict certain contents are rendered partial and hence objectively conscious."2 Perhaps Dewey means to say that truth is determined by this cosmic automatism. It is confusing, however, to be told in one moment that thought transforms experience, and in another that experience transforms itself.

Experience, not reflection, is, then, the test of truth and thought. Such a statement would not be possible, except in connection with a psychology which deliberately sets experience over against reflection, making the latter a peculiar, although dependent, process. Lotze, indeed, makes the separation of thought from experience quite complete. Dewey attempts to

1 op. cit., p. 85.

${ }^{2}$ Ibid. 
bring them together by his psychological method, but does not completely succeed. In the meantime modern idealism has suggested that thought and experience are merely parts of one general process, constantly operating in conjunction. To one who believes that the various processes or 'functions' of experience constitute a single organ of life, the proposition that experience, rather than reflection, is the judge of truth, becomes meaningless.

In an essay on "The Logical Conditions of a Scientific Treatment of Morality" in another volume of the Chicago Publications of $1903,{ }^{1}$ Dewey presents a positive statement of his logical theory which is an excellent supplement to the critical study of Lotze.

Science, Dewey remarks in introducing this essay, is a systematized body of knowledge. Knowledge may be taken either as a body of facts or as a process of arranging a body of facts; as results or the acquiring of results. The latter phase of science is the more important. "As used in this article, 'scientific' means regular methods of controlling the formation of judgments regarding some subject-matter." 2 In the scientific attitude, beliefs are looked upon as conclusions, and as conclusions they look in two directions. They look backward towards the ground from which they are empirically derived, and which renders them valid, and they look forward, as meaning, to being the ground from which further conclusions can be deduced. "So far as we engage in this procedure, we look at our respective acts of judging not as independent and detached, but as an interrelated system, within which every assertion entitles us to other assertions (which must be carefully deduced since they constitute its meaning) and to which we are entitled only through.other assertions (so that they must be carefully searched for). 'Scientific' as used in this article thus means the possibility of establishing an order of judgments such that each one when made is of use in determining other judgments, thereby securing control of their formation."”3

1 Decennial Publications of the University of Chicago, First Series, Vol. III, pp. II 5-I39.

2 Ibid., p. II 5.

3 Ibid., p. II6. 
This view of science as an order of judgments requires a special treatment of the generic ideas, the 'conclusions,' or universals of science. The individual judgment, 'This, $A$, is $B$,' expresses an identity. But it is much better expressed in hypothetical form. "Identification, in other words, is secure only when it can be made through (I) breaking up the analyzed. This of naïve judgment into determinate traits, (2) breaking up the predicate into a similar combination of elements, and (3) establishing uniform connection between some of the elements in the subject and some in the predicate."1 Identity exists amid relevant differences, and the more intimately the system of differents is understood, the more positive is the determination of identity. This will be recognized as the 'concrete universal' of the Hegelian logicians.

But, Dewey says, modern logicians tend to disregard judgment as act, and pay attention to it only as content. The generic ideas are studied in independence of their applications, as if this were a matter of no concern in logic. "In truth, there is no such thing as control of one content by mere reference to another content as such. To recognize this impossibility is to recognize that the control of the formation of the judgment is always through the medium of an act by which the respective contents of both the individual judgment and of the universal proposition are selected and brought into relationship to each other."2 The individual act of judgment is necessary to logical theory, because the act of the individual forms the connecting link between the generic idea and the specific details of the situation. There must be some means whereby the instrumental concept is brought to bear upon its appropriate material. "The logical process includes, as an organic part of itself, the selection and reference of that particular one of the system which is relevant to the particular case. This individualized selection and adaptation is an integral portion of the logic of the situation. And such selection and adjustment is clearly in the nature of an act."3

This problem of the relation of the categories to their subject-

1 Op. cit., p. 120.

2 Ibid., p. I $2 \mathrm{I}$.

${ }^{3}$ Ibid., p. 122. 
matter is an acute one for Dewey, because of limitations placed upon thought. He decides that the idea must be, in some fashion, self-selective, must signify its own fitness to a given subjectmatter. But it can only be self-selective by being itself in the nature of an act. - It turns out that the generic idea has been evolved in connection with acts of judgment, and its own applicability is born in it. "The activity which selects and employs is logical, not extra-logical, just because the tool selected and employed has been invented and developed precisely for the sake of just such future selection and use." 1

The logic and system of science must be embodied in the individual. He must be a good logical medium, his acts must be orderly and consecutive, and generic ideas must have a good motor basis in his organism, if he is to think successfully. This is the essence of Dewey's argument in the essay under discussion. The inference seems to be that logic cannot be separated from biology and psychology, since the act of knowing and the ideas which it employs have a physiological basis.

It is difficult to see, however, how such a standpoint could prove useful in the practical study of logic. Certainly little headway could be made toward a study of the proper use and limitations of the categories by an investigation of the human nervous system. And to what extent would physiology illuminate the problem of the relation of the generic ideas to their appropriate objects? Although Dewey decides that the relationship must have its ground in the motor activities of the organism, his conclusion has little empirical evidence to support it.

A practical, workable conception of the relations between generic ideas and their objects must be based on considerations less obscure. Why not be content to verify, by criticism, the truth that experience and thoughts about experience develop together, with the result that each theory, hypothesis, or method is applicable within the sphere where it was born? Why wait upon psychology for confirmation of a truth so obvious and important?

Bosanquet remarks: "Either one may speak as if reality were 1 op. cit. 
relative to the individual mind, a ridiculous idea . . . , or one may become interested in tracing the germination and growth of ideas in the individual mind as typical facts indeed, but only as one animal's habits are typical of those of others, and we may slur over the primary basis of logic, which is its relation to reality. For mental facts unrelated to reality are no knowledge, and therefore have no place in logic."1 Bosanquet emphasizes an important truth neglected by Dewey. Logic is not concerned with ideas as things existing in individuals, nor with conceptions as individual modes of response. Truth has little to do with the individual as such, though the individual might well concern himself about truth. Truth is objective, super-individual, and logic is the study of the objective verity of thought. The proposition, 'All life is from the living,' finds no premises in the nerve tissues of the scientist who accepts it. How does the proposition square up with reality or experience? That is the question, and it can only be answered by turning away from psychology to empirical verification, involving a critical test of the applicability of the thought to reality.

In the strictly ethical part of the essay, Dewey tries to show that moral judgments, at least, involve the character of the agent and his specific acts as data. Intellectual judgments, on the other hand, may disregard the acts of the individual; they are left out of account, "when they are so uniform in their exercise that they make no difference with respect to the particular object or content judged."' It will be seen that the distinction between moral and intellectual judgments is made on the basis of their content. But Dewey is commited to the doctrine that judgments are to be differentiated as acts, on a psychological basis. In any case, if the character and acts of a man are to be judged, they must be treated objectively, and the relevance of the judge's ideas to the man's actual character cannot be decided by a psychological analysis of the judge's mind. Right and wrong, whether moral or intellectual, are not attributes of the individual nervous system.

1 Logic, second ed., Vol. I, p. 232.

${ }^{2}$ Decennial Publication of the University of Chicago, First Series, Vol. III, p. I27. 


\section{CHAPTER VII}

\section{THE POLEMICAL PERIOD}

Afrer the publication of the Studies in Logical Theory, Dewey entered upon what may be called the polemical period of his career. He joined forces with James and Schiller in the promotion of the new movement called 'Pragmatism.' The Journal of Philosophy, Psychology, and Scientific Methods, instituted at Columbia University in I904, the same year in which Dewey accepted a professorship in that institution, became a convenient medium for the expression of his views, and every volume of this periodical will be found to contain notes, discussions, and articles by Dewey and his followers, bearing on current controversy. He also published many articles in other journals, technical and popular. In I9Io, the most important of these essays were collected into a volume, published under the title, The Influence of Darwin on Philosophy, and Other Essays. For purposes of discussion, these essays may be divided into two classes: those of a more constructive character, setting forth Dewey's own standpoint, and those which are mainly polemical, directed against opposing standpoints, chiefly the idealistic. The constructive writings will be given first consideration.

The essay on "The Postulate of Immediate Empiricism," first published in the Journal of Philosophy, Psychology, and Scientific Methods, in July, I905, and later reprinted in the volume of collected. essays, offers a convenient point of departure. Dewey observes that many of the difficulties in current controversy can be traced to presuppositions tacitly held by thinkers as to what experience means. Dewey attempts to make his own presuppositions explicit, with the object of clearing up this confusion.

"Immediate empiricism," he says, "postulates that thingsanything, everything, in the ordinary or non-technical use of the term 'thing' - are what they are experienced as. Hence, if one 
wishes to describe anything truly, his task is to tell what it is experienced as being." 1 The idealists, on the contrary, hold "that things (or, ultimately, Reality, Being) are only and just what they are known to be or that things are, or Reality is, what it is for a conscious knower-whether the knower be conceived primarily as a perceiver or as a thinker being a further, and secondary; question. This is the root-paralogism of all idealisms, whether subjective or objective, psychological or epistemological."2 Knowing is merely one mode of experiencing, and things may be experienced in other ways, as, for instance, aesthetically, morally, technologically, or economically. This follows Dewey's familiar division of the processes of experience into separate 'functions' or activities. It becomes the duty of the philosopher, following this scheme, to find out "what sort of an experience knowing is-or, concretely how things are experienced when they are experienced as known things." 3

Dewey fails, in this essay, to draw a distinction which is highly important, between knowledge as awareness and knowledge as reflection. This results in some confusion. For the present, he is concerned with knowledge as awareness. He employs an illustration to make his meaning clear; the experience of fright at a noise, which turns out, when examined and known, to be the tapping of a window shade. What is originally experienced is a frightful noise. If, after examination, the 'frightfulness' is classified as 'psychical,' while the 'real' fact is said to be harmless, there is no warrant for reading this distinction back into the original experience. The argument is directed against that mode of explaining the difference between the psychical and the physical which employs a subjective mind or 'knower' as the container of the merely subjective aspects of reality. Dewey would hold that mind, used in this sense, is a fiction, having a small explanatory value, and creating more problems than it solves. The difference between psychical and physical is relative,

1 The Influence of Darwin on Philosophy, p. 227.

2 Ibid., p. 228. In connection with the discussion which follows see Bradley "On Our Knowledge of Immediate Experience," in Essays on Truth and Reality, Chapter VI.

${ }^{3}$ Ibid., p. 229. 
not absolute. The frightful noise first heard was neither psychical nor physical; it was what it was experienced as, and the experience contained no such distinction, nor did it contain a 'knower.' The noise as known, after the intervention of an act of judgment, contained these elements (except the 'knower'), but the thing is not merely what it is known as. There is no warrant for reading the distinctions made by judgment back into a situation where judgment was not operative. The original fact was precisely what it was experienced as.

Dewey's purpose, though not well stated, seems to be the complete rejection of the notion of knowledge as awareness, or of the subjective knower. He discovers at the same time an opportunity to substantiate his own descriptive account of knowing (or reflection) as an occasional function. The two enterprises, however, should be kept distinct. Granting that the subjective knower of the older epistemology should be dismissed from philosophy, it does not follow that Dewey's special interpretation of the function of reflection is the only substitute.

The principle of immediate empiricism, Dewey says, furnishes no positive truth. It is simply a method. Not a single philosophical proposition can be deduced from it. The application of the method is indicated in the following proposition: "If you wish to find out what subjective, objective, physical, mental, cosmic, psychic, cause, substance, purpose, activity, evil, being, quality - any philosophic term, in short-means, go to experience and see what the thing is experienced as." 1 This recipe cannot be taken literally. Dewey probably means that each concept has, or should have, a positive empirical reference, and is significant only in that reference. He is a firm believer, however, in the descriptive method. In a note, he remarks that he would employ in philosophy "the direct descriptive method that has now made its way in all the natural sciences, with such modifications, of course, as the subject itself entails."2 This remark calls for closer examination than can be made here. It may be said in passing, however, that 'scientific description'

1 Op. cit., p. 239.

${ }^{2}$ Ibid., p. 240. 
is by no means so simple a method of procedure as Dewey would seem to indicate. 'Scientific description,' as actually employed, is a highly elaborated and specialized method of dealing with experience. The whole subject, indeed, is involved, and requires cautious treatment. Dewey's somewhat ingenuous hope, that the identification of his method with the methods of science will add to its impressiveness, is in danger, unfortunately, of being vitiated through the suspicion that he is, after all, not in close touch with the methods of science.

Dewey employs the descriptive method chiefly as a means for substantiating his special interpretation of the judgment process. His use of the method in this connection is well illustrated by an article called "The Experimental Theory of Knowledge"1 (I906), in which he attempts "to find out what sort of an experience knowing is" through an appeal to immediate experience. "It should be possible," he says, "to discern and describe a knowing as one identifies any object, concern, or event. . . What we want is just something which takes itself as knowledge, rightly or wrongly." 2 The difficulty lies not in finding a case of knowing, but in describing it when found. Dewey selects a case to be described, and, as usual, chooses a simple one.

"This means," he says, "a specific case, a sample. . . . Our recourse is to an example so simple, so much on its face as to be as innocent as may be of assumptions. . . . Let us suppose a smell, just a floating odor." ${ }_{3}$ The level at which this illustration is taken is significant. Is it possible to suppose that anything so complex, varied, myriad-sided as that something we call knowledge, can be discovered and described within the limits of so simple an instance?

Dewey employs the smell in three situations, the first representing the 'non-cognitional,' the second the 'cognitive,' and the third the genuinely 'cognitional' situation. The first, or 'non-cognitional' situation is described as follows: "But, let us say, the smell is not the smell of the rose; the resulting change of the organism is not a sense of walking and reaching; the delicious

1 The Influence of Darwin on Philosophy, pp. 77-III.

2 Ibid., p. 77.

${ }^{3}$ Ibid., p. 78. 
finale is not the fulfilment of the movement, and, through that, of the original smell; 'is not,' in each case meaning is 'not experienced as' such. We may take, in short, these experiences in a brutely serial fashion. The smell, $S$, is replaced (and displaced) by a felt movement, $K$, this is replaced by the gratification, $G$. Viewed from without, as we are now regarding it, there is $S-K-G$. But from within, for itself, it is now $S$, now $K$, now $G$, and so on to the end of the chapter. Nowhere is there looking before and after; memory and anticipation are not born. Such an experience neither is, in whole or in part, a knowledge, nor does it exercise a cognitive function." 1

It will be seen at once that this is not a description of an actual human experience, but a schematic story designed to illustrate a comparatively simple point. In this situation the person concerned does not deliberately and consciously recognize the smell as the smell of a rose; he is not aware of any symbolic character in the smell, it does not enter as a middle term into a process of inference. In such a situation, Dewey believes, it would be wrong to read into the smell a cognitive property which it does not, as experienced, possess.

In the second, or 'cognitive' situation, the smell as originally experienced does not involve the function of knowing, but turns out after the event, as reflected upon, to have had a significance. "In saying that the smell is finally experienced as meaning gratification. . . we retrospectively attribute intellectual force and function to the smell-and this is what is signified by 'cognitive.' Yet the smell is not cognitional, because it did not knowingly intend to mean this; but is found, after the event, to have meant it." 2 The moral is, as usual, that the findings of reflection must not be read back in to the former unreflective experience.

In the truly 'cognitional' experience the smell is then and there experienced as meaning or symbolizing the rose. "An experience is a knowledge, if in its quale there is an experienced distinction and connection of two elements of the following sort: one means

${ }^{1}$ Op. cit.

${ }^{2}$ Ibid., p. 84 . 
or intends the presence of the other in the same fashion in which itself is already present, while the other is that which, while not present in the same fashion, must become so present if the meaning or intention of its companion or yoke-fellow is to be fulfilled through the operation it sets up."' In the "cognitional' situation, the smell is then and there experienced as signifying the presence of a rose in the vicinity, and the rose must be experienced as a present fact, before the meaning of the smell is completely fulfilled and verified.

It will be seen at once that this description of knowing follows the lines laid down by James in his chapter on "Reasoning" in the Principles of Psychology. In the process of reasoning the situation is analyzed; some particular feature of it is abstracted and made the middle term in an inference. The smell, as thus abstracted, is said to have the function of knowing, or meaning, the rose whose reality it evidences.

Dewey's treatment of knowledge, however, is far too simple. The function of meaning, symbolizing, or 'pointing' does not reside in the abstracted element as such; for the context in which the judgment occurs determines the choosing of the 'middle term,' as well as the direction in which it shall point. The situation as a whole has a rationality which resides in the distinctions, identities, phases of emphasis, and discriminations of the total experience. Rationality expresses itself in the organized system of experience, not in particular elements and their 'pointings.' Taken in this sense, rationality is present in all experience. The smell, in Dewey's first situation, is not 'cognitional' because the situation as a whole does not permit it to be, if such an expression may be used. The intellectual drift of the moment drives the smell away from the centre of attention at one time, just as at another it selects it to serve as an element in judgment. It is only with reference to a system of some kind that things can be regarded as symbols at all. Things do not represent one another at haphazard, but definitely and concretely; they imply an organization of elements having mutual implications. One thing implies another because both are elements in a whole which determines their mutual reference. This organization is present

${ }^{1}$ Op. cit., p. 90. Author's italics. 
in all experience, not in the form of 'established habits,' but in the form of will and purpose.

In the course of his further discussion, which need not be followed in detail, Dewey passes on to a consideration of truth. Truth is concerned with the worth or validity of ideas. But, before their validity can be determined, there must be a 'cognitional' experience of the type described above. "Before the category of confirmation or refutation can be introduced, there must be something which means to mean something and which therefore can be guaranteed or nullified by the issue."1 Ideas, or meanings, as directly experienced, are neither true nor false, but are made so by the results in which they issue. Even then, the outcome must be reflected upon, before they can be designated true or false. "Truth and falsity present themselves as significant facts only in situations in which specific meanings and their already experienced fulfilments and non-fulfilments are intentionally compared and contrasted with reference to the question of the worth, as to reliability of meaning, of the given meaning or class of meanings." 2 This makes the whole problem of truth a relatively simple affair. The symbol and its 'pointing' are taken as a single, objective fact, to be tested, and, if verified, labelled 'true.' Meanings, after all, are not so simple as this scheme would imply.

As the intellectual life of man is more subtle and universal than Dewey represents it to be, so is truth, as that which thought seeks to establish, something deeper-lying and more comprehensive. Ideas are not simple and isolated facts; their truth is not strictly their own, but is reflected into them from the objective order to which they pertain. The possibility of making observations and experiments, and of having ideas, rests upon the presence in and through experience of that directing influence which we call valid knowledge, or truth. An idea, to be true, must fit in with this general body of truth. Not correspondence with its single object, but correspondence with the whole organized body of knowledge, is the test of the truth of an idea. The attempt to describe knowledge as a particular occurrence, fact,

${ }^{1}$ Op. cit., p. 87.

2 Ibid., p. 95. Author's italics. 
or function, is foredoomed to failure. It should be noted also that Dewey's 'description,' throughout this essay, is anything but a direct, empirical examination of thought. He presents a schematized picture of reality which, like an engineer's diagram, leaves out the cloying details of the object it is supposed to represent.

The sceptical and positivistic results of Dewey's treatment of knowledge are set forth in an article entitled "Some Implications of Anti-Intellectualism," published in the Journal of Philosophy, Psychology, and Scientific Methods, in 1910.' This was not included in the volume of collected essays published in the same year, but may be regarded as of some importance.

After some comments on current anti-intellectualistic tendencies, Dewey proceeds to distinguish his own anti-intellectualism from that of others. This type "starts from acts, functions, as primary data, functions both biological and social in character; from organic responses, readjustments. It treats the knowledge standpoint, in all its patterns, structures, and purposes, as evolving out of, and operating in the interests of, the guidance and enrichment of these primary functions. The vice of intellectualism from this standpoint is not in making of logical relations and functions in and for knowledge, but in a false abstraction of knowledge (and the logical) from its working context.",2

The manner in which this exaltation of the "primary" functions at the expense of knowledge affects philosophy is indicated in the following passage: "Philosophy is itself a mode of knowing, and of knowing wherein reflective thinking is much in play. . . . As a mode of knowledge, it arises, like any intellectual undertaking, out of certain typical perplexities and conflicts of behavior, and its purpose is to help straighten these out. Philosophy may indeed render things more intelligible or give greater insight into existence; but these considerations are subject to the final criterion of what it means to acquire insight and to make things intelligible, $i$. e., namely, service of special purposes in behavior, and limit by the special problems in which the need of insight

1 Vol. VII, pp. 477-48r.

2 Ibid., p. 478. 
arises. This is not to say that instrumentalism is merely a methodology or an epistemology preliminary to more ultimate philosophic or metaphysical inquiries, for it involves the doctrine that the origin, structure, and purpose of knowing are such as to render nugatory any wholesale inquiries into the nature of Being." 1

In the last analysis, this appears to be a confession, rather than an argument. It is the inevitable outcome of the functional analysis of intelligence. Thought is this organ, with these functions, and is capable of so much and no more. The limit to its capacity is set by the description of its nature. The nature of the functionalistic limitation of thought is well expressed in the words 'special' and 'specific.' Since thought is the servant of the 'primary' modes of experience, it can only deal with the problems set for it by preceding non-reflective processes. These problems are 'specific' because they are concrete problems of action, and are concerned with particular aspects of the environment. Dewey's formidable positivism would vanish at once, however, if his special psychology of the thought-process should be found untenable. Thought is limited, according to Dewey, because it is a very special form of activity, operating occasionally in the interest of the direct modes of experiencing.

Probably every philosopher recognizes that speculation cannot be allowed to run wild. Some problems are worth while, others are artificial and trivial, and some means must be found for separating the sound and substantial from the tawdry and sentimental. The question is, however, whether Dewey's psychology furnishes a ground for such distinctions. Again, it should be noted that, in spite of the limitations placed upon thought by its very nature, as described by Dewey, certain philosophers, by his own confession, are guilty of "wholesale inquiries into the nature of Being." If thought can deal only with specific problems, then there can be no question as to whether philosophy ought to be metaphysical. It is a repetition of the case of psychological versus ethical hedonism.

Modern idealists would resent the imputation that there is any 1 Op. cit., p. 479. 
inclination on their part to deny the need for a critical attitude toward the problems and methods of philosophy. Kant's criticism of the 'dogmatists' for their undiscriminating employment of the categories in the interpretation of reality, established an attitude which has been steadily maintained by his philosophical descendants. The idealist, in fact, has accused Dewey of laxity in the criticism of his own methods and presuppositions. The categories of description and natural selection by means of which his functionalism is established, it is argued, are of little service in the sphere of mind. And while Dewey accepts an evolutionary view of reality in general, the idealist has found evolutionism, at least in its biological form, too limited in scope to serve the extensive interests of philosophy. Dewey is right in opposing false problems and fanciful solutions in philosophy; but these evils are to be corrected, not by functional psychology, but by an empirical criticism of each method and each problem as it arises.

It has been seen that, even in these more constructive essays, Dewey's position is largely defined in negatives. What might be expected, then, of the essays which are primarily critical? Perhaps the best answer will be afforded by a close analysis of one or more of them. Idealism, as has been said, receives most of Dewey's attention. There are three essays in The Influence of Darwin on Philosophy, which bear directly against idealism. One, "The Intellectualist Criterion of Truth," is directed against Bradley; another, "Experience and Objective Idealism," is a historical discussion of idealistic views. The third, which is broadest in scope, is entitled "Beliefs and Existences." This was originally delivered as the presidential address at the meeting of the American Philosophical Association in December, 1905, and was printed in the Philosophical Review in March, I906, under the title, "Beliefs and Realities."

Dewey begins with a discussion of the personal and human character of beliefs. "Beliefs," he says, "look both ways, towards persons and towards things. . . . They form or judgejustify or condemn-the agents who entertain them and who insist upon them. . . To believe is to ascribe value, impute 
meaning, assign import."1 Beliefs are entertained by persons; by men as individuals and not as professional beings. Because they are essentially human, beliefs issue in action, and have their import in conduct. "That believed better is held to, asserted, affirmed, acted upon. . . . That believed worse is fled, resisted, transformed into an instrument for the better."' Beliefs, then, have a human side; they belong to people, and have a character which is expressed in the conduct to which they lead.

On the other hand, beliefs look towards things. "'Reality' naturally instigates belief. It appraises itself and through this self-appraisal manages its affairs. . . . It is interpretation; not merely existence aware of itself as fact, but existence discerning, judging itself, approving and disapproving."'3 The vital connection between belief as personal, and as directed upon things, cannot be disregarded. "We cannot keep connection on one side and throw it away on the other. We cannot preserve significance and decline the personal attitude in which it is inscribed and operative. . . ." 4 To take the world as something existing by itself, is to overlook the fact that it is always somebody's world, "and you shall not have completed your metaphysics till you have told whose world is meant and how and what for-in what bias and to what effect."5

But philosophers have been guilty of error here. They have thrown aside all consideration of belief as a personal fact in reality, and have taken "an oath of allegiance to Reality, objective, universal, complete; made perhaps of atoms, perhaps of sensations, perhaps of logical meanings." 6 This Reality leaves no place for belief; for belief, as having to do with human adventures, can have no place in a cut and dried cosmos. The search for a world which is eternally fixed in eternal.meanings has developed the present wondrous and formidable technique of philosophy.

1 Influence of Darwin on Philosophy, p. 169.

${ }^{2}$ Ibid., p. 170.

${ }^{3}$ Ibid., p. I7I.

4 Ibid.

${ }^{5}$ Ibid.

B Ibid., p. 172. 
The attempt to exclude the human element from belief has resulted in philosophical errors. Philosophers have divided reality into two parts, "one of which shall alone be good and true 'Reality,' . . . while the other part, that which is excluded, shall be referred exclusively to belief and treated as mere appearance. . . ." 1 To cap the climax, this division of the world into two parts must be made by some philosopher who, being human, employs his own beliefs, and classifies things on the basis of his own experience. Can it be done? We are today in the presence of a revolt against such tendencies, Dewey says; and he proposes to give some sketch, "( $\mathrm{r}$ ) of the historical tendencies which have shaped the situation in which a Stoic theory of knowledge claims metaphysical monopoly, and (2) of the tendencies that have furnished the despised principle of belief opportunity and means of reassertion." 2

Throughout this introduction Dewey speaks with considerable feeling, as if the question were a moral one, rather than a disquisition concerning the best method of dealing with the personal aspects of thought. His meaning, however, is far from being apparent. What does it mean to say that a Stoic theory of knowledge holds a monopoly in modern philosophy? In what sense has the philosophy of the past been misanthropic? Is Humanism a product of the twentieth century? Dewey's assertions are broad and sweeping; too broad even for a popular discourse, let alone a philosophical address. Perhaps his attitude will be more fully expressed in the historical inquiry which follows.

Dewey begins this inquiry with the period of the rise of Christianity, which, because it emphasized faith and the personal attitude, seemed in a fair way to do justice to human belief. "That the ultimate principle of conduct is affectional and volitional; that God is love; that access to the principle is by faith, a personal attitude; that belief, surpassing logical basis and warrant, works out through its own operation its own fulfilling evidence: such was the implied moral metaphysic of Christianity."'3 But these implications had to be worked out into a

${ }^{1}$ Op. cit., p. I75.

2 Ibid., p. 177.

${ }^{3}$ Ibid., p. I 7 ? 
theory, and the only logical or metaphysical systems which offered themselves as a basis for organization were those Stoic systems which "identified true existence with the proper object of logical reason." Aristotle alone among the ancients gave practical thought its due attention, but he, unfortunately, failed to assimilate "his idea of theoretical to his notion of practical knowledge." In the Greek systems generally, "desiring reason culminating in beliefs relating to imperfect existence, stands forever in contrast with passionless reason functioning in pure knowledge, logically complete, of perfect being."'

Dewey's discussion moves too rapidly here to be convincing. He does not take time, for instance, to make a very important distinction between the Greek and Hellenistic philosophies. He does not do justice to the purpose which animated the Greeks in their attempt to put thought on a 'theoretical' basis. His confusion of Platonism with Neo-Platonism is especially annoying. And, most assuredly, his estimate of primitive Christianity needs corroboration. Probably Christianity, in its primitive form, did lay great stress upon individual beliefs and persuasions, but it was expected, nevertheless, that the Holy Spirit working in men would produce uniform results in the way of belief. When the uniformity failed to materialize, Christianity was forced, in the interests of union, to fall back upon some objective standard by which belief could be tested. After this was established, an end was made of individual inspiration. From the earliest times, therefore, it may be said, Christianity sought means for the suppression of free inquiry and belief, a proceeding utterly opposed to the spirit of ancient Greece.

"I need not remind you," Dewey continues, "how through Neo-Platonism, St. Augustine, and the Scholastic renaissance, these conceptions became imbedded in Christian philosophy; and what a reversal occurred of the original practical principle of Christianity. Belief is henceforth important because it is the mere antecedent in a finite and fallen world, a temporal and phenomenal world infected with non-being, of true knowledge to

1 Op. cit., p. 179.

2 Ibid. 
be achieved only in a world of completed Being."1 Through the hundreds of years that intervened before the world's awakening, the 'Stoic dogma,' enforced by authority, held the world in thrall. And still Dewey finds the mediaeval Absolutism in many respects more merciful than the Absolutism of modern philosophy. "For my part, I can but think that mediaeval absolutism, with its provision for authoritative supernatural assistance in this world and assertion of supernatural realization in the next, was more logical, as well as more humane, then the modern absolutism, that, with the same logical premises, bids man find adequate consolation and support in the fact that, after all, his strivings are already eternally fulfilled, his errors already eternally transcended, his partial beliefs already eternally comprehended."2 Dewey takes no note of the fact that philosophy, as involving really free inquiry, was dead during the whole period of mediaeval predominance.

The modern age, Dewey continues, brought intelligence back to earth again, but only partially. Fixed being was still supposed to be the object of thought. "The principle of the inherent relation of thought to being was preserved intact, but its practical locus was moved down from the next world to this." Aristotle's mode of dealing with the Platonic ideas was followed, and Spinoza was the great exponent of "the strict correlation of the attribute of matter with the attribute of thought."

But, again, the modern conception of knowledge failed to do justice to belief, in spite of the compromise that gave the natural world to intelligence, and the spiritual world to faith. This compromise could not endure, for Science encroached upon the field of religious belief, and invaded the sphere of the personal and emotional. "Knowledge, in its general theory, as philosophy, went the same way. It was pre-committed to the old notion: the absolutely real is the object of knowledge, and hence is something universal and impersonal. So, whether by the road of sensationalism or rationalism, by the path of mechanicalism or objective idealism, it came about that concrete selves, specific

1 Op. cit.

2 Ibid., p. I80.

${ }^{3}$ Ibid., p. I8r. 
feeling and willing beings, were relegated with the beliefs in which they declare themselves to the 'phenomenal."'1 Feeling, volition, desiring thought have never received the justice due them in the whole course of philosophy. This is Dewey's conclusion. Little can be said in praise of his historical survey. There is scarcely a statement to which exception could not be taken, for the history of philosophy is not amenable to generalized treatment of this character.

The reader turns more hopefully toward the third part of the essay, in which he is promised a positive statement of the new theory which does full justice to belief. "First, then, the very use of the knowledge standpoint, the very expression of the knowledge preoccupation, has produced methods and tests that, when formulated, intimate a radically different conception of knowledge, and of its relation to existence and belief, than the orthodox one."'2

But after this not unpromising introduction, Dewey falls into the polemical strain again. The argument need not be followed in detail, since it consists largely in a reassertion of the validity of belief as an element in knowledge. The general conclusion is that modern scientific investigation reveals itself, when examined, as nothing more that the "rendering into a systematic technique, into an art deliberately and delightfully pursued, the rougher and cruder means by which practical human beings have in all ages worked out the implications of their beliefs, tested them, and endeavored in the interests of economy, efficiency, and freedom, to render them coherent with one another." 3 This is presumably true. If no more is implied than is definitely asserted in this passage, the reader is apt to wonder who would deny it.

Dewey again claims for his theory the support of modern science. "Biology, psychology, and the social sciences proffer an imposing body of concrete facts that also point to the rehabilitation of belief...." ${ }_{4}$ Psychology has revised its

1 Op. cit., p. 183 .

${ }^{2}$ Ibid., p. 184.

${ }^{3}$ Ibid., p. 187.

${ }^{4}$ Ibid., p. 189. 
notions in terms of beliefs. 'Motor' is writ large on the face of sensation, perception, conception, cognition in general. Biology shows that the organic instruments of the intellectual life were evolved for specifically practical purposes. The historical sciences show that knowledge is a social instrument for the purpose of meeting social needs. This testimony is not philosophy, Dewey says, but it has a bearing on philosophy. The new sciences have at least as much importance as mathematics and physics. "Such being the case, the reasons for ruling psychology and sociology and allied sciences out of competency to give philosophic testimony have more significance than the bare denial of jurisdiction."1 The idealists, apparently, have been the worst offenders in this connection. "One would be almost justified in construing idealism as a Pickwickian scheme, so willing is it to idealize the principle of intelligence at the expense of its specific undertakings, were it not that this reluctance is the necessary outcome of the Stoic basis and tenor of idealismits preoccupation with logical contents and relations in abstraction from their situs and function in conscious living beings." 2

In conclusion, Dewey warns against certain possible misunderstandings. The pragmatic philosopher, he says, is not opposed to objective realities, and logical and universal thinking. Again, it is not to be supposed that science is any the less exact by reason of being instrumental to human beliefs. "Because reason is a scheme of working out the meanings of convictions in terms of one another and of the consequences they import in further experience, convictions are the more, not the less, amenable and responsible to the full exercise of reason." 3 And finally, Dewey assures the reader that the outcome of his discussion is not a solution, but a problem. Nobody is apt to dispute that statement.

This very unsatisfactory essay is, nevertheless, a fair specimen of the polemical literature which was produced by Dewey and others during these years. Pragmatism was trying to make converts, and the argumentum ad hominem was freely employed.

1 Op. cit., p. 190.

${ }^{2}$ Ibid., p. I9I f.

${ }^{3}$ Ibid., p. I94. 
If the opposition was painted a good deal blacker than was necessary, the end was supposed to justify the evident exaggeration. And so, in this essay, after accusing his contemporaries of adherence to tenets that they would have indignantly repudiated, after a wholesale and indiscrimate condemnation of idealism, Dewey concludes with - a problem. This period of propaganda is now quite definitely a thing of the past. Philosophical discussion, especially since the beginning of the great war, has entered upon a new epoch of sanity, and, perhaps, of constructive effort. 


\section{CHAPTER VIII}

\section{LATER DEVELOPMENTS}

NEO-REALISM began to flourish in this country after I900, its rise being nearly contemporary with the spread of pragmatism. Many neo-realists, indeed, consider themselves followers of James. Dewey views the new realism, along with pragmatism and 'naturalistic idealism,' as 'part and parcel of a general movement of intellectual reconstruction." 1 The neo-realists, like the pragmatists, have been active in the field of controversy, and the pages of the Journal of Philosophy, Psychology, and Scientific Methods are filled with exchanges between the representatives of the two schools, in the form of notes, articles, discussions, agreements, and disclaimers. Dewey has more sympathy for realism than for idealism. He finds among the writers of this school, however, a tendency toward the epistemological interpretation of thought which he so strongly opposes. An excellent statement of his estimate of realism is furnished by his "Brief Studies in Realism," published in the Journal of Philosophy, Psychology, and Scientific Methods, in I9I I. ${ }^{2}$

In beginning these studies Dewey observes that certain idealistic writers (not named) have been employing in support of their idealism certain facts which have an obvious physical nature and explanation. Such illusions as that of the bent stick in the water, the converging railway tracks, and the double image that occurs when the eye-ball is pressed, have, as the realists have well proved, a physical explanation which is entirely adequate. Why is it that the idealists remain unimpressed by this demonstration? There is a certain element in the realistic explanation which undoubtedly explains the reluctance of the idealists to be convinced. "Many realists, in offering the type of explanation,

1 Influence of Darwin on Philosophy, Introduction, p. iv.

2 Vol. VIII: “I. Naïve Realism vs. Presentative Realism," pp. 393-400. “II. Epistemological Realism: The Alleged Ubiquity of the Knowledge Relation," pp. 546-554. 
adduced above, have'treated the cases of seen light, doubled imagery, as perception in a way that ascribes to perception an inherent cognitive status. They have treated the perceptions as cases of knowledge, instead of as simply natural events. . . . "1

Dewey draws a distinction, at this point, between naïve and presentative realism, employing, by way of illustration, the 'star' illusion, which turns upon the peculiar fact that a star may be seen upon the earth long after it has ceased to exist. The naïve realist remains in the sphere of natural explanation. $\mathrm{He}$ accounts for the star illusion in physical terms. The astronomical star and the perceived star are two physical events within a continuous physical order or process. But the presentative realist maintains that, since the two stars are numerically separate, the astronomical star must be the 'real' star, while the perceived star is merely mental; the real star exists in independence of a knowing subject, while the perceived star is related to a mind. The naive realist has no need of the hypothesis of a knower, since he can furnish an adequate physical account of the numerical duplicity of the star. Dewey favors the naive standpoint, and affirms that presentative realism is tainted by an epistemological subjectivism. "Once depart," he says, "from this thorough naiveté, and substitute for it the psychological theory that perception is a cognitive presentation of an object to a mind, and the first step is taken on the road which ends in an idealistic system." 2

The presentative realist, Dewey continues, finds himself possessed of two kinds of knowledge, when he comes to take account of inference; for inference is "in the field as an obvious and undisputed case of knowledge." There is the knowledge of perception by a knower, and the inferential knowledge which passes beyond perception. All reality, consequently, is related, directly or indirectly, to the knowing subject, and idealism is triumphant. But the real difficulty of the realist's position is that, if perception is a mode of knowing, it stands in unfavorable contrast with knowledge by inference. How can the inferred reality of the

1 Op. cit., p. 395.

2 Ibid., p. 397. 
star be established, considering the subjectivity of all perception?

Dewey is alert to the dangers which result from subjectivism, but does not distinguish, as carefully as he might, between knowledge as inference, and knowledge as perceptual awareness. Thus, while it might be granted that the subjective mind is a vicious abstraction, it does not follow that Dewey's particular interpretation of the function of inference is correct. And, although the "unwinking, unremitting eye" of the subjective knower might make experience merely a mental affair, there is no reason to believe that the operation of inference in perception would lead to the same result, for inference and awareness are quite distinct, in historical meaning and function. It is, in fact, a mere accident that inference and awareness (in the subjective sense) should both be called knowledge.

In opposition to presentative realism, Dewey offers his 'naturalistic' interpretation of knowledge. ${ }^{1}$ He finds that the function of inference, "although embodying the logical relation, is itself a natural and specifically detectable process among natural things-it is not a non-natural or epistemological relation, that is, a relation to a mind or knower not in the natural series. . . ."2 As has been observed, Dewey is safe in maintaining that inference is not an operation performed by a subjective knower, but it does not follow from this that his interpretation of inference is correct. In fact, a discussion of inference is irrelevant to the matters which Dewey is here considering.

In the second part of the essay, the discussion passes into a keen and rather clever recital of the difficulties that result from taking the knowledge relation to be 'ubiquitous.' 3 Since this

1 In this connection Dewey's disagreements with Professor McGilvary are of especial interest. See especially McGilvary's article, "Pure Experience and Reality" (Philosophical Review, Vol. XVI, I907, pp. 266-284) and Dewey's reply, together with McGilvary's rejoinder (Ibid., pp. 4I9-424). McGilvary failed to understand that Dewey's argument was conducted on a purely 'naturalistic' basis, an almost inevitable error, in view of Dewey's practical identification of psychology, biology, and logic.

2 Ibid., p. 399.

${ }^{3}$ Dewey is here dealing with the 'epistemological' realists, among whom he includes such writers as Bertrand Russell. In an article entitled "The Existence of the World as a Problem" (Philosophical Review, Vol. XXIV, I915, pp. 357-370), Dewey argues that Russell, in making a problem of the existence of the external 
relation is a constant factor in experience, it would seem as if it might be eliminated from philosophical calculations. The realist would be glad to eliminate it, but the idealist is not so willing; for, "since the point at issue is precisely the statement of the most universally defining trait of existence as existence, the invitation deliberately to disregard the most universal trait is nothing more or less than an invitation to philosophic suicide." 1 It is, Dewey says, as if two philosophers should set out to ascertain the relation which holds between an organism as 'eater' and the environment as 'food,' and one should find the essential thing to be the food, the other the eating. The 'foodists' would represent the realists, the 'eaterists' the idealists. No advance, he believes, can be made on this basis.

In opposition to the epistemologists, Dewey would consider the knowledge relation not ubiquitous, but specific and occasional. As man bears other relations to his environment than that of eater, so is he also something more than a knower. "If the one who is knower is, in relation to objects, something else and more than their knower, and if objects are, in relation to the one who knows them, something else and other than things in a knowledge relation, there is somewhat to define and discuss. ..." Dewey proposes to advance certain facts to support his contention that knowing is "a relation to things which depends upon other and more primary connections between a self and things; a relation which grows out of these more fundamental connections and which operates in their interests at specifiable crises.",3

This brings the discussion back to familiar ground again, and nothing is added to his previous statements of the functional conception of knowledge. While the realist (explicitly or implicitly) conceives the knowledge relation as obtaining between a subject knower and the external world, Dewey interprets the

world, implies its existence in his formulation of the problem. Dewey argues that, since the existence of the world is presupposed in every such formulation, it cannot be called in question. This is like disposing of Zeno's paradox on the ground that arrows fly anyway.

1 Op. cit., p. 548.

${ }^{2}$ Ibid., p. $55^{2}$.

${ }^{3}$ Ibid. 
knowledge relation in terms of organism and environment. The 'ubiquity' of the knowledge relation is disposed of, as has been seen, by conceiving knowledge from an entirely different standpoint; by reducing all knowledge to inference, and abolishing the knowing subject. Dewey is plainly under the impression that the only alternative to the ubiquitous knower is his naturalistic, biological interpretation of the processes of inference.

In support of his naturalistic logic, Dewey argues as follows: (I) All perception involves reference to an organism. "We might about as well talk of the production of a specimen case of water as a presentation of water to hydrogen as talk in the way we are only too accustomed to talk about perceptions and the organism."1 (2) Awareness is only a single phase of experience. We 'know' only a small part of the causes which affect us as agents. "This means, of course, that things, the things that come to be known, are primarily not objects of awareness, but causes of weal and woe, things to get and things to avoid, means and obstacles, tools and results." ${ }^{2}$ (3) Knowing is only a special phase of the behaver-enjoyer-sufferer situation, but very important as having to do with means for the practical and scientific control of the environment.

In the final analysis, it will be seen that Dewey refutes the realist by substituting inference for what the realist calls 'consciousness,' and settling the issue by this triumph in the field of dialectics, rather than by an appeal to the facts. Nowhere does Dewey do justice to those concrete situations which, to the realist, seem to necessitate a definition of consciousness as awareness. His attitude toward the realists may be summed up in the statement that he finds in most realistic systems the fault to which his logical theory is especially opposed: the tendency to define the problem of logic as that of the relation of thought at large to reality at large, and to distinguish the content of mind from the content of the world on an existential rather than on a functional basis.

One of Dewey's more recent studies, "The Logic of Judgments 1 Op. cit.

${ }^{2}$ Ibid., p. 553. 
of Practise,"1 seems to add something positive to his interpretation of knowledge. A practical judgment, Dewey explains at the outset of this study, is differentiated from others, not by having a separate organ and source, but by having a specific sort of subject-matter. It is concerned with things to be done or situations demanding action. "He had better consult a physician," and "It would be well for you to invest in these bonds," are examples of the practical judgment.

These propositions, as will be seen, are not cast in what the logician calls logical form, with regular terms and copula. When put in that form, they seem to lose the direct reference to action which, Dewey says, differentiates them from the 'descriptive' judgment of the form $S$ is $P .{ }^{2}$ This apparently trivial matter is really important. Although every statement embodies judgment, some statements do not reflect the ground upon which they are asserted. In this condition they may be viewed as opinions, suggestions, or guesses, looking towards judgment rather than reflecting its results. True judgment is occupied with reasons, proofs, and grounds, and does not concern itself with action as action. Only when taken as the expression of an individual's attitude, do Dewey's practical judgments (or assertions) possess the direct reference to action which he selects as their chief characteristic. The statement, "You ought to invest in these bonds," does, indeed, suggest a specific action, but in so doing it loses its character as a judgment. Put in more logical form, "You are one of those who should invest in these bonds," the proposition is more clearly the expression of a judgment, and leads back to its premises. Attention turns from specific action as such to action as a typical or universal fact. In short, Dewey's practical judgment is not a true judgment; it will be seen that it is studied, not as a logical, but as a psychological phenomenon.

In pursuance of his psychological method, Dewey discovers several interesting facts about judgments of practice. These judgments imply an incomplete situation,-concretely and specifically incomplete; they express a need. (2) The judg-

1 Journal of Philosophy, Psychology, and Scientific Methods, Vol. XII, I9I5. Parts I and II, pp. 505-523; Part III, pp. 533-543.

${ }^{2}$ Ibid., p. 506. 
- ment is itself a factor in assisting toward the completion of the situation, since it directs an action necessary to the fulfilment of the need. (3) The subject-matter of the judgment expresses the fact that one outcome is to be preferred to another. The element of preference is peculiar to the practical judgment, for it is not found in merely descriptive judgments, or those 'confined to the given.' (4) A practical judgment implies both means and end, the act that completes, and the completeness. It is in this respect 'binary.' (5) The judgment of what is to be done demands an accurate statement of the course of action to be pursued and the means to be employed, and these are to be determined relatively to the end in view. (6) It finally appears that what is true of the practical judgment may be true of all judgments of fact; it may be held that "all judgments of fact have reference to a determination of courses of action to be tried and the discovery of means for their attempted realization."1

This ingenious reading of functionalism out of the practical judgment is, after all, merely a drawing forth of the psychological implications previously placed in it. That judgment is an instrument for completing a situation; that it is linked up with action through desire and preference; that it seeks to determine the means for effecting a practical outcome,-these typically instrumental notions are of one piece with the system of belief that led Dewey to hit upon the practical judgment as the embodiment of a direction to action. It is important to distinguish between the logical and the psychological aspects of these propositions. Action as psychological is one thing; as the subject-matter of judgment, it is another. In coming to a decision as to how to act, the agent sets his proposed action over against himself, and considers it in its universal and typical character. His motor tendencies, his feelings, his desires factor in the situation psychologically considered; but they do not enter judgment as psychological facts, but rather, if at all, as data which have a significance beyond their mere particularity. Dewey remains at the psychological standpoint, giving no attention to the genuinely logical aspects of his 'judgments of practice.'

1 Op. cit., p. 5 I r. 
From the study of the practical judgment, Dewey passes on to a consideration of judgments of value, proposing to maintain that "value judgments are a species of practical judgments." There will be a distinct gain for moral and economic theory, he believes, in treating value as concerned with acts necessary to complete a given need-situation. There is no obvious reason why Dewey should pass to the pragmatic theory of value through the medium of the practical judgment, since it could be directly considered on its own account. At any rate, the discussion of value judgments which follows must stand on its own merits; it has no vital relation to what precedes.

It is, as usual, the psychological characteristics of the value judgment that attract Dewey's attention. Any process of judgment, according to his analysis, deals with a specific subjectmatter, not from the standpoint of any objective quality it may possess, but with reference to its functional capacity. "Relative, or comparative, durability, cheapness, suitability, style, esthetic attractiveness [e.g., in a suit of clothes] constitute value traits. They are traits of objects not per se, but as entering into a possible and foreseen completing of the situation. Their value is their force in precisely this function." 2

Attention should not be distracted from this interpretation of value, Dewey warns, through confusing the value sought with the price or market value of the goods. Price values, like the qualities and patterns of the goods, are data which must be considered in making the judgment, but they are not the values which the judgment seeks. The value to be determined is here, is specific, and must be established by reference to the specific or psychological situation as it presents itself.

It is true, as Dewey says, that in judgment a value is being established which has not been determined previously. But it must be insisted that this value is not estimated by reference to the specific situation in its limited aspects. The weight of the past bears against the moment; the act of judgment bases itself upon knowledge objective and substantial; the test of the value

${ }^{1}$ Op. cit., p. 514.

${ }^{2}$ Ibid., p. 5 I5. 
of the thing is its place and function, not in the here and now, but in the whole system of experience. Dewey has excluded the reference of the thing to objective, organized reality, by specifying that its value shall be decided upon with reference to a specific situation. This limitation of the judgment situation is imposed upon it from without, and from a special point of view,that of functional psychology. Every object and every situation has its quality of uniqueness and particularity; but the judgment, as judgment, is not concerned with this aspect of things. Judgment seizes upon the generic aspect of objects; this kind of a suit of clothes is the kind that is appropriate to this type of situation. The movement of judgment is objective and universal, not subjective and psychological.

Dewey finds one alternative especially opposed to his 'specific' judgment of value; that is, the proposition that evaluation involves a comparison of the present object with some fixed standard. When the fixed standard is investigated, it is found to depend on something else, and this on something else again in an infinite regress. Finally, the Summum Bonum, as the absolute end term of such a regressus, turns out to be a fiction. Dewey is quite right in maintaining that value is not something eternally fixed. This does not, however, remove the possibility of 'real' value, as opposed to mere expediency.

Value as established, Dewey continues, must be taken into consideration in making a value judgment. At the same time, it will not do to accept the established value from mere force of habit. Ultimately, he finds, all genuine valuation implies a degree of revaluation. "To many," he observes, "it will appear to be a survival of an idealistic epistemology,"1 presumably because it implies a real change in reality, as opposed to a fixed and rigid order of external reality. But practical judgments, Dewey says, as having reference to proposed acts, necessarily look toward some proposed change which the act is to effect. It is not in an epistemological, but in a practical sense, that judgment involves a change in values.

The outcome of the discussion so far, Dewey believes, is to

1 Op. cit., p. $52 \mathrm{I}$. 
show, first of all, that "the passage of a proposition into action is not a miracle, but the realization of its own character-its own meaning as logical,"1 and, in the second place, to suggest that all judgments, not merely practical ones, may have their import in reference to some difference to be brought about through action.

In the third part of the essay, Dewey's discussion leads him back to sense perceptions as forms of practical judgment. There is no doubt, in his mind, that many perceptions do have an import for action. Not merely sign-posts, and familiar symbols of the kind, but many perceptions lacking this obvious reference, have a significance for conduct. It must not, of course, be supposed that all perception, at any one time, has cognitive properties; for some of the perceptions have esthetic, and other noncognitive properties. Only certain elements of a situation have the function of cognition.

Dewey goes on to say that care must be taken in the use made of these sign-functions in connection with inference. "There is a great difference between saying that the perception of a shape affords an indication of how to act and saying that the perception of shape is itself an inference."'2 No judgment, Dewey seems to imply, is involved in responding to the motor cue furnished by a familiar object. Again, the common idea that present perception consists of sensations as immediate, plus inferred images, implies that every perception involves inference. But the merging of sensations and images in perception can be explained naturally, by the fusion of nervous processes, and no supplementary (transcendental) act of mind is needed to explain the integrity of experience.

The tendency to take perception as the object of knowledge, Dewey continues, instead of as simply cognitive, a term in knowledge, is due to two chief causes. The first is that in practical judgments the pointing of the thing towards action is so universal a trait as to be overlooked, and the second is that signs, because of their importance, become objects of study on their own account, and in this condition cease to function directly

1 Op. cit., p. $522 \mathrm{f}$.

${ }^{2}$ Ibid., p. 536. 
as cognitive. Dewey means, apparently, that because the cognitive aspect of things is never attended to except when they are 'known,' or treated as objects of judgment, there is a tendency to suppose that they always have the character that pertains to them as 'known' things.

Again, Dewey says, perception may be translated as the effect of a cause that produced it. But the cause does not ordinarily appear in experience, and the perceptions, as effects, remain isolated from the system of things. Truth and error then become matters of the relation of the perception to its cause. The difficulties attendant upon this view can be avoided by taking sense perceptions as terms in practical judgments. Here the 'other term' which is sought is the action proposed by the perception. "To borrow an illustration of Professor Woodbridge's: A certain sound indicates to the mother that her baby needs attention. If there is error it is not because the sound ought to mean so many vibrations of the air, while as matter of fact it doesn't even suggest air vibrations, but because there is wrong inference as to the act to be performed." $\quad$ The idea is tested, not by its correspondence with some formal reality, but by its ability to lead up to the experience to which it points.

From the consideration of error as cognitive, Dewey passes on to consider its status as primitive sense data. He draws a distinction between sensation as psychological and as logical. Ordinary sensation, just as it comes, is often too confused to serve as a basis for inference. "It has often been pointed out that sense qualities being just what they are, it is illegitimate to introduce such notions as obscurity or confusion into them: a slightly illuminated color is just as irretrievably what it is, as clearly itself, as an object in the broad glare of noon-day."2 But when a confused object is made a datum for inference, its confusion is just the thing to be got rid of. It is broken up by analysis into simple elements, and the psychologist's sensations are logical products, not psychological facts. "Locke writes a mythology of the history of knowledge, starting from clear and

1 Op. cit., p. 538.

2 Ibid., p. 540. 
distinct meanings, each simple, well-defined, sharply and unambiguously just what it is on its face, without concealments and complications, and proceeds by ' natural' compoundings up to the store of complex ideas, and the perception of simple relations of agreement among ideas: a perception always certain if the ideas are simple, and always controllable in the case of the complex ideas if we consider the simple ideas and connections by which they are reached. Thus he established the habit of taking logical discriminations as historical or psychological primitivesas 'sources' of beliefs and knowledge instead of as checks upon inference." 1 This way of treating perception found its way into psychology and into empirical logic. The acceptance of the doctrine that all sense involves knowledge, Dewey believes, leads to an epistemological logic; but all perception must involve thought if the 'given' is the simple sensation.

There is nothing especially new in this critique of sensationalism. Historically, sensationalism had been displaced by idealism, and the idea that reality is a construct of ideas held together by logical relations was given up long before functionalism arrived on the scene. But if inference, or rationality, is not present in all experience as the combiner of simple into complex ideas, it may be present in some other form, even more vital. Dewey, however, does not consider such possibilities.

Finally, in an article of slightly earlier date than the studies which have just been considered, Dewey returns to a consideration of metaphysics, and the possibility of a metaphysical standpoint in philosophy. This article, entitled "The SubjectMatter of Metaphysical Inquiry,",2 deserves careful notice.

The comments of a number of mechanistic biologists on vitalism furnish the point of departure for Dewey's discussion. These scientists hold that, if the organism is considered simply as a part of external nature, as an existing system, it can be satisfactorily analyzed by the methods of physico-chemical science. But if the question of ultimate origins is raised, if it be asked why nature exhibits certain innate potentialities for pro-

1 Op. cit., p. 54r.

2 Journal of Philosophy, Psychology, and Scientific Methods, Vol. XII, I915, pp. 337-345. 
ducing life, science can give no answer. These questions belong to metaphysics, and vitalistic or biocentric conceptions may be valid in the metaphysical sphere.

This raises the question of the nature of metaphysical inquiry. Dewey says that the ultimate traits or tendencies which give rise to life need not necessarily be considered ultimate in a temporal sense. On the contrary, they may be viewed as permanent, 'irreducible traits,' which are ultimate in the sense of being always present in reality. The inquiry and search for these ultimate traits is what constitutes valid metaphysics. "They are found equally and indifferently whether a subject-matter in question be dated I9I5 or ten million years B. C. Accordingly, they would seem to deserve the name of ultimate, or irreducible, traits. As such they may be made the object of a kind of inquiry differing from that which deals with the genesis of a particular group of existences, a kind of inquiry to which the name metaphysical may be given."1

The irreducible traits which Dewey finds are, in the physical sciences, plurality, interaction, and change. "These traits have to be begged or taken in any case," for wherever and whenever we take the world, we must explain it as "a plurality of diverse interacting and changing existences." 2 The evolutionary sciences add another trait; that is, evolution, or development in a direction. "For evolution appears to be just one of the irreducible traits. In other words, it is a fact to be reckoned with in considering the traits of diversity, interaction, and change which have been enumerated as among the traits taken for granted in all scientific subject-matter."3

The doctrine that plurality, interaction, change, and evolution are permanent traits of reality gains in clearness when contrasted with the opposed theories which involve creation, absolute origins, or temporal ultimates. The term 'ultimate origins' may be taken in a merely relative sense which is valid. The French language has an origin in the Latin tongues, which is an ultimate origin for French, but this is not an absolutely ultimate

1 Op. cit., p. 340.

${ }^{2}$ Ibid.

3 Ibid., p. 345. 
origin, since the Latin tongues, in their turn, have origins. It is, for instance, meaningless to inquire into the ultimate origin of the world as a whole; and it is equally futile to trace any part of the world back to an absolute origin. "That scientific inquiry does not itself deal with any question of ultimate origins, except in the purely relative sense already indicated, is, of course, recognized. But it also seems to follow from what has been said that scientific inquiry does not generate, or leave over, such a question for some other discipline, such as metaphysics, to deal with."'1

Theories like that of Laplace, for instance, trace the world back to an origin in some undifferentiated universe; or, in Spencer's terms, some state of homogeneity. From this original state the world is said to evolve. But the undifferentiated mass lacks the plurality, interaction, and change which are presupposed in all scientific explanation. These traits must be present before development can occur. "To get change we have to assume other structures which interact with it, existences not covered by the formula."' 2 In short, although Dewey only implies this, all scientific explanation presupposes a system of interacting parts; nothing can be explained by reference to an undifferentiated world which lacks such traits.

Dewey is particularly interested in the origin of mind or intelligence. In dealing with mind, he says, we must begin with the present, and in the present we find that the world has an organization, "in spots," of the kind we call intelligence. This existing intelligence cannot be explained by any theory which reduces it to something inferior. The "attempt to give an account of any occurrence involves the genuine and irreducible existence of the thing dealt with."3 Mind cannot be explained by being explained away, nor can it be explained as a development out of an original source in which the potentiality, or direction of change towards mind, was lacking.

The evolution of things, Dewey says, is a real fact, and is to be reckoned with. Moreover, if everything that exists changes,

1 Op. cit., p. 339.

2 Ibid., p. 343.

3 Ibid., p. 344 . 
then the evolution of life and mind surely have a bearing on the nature of physico-chemical things. They must have in them the trait of direction of change towards life and mind. "To say, accordingly, that the existence of vital, intellectual, and social organization makes impossible a purely mechanistic metaphysics is to say something which the situation calls for." 1 In other words, the world, metaphysically considered, must have evolution, as well as the physico-chemical traits. "Without a doctrine of evolution we might be able to say, not that matter caused life, but that matter under certain conditions of highly complicated and intensified interaction is living. With the doctrine of evolution, we can add to this statement that the interactions and changes of matter are themselves of a kind to bring about that complex and intensified interaction which is life." 2 Dewey holds that evolution rests upon the reality of time: "time itself, or genuine change in a specific direction, is itself one of the ultimate traits of the world irrespective of date." 3

This article presents on the whole a distinct advance over the position taken in the earlier essay, "Some Implications of AntiIntellectualism," which was reviewed in the last chapter. Dewey is not now, to be sure, instituting a wholesale inquiry into the nature of being, but he betrays an interest in the general, as opposed to the specific traits of reality. He inquires into the real nature of the world, and believes that he discovers its ultimate traits. This essay, of course, is incomplete, and consequently indefinite in certain important respects. It may be said, nevertheless, to give an accurate view of the metaphysical back-ground against which all of Dewey's theories are projected. His metaphysics, as would be expected, are evolutionary throughout, and evolution is conceived, where he is at all definite, in biological terms.

1 Op. cit., p. 345.

2 Ibid.

${ }^{3}$ Ibid. 


\section{CHAPTER IX}

\section{CONCLUSIONS}

DEWEy's interest as a philosopher centres, from first to last, upon knowledge and the knowing process. All that is vital in his ethical, social, and educational theories depends ultimately upon the special interpretation of the function of knowledge which constitutes his chief claim to philosophical distinction. Dewey's logical theory, as has been seen, was the natural and inevitable outcome of his demand for an empirical and 'psychological' description of thought as a 'transformatory' process working actual changes in reality. If in the beginning of his career he found the problem of the nature of knowledge all-important for his own interests, he came in the end to regard it as the problem of problems for all philosophers. There is no mistaking Dewey's conviction that the special interpretation of knowledge which he advocates opens the door to important advances in philosophical speculation, while it ends all discussion of those pseudo-problems which result from a false, epistemological formulation of the function of knowledge.

The history of the development of Dewey's thought, set forth in the preceding chapters, does not pretend to furnish an adequate estimate of his philosophical system. The two questions, of /origin and worth, are, after all, distinct. IThe genetic account of Dewey's theory of knowledge may serve to make its bearings and implications better understood, may reveal its deeper meaning and import, but the final estimate of its value as a philosophical hypothesis depends on other considerations. In this final chapter, it is proposed to deal with the question of the positive value.) of functionalism as a working hypothesis. This criticism may also serve to gather together the threads of criticism and comment which run through the previous chapters, and reveal the general ground upon which the writer's opposition to Dewey's theory is based. 
There can be no question that Dewey's theory of knowledge rests, finally, upon the doctrine of 'immediate empiricism;' upon his belief in "the necessity of employing in philosophy the direct descriptive method that has now made its way in all the natural sciences. ..." ${ }^{\prime}$ This doctrine is clearly stated in the first essay reviewed in this study, "The Psychological Standpoint" (I886). To quote again from that essay: "The psychological standpoint as it has developed itself is this: all that is, is for consciousness or knowledge. The business of the psychologist is to give a genetic account of the various elements within this consciousness, and thereby fix their place, determine their validity, and at the same time show definitely what the real and eternal nature of this consciousness is." $2 \backslash$ The descriptive method here advocated does not differ, as an actual mode of procedure, from that of Dewey's later empiricism. It lies at the basis of all his speculation, earlier as well as later, and is undoubtedly the most important single element in his philosophical system.

In "The Psychological Standpoint" Dewey ascribes the failure of the earlier empiricists to their desertion of the direct descriptive method (a criticism repeated frequently in later essays). Locke, for instance, instead of describing experience as it actually occurs, interprets it in terms of certain assumed simple sensations, the products of reflection. These non-experienced elements, Dewey believes, have no place in a purely empirical philosophy.

But the empiricist must deal in some manner with the products of reflection. The atoms of chemistry and the elements of the psychologist are not experienced facts, but still they play a valuable, indispensable role in the technique of the sciences. What is to be done with them? It must be made to appear that they are valid within knowledge, but invalid elsewhere. This leads to a separation of knowing from other modes of experiencing, and the descriptive method is depended upon to maintain the empirical validity of the separation. $\backslash$ It has been seen how Dewey's attempt to interpret knowledge led gradually to a dis-

1 The Influence of Darwin on Philosophy, p. 240.

${ }^{2} O$ p. cit., Mind, Vol. XI, p. 8 f. 
tinction between the 'cognitional' and the 'non-cognitional' processes of experience.

The completed theory of knowledge depends for its validity upon the distinction thus established between knowing (as reflective thought) and the practical attitudes of life. The concepts, elements, and other apparatus of reflection are employed, it is said, only when there is thinking,- -and this is only occasionally. Theory is an instrument to be used in connection with that special activity, reflective thought, the general aim of which is the furtherance of the practical ends of life.

One fairly obvious difficulty with this separation of reflection from the other life activities is that the 'direct descriptive method,' as here employed, is itself reflective. How does it come, then, that this particular method achieves such an effective hegemony over the other modes of reflection? The 'descriptive method,' as the method of pure experience, is made to determine or supplant all other methods. It defines the limits and aims of conceptual systems; it marks out the limits, aims, and tests of reflective thought in general. How, it may be asked, does the 'direct descriptive method' escape the limitations which it imposes upon the other forms of reflective thought?

It has been seen that in Dewey's view logic is subsidiary to psychology. But psychology (his psychology) results from the application of the 'descriptive method' to experience. The 'descriptive method,' it may be inferred from this, is not subject to logical criticism. On the contrary, it is the basis of all logic. Logic, as the criticism of categories, is confined to the study of the instrumental concepts as functioning within the knowledge experience, and its limits are set by descriptive psychology. There is, apparently, no means by which the 'direct descriptive method' can itself be brought under criticism.

Dewey says: "By our postulate, things are what they are experienced to be; and, unless knowing is the sole and only genuine mode of experiencing, it is fallacious to say that Reality is just and exclusively what it is or would be to an all-competent all-knower; or even that it is, relatively and piece-meal, what it is to a finite and partial knower." Reality is not simply what

1 “"The Experimental Method," Influence of Darwin on Philosophy, p. 228. 
it is known as, for it is experienced in other ways than by being known. "But I venture to repeat that ... the inferential factor must exist, or must occur, and that all existence is direct and vital, so that philosophy can pass upon its nature-as upon the nature of all of the rest of its subject-matter-only by first ascertaining what it exists or occurs as."1

Reflection, then, is not designed to furnish an insight into the nature of things. Acquaintance with reality must be obtained, not by reflecting upon it, but by describing it as it occurs. Whatever else this may mean, it certainly aims at demonstrating the superiority of description to the supposedly less effective modes of thought. It cannot be conceded, however, that 'description,' as employed by Dewey, is non-reflective, or super-reflective. If things are not what they are known as, then they are not what they are known as to a describer. The point of this objection will be obvious if it is remembered that it is the method of 'direct description' which enables Dewey to distinguish between the 'cognitional' and the 'non-cognitional' activities of life, and make thought the servant of action. If Dewey's descriptive method is not reflective, then there is no such thing as reflection.

Passing for the moment from this criticism, which is not apt to be convincing in such abstract form, it may be well to consider for a time the psychology upon which Dewey's logical theory is grounded: the psychology which is established by the 'direct descriptive method.'

From the standpoint of the nervous correlates of experience, Dewey's theory involves two postulates: first, that customary conduct is carried on by an habitual set of nervous adjustments, and, second, that reflection is a process whereby new reactions are established when habitual modes of response fail to meet a critical situation.

It must be clearly recognized that, so far as the nervous system is concerned, the scheme is highly speculative. The advance made by physiology towards an analysis and understanding of the minute and specialized parts of the nervous organism has necessarily been slow and uncertain. Whatever

1 "The Experimental Method," Influence of Darwin on Philosophy, p. 240. 
plausibility Dewey's theory possesses must depend, not upon the technical results of neurology, but upon the external evidence which seems to justify some such scheme of nervous organization.

An examination of this evidence shows that it falls under two main heads: (I) facts drawn from the observation of the outward behavior of the organism, and (2) facts derived from an introspective analysis of the thought-process.

The study of behavior shows that man thinks only now and then. Most of his conduct is, literally, thoughtless. It is said that thought is outwardly manifested by a characteristic attitude, marked by hesitation and an obvious effort at adjustment. The introspective analysis of the thought-process shows that it alone, among experiences, is accompanied by analysis, abstraction, and mediation. Again, both the internal and external evidence show that a puzzling situation (whose nervous correlate is a conflict of impulses) is the stimulus which awakens thought. These are important items in the list of evidence which supports the functional theory.

It would be a tedious and unnecessary task to subject each of these bits of evidence to empirical criticism. It will be better to deal with them by showing that they do not necessarily imply functionalism, since they are compatible with a psychology directly opposed to the fundamental assumptions of Dewey theory.

It is doubtless true that men think only occasionally and with some reluctance. This is a common observation. What is to be made of this intermittance of thought? The evidence merely shows that man is more wide awake, energetic, and alert at some times than at others. On these occasions every faculty of the organism is in operation, higher as well as lower centres are pitched to a high degree of responsiveness, not at hap-hazard, to be sure, but apropos-tuned to the situation. In saying that men think only now and then nothing more is necessarily implied than that men are for the most part sluggish and indifferent, and the periods of high intensification of the normal processes contrast sharply with the habitual lethargy of conduct.

Against Dewey, it will be maintained here that thought cannot 
be defined as a special kind of activity considered from the side of the organism. The life processes are constantly welded into a single unified activity, which may, as a whole, be directed upon different objects. Thus, from the side of its objects, this life activity may be called eating, running, reading, and whatever else one chooses. Thinking, from this standpoint, may be defined as the direction of effort upon symbols and abstract terms. But thinking in this case would be identified on the basis of its content, not in terms of special nervous activities in the organism. Whether, therefore, thinking signifies that intense periodical activity which has been noted, or preoccupation with a certain kind of subject-matter, it in no case implies the operation of a special organic faculty of the type described by Dewey.

But, again, it is said that true reflection is marked by a certain characteristic bodily attitude, which bespeaks inner conflict and a search for adjustment. This contention seems to have little ground in fact. The puzzled, hesitating, undecided expression that is usually supposed to betray deep cogitation may in fact mean simply hesitation and bewilderment,- the need for thought, rather than its presence. The expression reveals a certain degree of incompetence and sluggishness in the individual concerned, and signifies a lack of wide-awakeness and responsiveness. A student puzzling over his algebra, a speaker extemporizing an argument, a ball-player using all his resources to defeat the enemy, have attitudes so unlike that no analysis could discover in them a common form of expression. And yet it would be madness to deny that thinking attends their various performances. There is, in short, no evidence from the side of bodily expression to indicate the presence in man of a special nervous faculty called reflection.

Consider next the contention that the cue to thought is a puzzling situation, involving a problem. No problem, no thought; no thought, no problem. This may mean either that a man finding himself in a difficult situation uses all his energy and resource to escape from it, or, that he never concerns himself with abstract symbols except under the spur of necessity. The former meaning contains some truth, but the latter is what 
Dewey would call a 'dark saying.' If by 'thought' be meant that period of high activity of all the faculties which is only occasional, it is doubtless true enough that a problem is frequently needed to awaken it. Man is content to let life glide along with a minimum of effort; he cannot, if he would, long maintain the state of high activity here called 'thinking.' As a consequence of not thinking when he should, man frequently finds himself involved in situations requiring the exercise of all the energy and resource he possesses. But the really efficient 'thinker' is the man who keeps his eyes open, who sees ahead. $\mathrm{He}$ is not efficient merely because of the excellence of his established modes of response, but, more particularly, because he is alive and alert. His thinking is effective in preventing difficult situations, as well as in getting out of them.

Defining 'thought,' however, as the direction of activity upon symbols and conceptions, there seems to be little warrant for asserting that it functions only on the occasion of a concrete, specific problem. One would say, on the contrary, that this would be an unfavorable occasion for the study of fundamental principles, whether scientific or practical. Summing up the external evidence, then, one would say that it accords as well with the hypothesis that the life processes constitute a single activity directed upon various objects, as with the hypothesis that thought is a very special organic activity, having a special biological function. At least, the evidence for the existence of such a special faculty is dubious and uncertain.

What does the internal evidence prove? The analysis of thought contained in James's chapter on "Reasoning" in the Principles of Psychology has been the guide for Dewey and other pragmatists in this connection. ${ }^{1}$ James undertakes to show that reasoning is marked off from other processes by the employment of analysis, abstraction, and the use of mediating terms. It must be urged here, not only against James, but against a considerable modern tradition, that this account of thinking is misleading and inaccurate. The question to be faced, of course, is whether the processes of thought differ radically from the non-

1 See the review of Dewey's essay, "The Experimental Method," in Chapter VII of this study, p. 9 I ff. 
reflective processes in kind, or whether they are simply the intensification of processes which attend all conscious life. It should be noted that no concession is made to the notion that thinking is a special kind of process; only its subject-matter is special, or else thought is simply a period of wide-awakeness and alertness. In the latter sense, thought involves an intensification of the powers of observation, an awakening of memory, a general stimulation of all the faculties. It calls for the fullest possible apprehension, demands the most complete insight in to the nature of the situation that the capacities can provide. The contrast between the adequate view of reality achieved in this manner and the common and inadequate apprehension of ordinary life is very great, and might easily lead to the supposition that thinking (so understood) contains elements which are added through the activities of a special nerve process.

But is it only in such moments that we deliberately resolve a situation into its elements, and abstract an 'essence' to serve as a middle term in inference? It is certain that at such moments these processes are more distinct than at other times; but the whole situation, for that matter, stands out more clearly and distinctly. Perception is keener, memory more definite, feeling more intense. In less degree, however, all attention involves analysis and abstraction. Experience has always a focus and a margin; there is a constant selecting and analyzing out of important elements, which in turn lead to further conclusions and acts, through associations by contiguity and similarity. This process appears in an intensified form in the high moments of life. In short, thought and passive perception are differentiated, not by the elements which compose them, but by the degree of energy that goes into perception, memory, feeling, and discrimination. There is nothing in the evidence to show that thinking is a special kind of activity, which operates now and then. On the contrary, there is every reason to hold to the position that the life processes are one and inseparable, operating continually in conjunction.

What shall be said, then, with reference to the assertion that thought operates in the interests of the non-cognitive life pro- 
cesses? That it comes 'after something and for the sake of something,' namely, 'direct' experience? Since the separation of the activities into various 'functions' cannot be allowed, by occasional thought must then be meant those moments of energetic aliveness described above. Translating, Dewey's theory would read something like this: Man employs his faculties to the fullest extent only when he is compelled to do so. He gets along habitually, that is, with a minimum of effort, as long as he can, but rouses himself and makes an earnest effort to comprehend the world only when his environment presents him with difficulties which demand solution. The test of man's thinking consists in its efficiency in getting him out of trouble, and enabling him to return to his habitual modes of sub-conscious conduct with a minimum of annoyance. In short, thinking is an instrument which subserves man's natural laziness, and its test is the efficiency with which it promotes an easy, or, at any rate, a satisfactory mode of existence.

No doubt some men, perhaps many men, do follow such a programme; but it would not be kind to Nature to assert that she planned it so.

This separation of the activities of life into several distinct processes having each a special function looks like a survival of the old faculty psychology, against which modern thought has protested as much as against anything whatever. The conception of the organic processes as separate in action has all the faults of a merely mechanical representation of consciousness. Doubtless some advantage is to be obtained, for purposes of investigation, by treating thought, appreciation, and affection separately; but it is a serious error to take this provisional distinction as real. It is a curious fact that Dewey, with all his opposition to such modes of procedure, himself falls into this abstract way of treating the 'functions' of experience, seeing not the beam that is in his own eye.

It is this very form of treatment, strangely enough, which enables Dewey to call biology to the support of his interpretation of the function of knowledge. According to the Darwinian theory, survival of the species is dependent upon the development 
of special structures and capacities which enable the organism to adjust itself to its environment. Dewey finds, following a familiar argument, that the lower animals are adapted to their environment by special habits of reaction which are relatively fixed and inelastic. Man, on the contrary, has an exceedingly plastic nervous system, which enables him to meet changing conditions. Man is not only highly adapted, but highly adaptable. This trait of plasticity, or adaptability, Dewey believes, is a product of natural selection, and, of course, in the final analysis, this high degree of plasticity is the thought function.

It is scarcely-necessary to say that this treatment of thought is highly speculative. Dewey offers little concrete evidence to support his position; indeed, it would require the labor of a Darwin to supply the needed evidence. Instead of grounding his theories upon the results of science, Dewey adapts the ever elastic 'evolutionary method' (not really that of biological evolution, however indeterminate) to his own scheme of things. It would be hard to discover in philosophical literature a method more purely theoretical and even dialectical than that whereby Dewey gives his logical theory the support of evolutionary theory.

The ultimately mechanical tendencies of his argument are conspicuous, in spite of all disclaimers. The effect of his analysis is to set plasticity or adaptability off by itself, as a special trait or feature of the nervous system. The lower forms of life are governed, we are told, by fixed reflexes, and the trait of adaptability appears at some higher stage in the process as a superadded capacity of the nervous system, correlated, no doubt, with special nervous structures. Evolutionism would not serve Dewey so well, had he not previously made this separation between the organic functions and their correlated structures; but, given this abstract treatment of the life processes, he is able to make the doctrine of selection contribute to its support. In opposition to Dewey's argument, it would be reasonable to contend that plasticity is inherent in all nervous substance. The higher organisms are more adaptable, because there is more to be modified in them,-more nerves and synapses, more pliability. There is no sound empirical reason for accepting Dewey's biological conclusions. 
Taking Dewey's theory at its face value,-and it would be presumptuous to search for hidden meanings,-its net result is to place the function of knowing in an embarrassing situation with respect to its capacity for giving a correct report of reality. Dewey expressly denies, indeed, that the purpose of knowing is to give an account of the nature of things. Reality, he asserts, is whatever it is 'experienced as being,' and it is normally experienced in other ways than by being known. The nature of reality is not hidden behind a veil, to be searched out; but is here and now, as it comes and goes in the form of passing experience. Knowing is designed to transform experience, not to bring it within the survey of consciousness.

How does it stand, then, with Dewey's own account of the knowledge process? He has reflected upon experience, and claims to have given a correct account of its nature. Dewey's conception of the processes of experience is genuinely conceptual, a thought product, designed to furnish a solid basis for belief and calculation. But reflection, by his own account, is shut in to its own moment, cannot apprehend the true nature of 'noncognitional' experiences, and cannot, therefore, deal adequately with any problems except such as are furnished it by other 'functions.' No wonder that 'anti-intellectualism' should result from such a conception of knowledge.

Philosophers have always held that the purpose of reflection (whatever reflection may be, psychologically) is the attainment of a reliable insight into the nature of the world. Practical considerations compel this view. Ordinary, casual observation is superficial and unsystematic; it never penetrates beneath the surface. Doubtless reality is, in some degree, what it is in unreflective moments; but it is frequently something more, as man learns to his sorrow. Reflection displaces the casual, haphazard attitude, in the attempt to get at the real nature of the world.

The results of reflection, moreover, are cumulative. It tends to build up, by gradual accretions, a conceptual view of reality which may serve as a relatively stable basis for conduct and calculation. Thought does, indeed, possess a transforming function. The reasoned knowledge of things is gradually extended beyond 
the occasional moments of inquiring thought, supplanting the casual view with a more penetrating insight; reality becomes more and better known, and less merely experienced.

Dewey reverses this view in a curious manner. It is 'experience' that is built up by the action of thought, not knowledge itself. This play on terms might be innocuous, if it were not accompanied by his separation of the knowing function from others. Dewey makes 'knowing' the servant of 'direct experience' by giving it the function of reconstructing the habits of the organism, in order that unreflective experience may be maintained with a minimum of effort. The non-reflective experience becomes the valuable experience, and knowledge is made to minister unto it. This is truly a 'transvaluation of values.'

Dewey asks: "What is it that makes us live alternately in a concrete world of experience in which thought as such finds not satisfaction, and in a world of ordered thought which is yet only abstract and ideal?"1 This sharp separation of thought from action is vigorously maintained. Following are some of the terms by means of which the difference between direct and reflective experience is expressed: 'direct practice,' 'derived theory;' 'primary construction,' 'secondary criticism;' 'living appreciation,' 'abstract description;' 'active endeavor,' 'pale reflection." This casual, easy distinction escapes criticism because it seems harmless and unimportant. The distinction, however, is not real. It does not correspond to the simple facts of life. Thinking, far from being 'pale reflection,' is often a strenuous and energetic 'activity.' Reflection, not 'direct experience,' is often, at least, at the high moment of life. Experience becomes unmeaning on any other basis. 'Living appreciation' and 'primary construction' involve thought in a high degree; 'pale reflection' is lazy contemplation, lacking the spark of life that characterizes true thought.

There is no escape from Dewey's needlessly alarming conclusions, except by maintaining that thought accompanies all conscious life, in greater or less degree, and that the moment of real, earnest thinking is at the high tide of life, when all the

1 Studies in Logical Theory, p. 4.

2 Ibid., p. 2. 
powers are awake and operating. Thought must be made integral with all other activities, a feature of the total life organization, rather than an isolated phenomenon. Man is a thinking organism, not an organism with a thinker.

It is not to be supposed for a moment that by 'thought' is here meant the activity of a merely subjective knower. Dewey does, indeed, deal effectively with the subjective ego, and with representative perceptionism. But by 'thought' is here meant reflection, judgment, inference; and in this sense thought is said to be present in all experience. There can be no question of the relation of thought, so understood, to reality; for the reason that it has been so integrated with experience as to be inseparable from it. Setting aside knowing as the awareness of a conscious subject, there remains an issue with Dewey concerning the actual place of thought, as an empirical process, in experience, and the issue must be settled on definite and really empirical grounds. So much, then, for 'functionalism' and its psychology.

Something should be said, before closing this discussion, concerning philosophical methods in general, since Dewey's psychological approach to the problems of philosophy must be held responsible for his anti-intellectualistic results, with their sceptical implications. In the beginning of his career, as has been seen, Dewey adopted the 'psychological method,' and he has adhered to it consistently ever since. This initial attitude, although he was not aware of it for many years, cut him off from the community of understanding that exists among modern idealists concerning the proper aims and purposes of philosophical inquiry. Although at first a professed follower of Green and Caird, Dewey's method was not reconcilable with idealistic procedure, and in a very real sense he never was an idealist. The virulence of his later attacks on 'intellectualism' may be explained in terms of his reaction against a philosophical method which interfered with the development of his own 'naturalistic' tendencies.

The method of idealism, or speculative philosophy, is logical; but it may perfectly well be empirical at the same time. To the 
anti-intellectualist empirical logic is an anomaly, a red blue-bird, so to speak. The philosophical logician is represented as one who evolves reality out of his own consciousness; who labors with the concepts which have their abode in the mental sphere, and, by means of the principle of contradiction, forces them in to harmony until they provide a perfectly consistent representation of the external world which, because of its perfect rationality, must somehow correspond with the cosmic reality. In spite of the fact that no man possesses, at least in a sane condition, the mental equipment requisite for such a performance, certain critics have not hesitated to impute this kind of logical procedure to the idealists. To quote from Dewey himself: "For modern philosophy is, as every college senior recites, epistemology; and epistemology, as perhaps our books and lectures sometimes forget to tell the senior, has absorbed Stoic dogma. Passionless imperturbability, absolute detachment, complete subjection to a ready-made and finished reality . . . is its professed ideal. . . . Philosophy has dreamed the dream of a knowledge which is other than the propitious outgrowth of beliefs that shall develop aforetime their ulterior implications in order to recast them ...., the dream of a knowledge that has to do with objects having no nature save to be known."1

This charge against modern idealism has little foundation. Speculative philosophy repudiated, long ago, the 'epistemological standpoint' as defined by Dewey. Idealists have not fostered the conception of a knowing subject shut in to its own states, seeking information about an impersonal reality over against itself. Note, for example, this comment of Pringle-Pattison on Kant, made over thirty-five years ago: "The distinction between mind and the world, which is valid only from a certain point of view, he took as an absolute separation. He took it, to use a current phrase, abstractly - that is to say, as a mere fact, a fact standing by itself and true in any reference. And of course when two things are completely separate, they can only be brought together by a bond which is mechanical, external, and

1 "Beliefs and Existences," The Influence of Darwin on Philosophy, p. $172 \mathrm{f}$. 
accidental to the real nature of both."1 Dewey himself never condemned 'epistemology' more effectively. But it is useless to cite instances, for any serious student familiar with the literature of modern philosophy ought to know that 'idealism' has never really been 'epistemological' in the sense meant by Dewey and his disciples. Subjectivism is not idealism,- the stolid dogmatism of neo-realism to the contrary notwithstanding.

Idealism holds, speaking more positively, that philosophers must submit the conceptions and methods which they employ to a preliminary immanent criticism, in order to determine the limits within which they may be validly applied. Every genuine category or method is valid within a certain sphere of relevance, and the business of criticism is to determine by empirical investigation or by 'ideal experiment' (which means much the same thing) what concrete significance the conception is capable of bearing. Dewey, from the standpoint of idealism, is guilty of a somewhat uncritical use of the categories of 'description' and 'evolution.' Are the categories of biology fitted to explain mind and spirit? Instead of instituting an inquiry designed to answer that question, Dewey accepts 'evolutionism' as final, and attempts to force all phenomena into conformity with his resulting logical scheme. He misses the valuable checks upon thought which are furnished by the 'critical method,' and is none too sensitive to the technical results of the special sciences.

The logical approach to philosophy strictly involves certain implications which have been overlooked by many of its critics. It may well be admitted that our real categories are not fixed and final, but are perpetually in process of reconstruction. The process of criticism inevitably makes manifest the human and empirical character of the particular forms of reflective thought. It recognizes the fact of development, both in knowledge and in reality, and by this very recognition the value of knowledge is enhanced. It is forced, by the very nature of its method, to recognize the concrete and practical bearings of thought. Indeed, there is a sense in which idealism would declare that there is no

1 The Philosophical Radicals, p. 297. The essay in which it occurs, "Philosophy as a Criticism of Categories," was first published in I883, in the volume Essays on Philosophical Criticism. 
thought-when thought, that is, is taken to mean an isolated fact out of relation to the world. It is not possible to make this retort upon the critics of idealism without recognizing that there has been a vast misjudgment, amounting almost to misrepresentation, of the intellectual ideals of modern speculative philosophy.

To conclude, it is neither by abstract logical processes, nor yet by the dogmatic employment of scientific categories, that philosophy makes progress, but by an empirical process which unites criticism and experiment. In speaking of the development of modern idealism, Bosanquet says: "All difficulties about the general possibility-the possibility in principle-of apprehending reality in knowledge and preception were flung aside as antiquated lumber. What was undertaken was the direct adventure of knowing; of shaping a view of the universe which should include and express reality in its completeness. The test and criterion were not any speculative assumption of any kind whatever. They were the direct work of the function of knowledge in exhibiting what could and what could not maintain itself when all the facts were confronted and set in the order they themselves demanded. The method of inquiry was ideal experiment."1

When all has been said, this method remains the natural and normal one. Dewey's 'psychological method,' by contrast, seems strained and far-fetched, an artificial and externally motived attempt to guide the intellect, which only by depending upon its own resources and its own increasing insight can hope to attain the distant and difficult, but never really foreign goal.

1 "Realism and Metaphysics," Philosophical Review, Vol. XXVI, 1917, p. 8. 




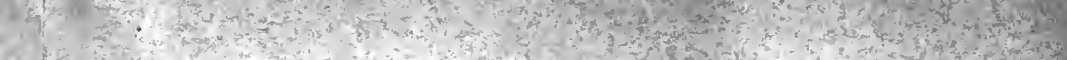

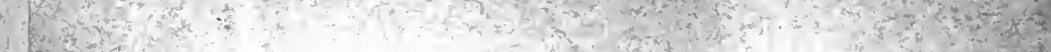

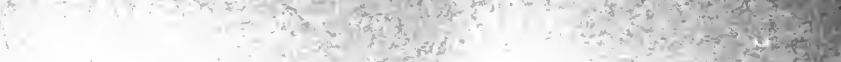

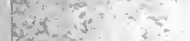

An

(16.

18
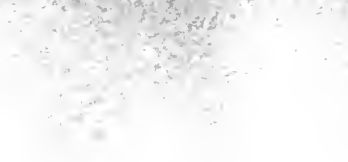

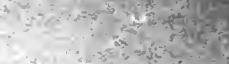

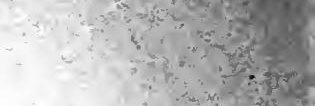

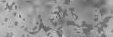

6 .

atis.

it $x+y$

(1) sions?

हैं कर ?

$\left(x x^{2}+2 x\right.$

$\operatorname{los}^{2}$

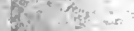

$\frac{1}{2}+2$

for a

$(4 x+2)=1$

aton

and

(x)

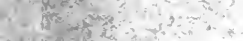

16.

(5) a

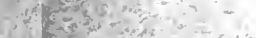

(bia $=2$

(2)

$T^{2}+x^{2}=$

$\frac{1}{2} x^{2}+2$

(1)

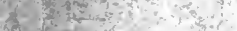

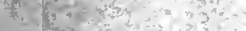

as ex

bis as

S.

? 4 तो

(x)

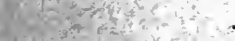

$140 \div-x_{1}-2$

the

$4 x^{2}-2 x^{2}+2$

I $3 b^{2}$

315

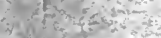

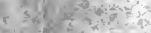

$m^{2} x^{2}=$

W.

* \%

$-7 x+x^{3}$

ant $x^{2}$

ating

3.t.

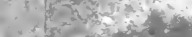

\section{$1+x^{3} 36=$}

wrat $x^{2}$

(1)

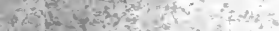

$4 x^{2}+1=$

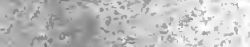

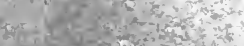

and $x$ and

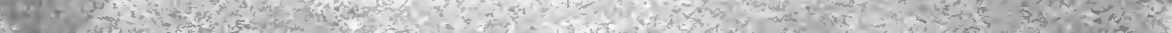




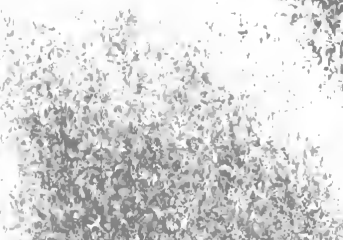
42 sरोil

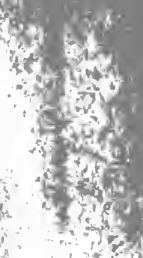

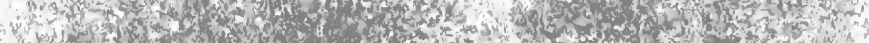

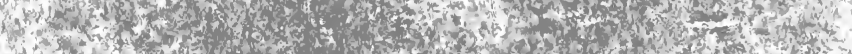

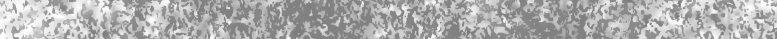

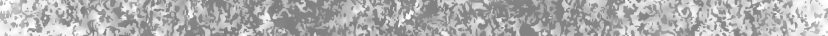

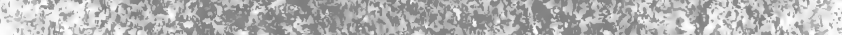

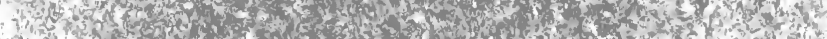
on mo

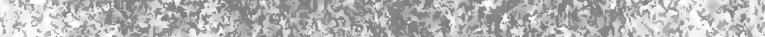

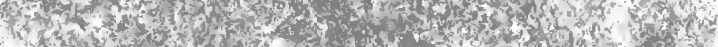

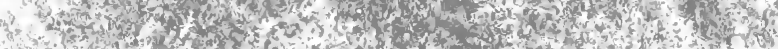

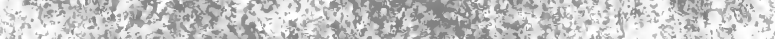

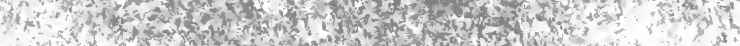

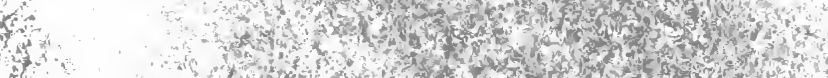
1.

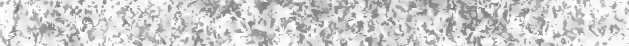

Qive

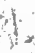

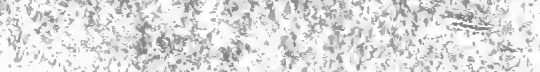

$$
\begin{aligned}
& y^{4}+w^{2}+y^{2} \\
& \text { Fing }
\end{aligned}
$$

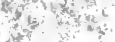

if

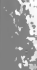

3

3

4

is $x$ ant हt: 3in zent

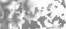
Plo

(4)

Fy

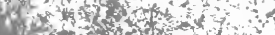

why$$
\text { e : }
$$

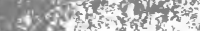

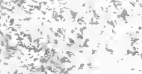

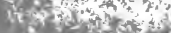

ent?

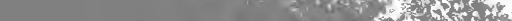


UNJ" ;

\author{
14 DAY USE
}

RETURN TO DESK FROM WHICH BORROWED

\title{
LOAN DEPT.
}

This book is due on the last date stamped below, or $\boldsymbol{t}$ on the date to which renewed.

Renewed books are subject to immediate recall.

\begin{tabular}{|c|c|}
\hline REC'D - L & $\begin{array}{l}\text { REC'D LD } \\
\text { III } 28,65-10 A M\end{array}$ \\
\hline$=9$ Nov'61BP & \\
\hline$K=C O$ and & \\
\hline NOV 12961 & \\
\hline I Aug'63MH & \\
\hline RECD LD & \\
\hline 31181963 & \\
\hline REC 7 M D LD & \\
\hline
\end{tabular}

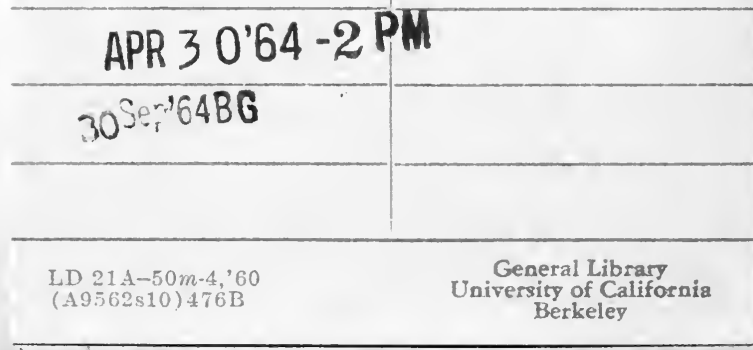




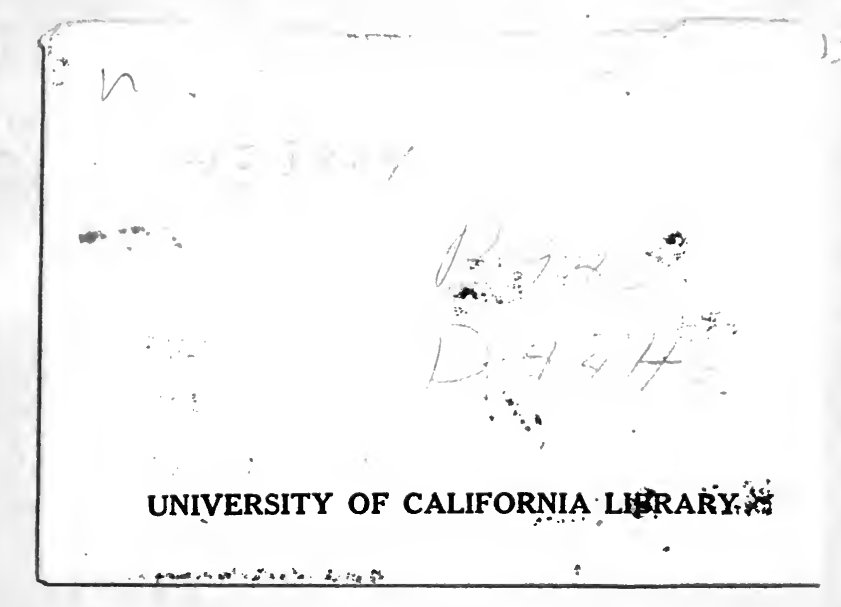


